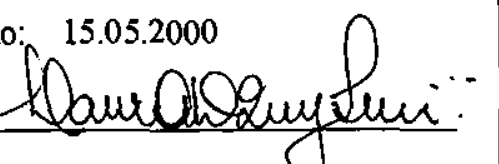

\title{
Meta-Heurísticas Evolutivas para Dimensionamento de Lotes com Restrições de Capacidade em Sistemas Multiestágios
}

\author{
Luiz Fernando Rodrigues
}

Orientadora: Profa. Dra. Regina Esther Berretta

Dissertação apresentada ao Instituto de Ciências Matemáticas e de Computação - ICMC-USP, como parte dos requisitos para obtenção do título de Mestre em Ciências - Área: Ciências de Computação e Matemática Computacional. 
A memória de Augusto Rodrigues. 


\section{AGRADECIMENTOS}

- a Deus, em especial pela família e pelos amigos que tenho, pois junto a eles minha vida torna-se absolutamente plena.

- a Regina pela orientação, apoio e estímulo, tão essenciais para o desenvolvimento desse trabalho.

- aos meus pais, Augusto e Olivia, pelo amor puro e incondicional durante toda minha vida.

- a Vania minha amiga, namorada e esposa por tanto amor, carinho e dedicação.

- a Maria Lucia, minha adorada irmã, pelo apoio e carinho.

- aos meus adorados irmãos Antonio, Neusa, Adilson, Carlos e Daniela pelo carinho.

- ao Milton pelo carinho e incentivo durante os momentos em que mais precisei.

- aos meus sobrinhos Adilson, Danitiele, Fábio, Bianca, Bárbara, Stefano, Roberta, Júnior, Pamela, Ruan e Vitoria por tornarem minha vida mais alegre.

- a minha mais nova família Norberto, Lindalva, Josmira, Erika, Emerson, Silvia e Vitoria.

- ao amigo Farias pelos conselhos e pelo apoio.

- ao sempre amigo Clodoaldo pela ajuda e alegria.

- ao amigo Valdemir pela presença em todos os momentos, felizes ou não.

- ao companheiro Marcelo pela valorosa presença em todos os dias dessa jornada.

- ao professor e amigo Trajano pelo incentivo.

- aos amigos matemáticos Pedro, Vladimir, Marcio, Marco, Erivaldo, Paulo, Nilton, Mauricio, Fabio e Adriano pelos momentos alegres.

- ao Pablo pela valorosa ajuda.

- a Maristela pelo apoio e interesse.

- aos amigos otimistas e analistas Fabio, Selma, Luciana, Ricardo, Fernando, Lilian, Rubia, Maju, Araxa, Thiago, Silvio, Gisele, Heloisa, Wellington, Luciane, Juliano, Vanderly e Lucimary.

- aos professores e funcionários do ICMC, pelo apoio.

- a FAPESP pelo apoio financeiro, fundamental para a realização desse trabalho. 


\section{ÍNDICE}

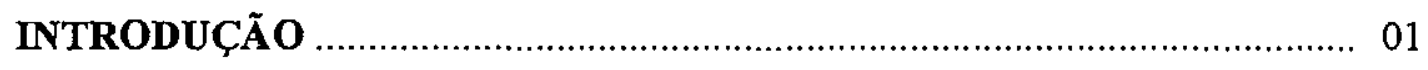

1 FORMULAÇÃO MATEMÁTICA ……................................................... 04

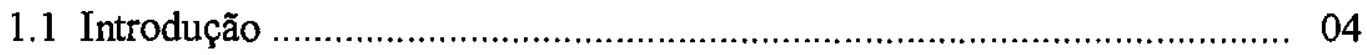

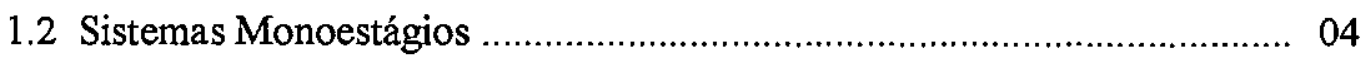

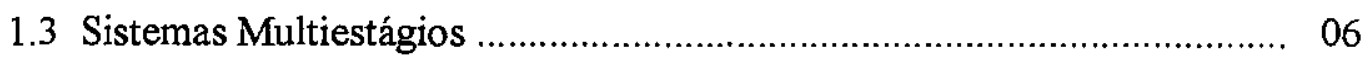

1.3.1 Formulação em Estoque Convencional ........................................... 08

1.3.2 Formulação em Estoque de Escalão.................................................. 09

1.4 Complexidade Computacional............................................................ 13

1.5 Revisão Bibliográfica ........................................................................ 14

2 META-HEURÍSTICAS EVOLUTIVAS .......................................... 21

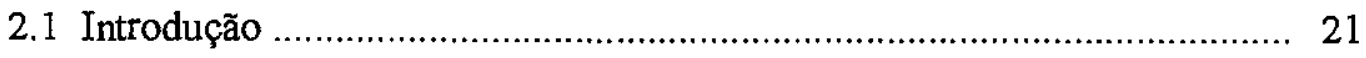

2.2 Heuristicas e Meta-Heurísticas ............................................................. 21

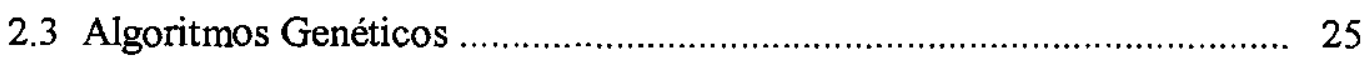

2.3.1 Um Algoritmo Genético para o Problema de Dimensionamento de Lotes Monoestágio ...................................... 33

2.4 Algoritmos Meméticos .................................................................... 35 


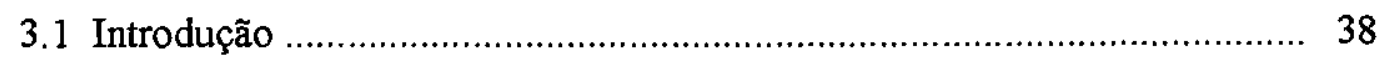

3.2 Procedimento para Obtenção de uma Solução Inicial - P1 ....................... 38

3.3 Características das Transferências .......................................................... 40

3.4 Procedimento de Factibilização - P2 …….......................................... 45

3.5 Procedimento de Melhoria - P3 ……................................................ 49

3.6 Procedimento de Alteração - P4 ........................................................ 53

3.7 Pseudo-Código da Heurística de França et al.(1997) ............................... 47

4 META-HEURÍSTICAS EVOLUTIVAS IMPLEMENTADAS ................ 57

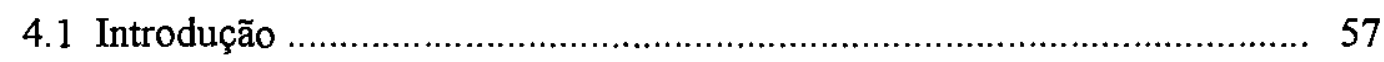

4.2 Componentes Básicos ................................................................... 57

4.2.1 Representação e Estrutura Populacional .......................................... 58

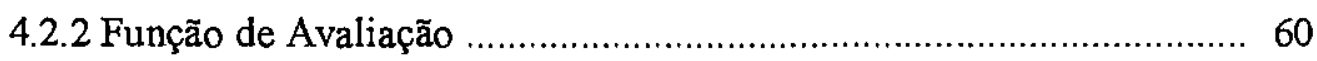

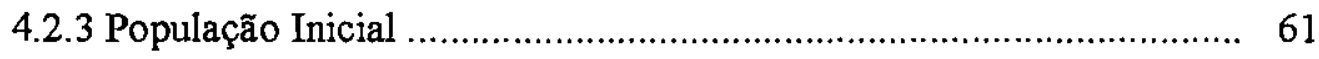

4.2.4 Mecanismos de Seleção dos Pais ..................................................... 62

4.2.5 Estratégias de Reprodução ........................................................... 62

4.3 Algoritmo Genético - GA ............................................................... 73

4.4 Algoritmo Memético - MA …………................................................ 75

5 RESULTADOS COMPUTACIONAIS …….......................................... 78

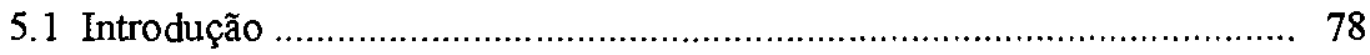

5.2 Geração dos Exemplos Numéricos ..................................................... 79

5.3 Análise dos Resultados dos Resultados para o Grupo 2 …..................... 82

5.3.1 Eficácia na Obtenção de Soluções Factíveis .................................. 83

5.3.2 Qualidade das Soluções Obtidas ................................................... 85

5.3.3 Análise da Infactibilidade .......................................................... 90 
5.3.4 Evolução da Incumbente 91

5.3.5 Análise do Tempo Computacional ........................................... 93

5.4 Análise dos Resultados para o Grupo 1 ............................................. 94

5.4.1 Eficácia na Obtenção de Soluções Factíveis ................................ 95

5.4.2 Qualidade das Soluções Obtidas ............................................. 96

6 CONCLUSÃO E PROPOSTAS FUTURAS ….................................. 100

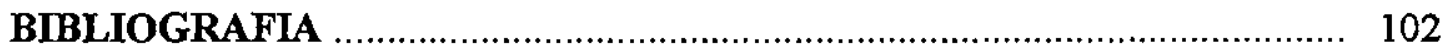




\section{RESUMO}

Esse trabalho aborda o problema de dimensionamento lotes com restrições de capacidade em sistemas multiestágios de produção, que consiste basicamente em determinar a quantidade e o período para produzir determinados produtos num dado horizonte de tempo de tal modo que uma certa demanda seja atendida. Em sistemas multiestágios de produção o planejamento de cada produto ainda depende do planejamento de outros, situados em níveis hierárquicos inferiores. Os modelos apresentados incluem custos e tempos de preparação, com o objetivo de melhor representar as caracteristicas dos problemas reais. Devido a complexidade envolvida na sua resolução, desenvolvemos métodos baseados em meta-heurísticas evolutivas, mais especificamente algoritmos genéticos e meméticos. As técnicas propostas foram avaliadas em conjuntos de exemplos numéricos gerados aleatoriamente. Os resultados obtidos foram comparados com a solução ótima para os exemplos de pequeno porte, e com um limitante inferior obtido pela aplicação da Relaxação Lagrangiana ao problema, para os exemplos de médio porte. 


\section{ABSTRACT}

This thesis deals with the multistage lotsizing problem with capacity constraints. The problem basically consists in determining the quantity to be produced in different periods in a planning horizon such that a forecast demand would be attained. In multistage production system the planning of each item depends on the production of others items, which are situated in inferior hierarchical levels. The mathematical models presented consider costs and setup times. Due the complexity to solve this problem, we developed methods based in the evolutionary metaheuristics, more specifically memetic and genetic algorithms. The heuristics proposed were evaluated in sets of instances randomly generated. The results obtained were compared with the optimal solution for instances of small sizes. For instances of medium size, the results were compared with a lower bound which was obtained by Lagrangian Relaxation. 


\section{INTRODUÇÃO}

$\mathrm{Na}$ atual conjuntura econômica, que apresenta uma economia globalizada e altamente competitiva, é fundamental que as empresas tenham um sistema de planejamento e controle da produção (PCP) eficiente. Esse setor é o responsável pela coordenação de todas as atividades inerentes ao processo produtivo, desde a compra da matéria-prima até a sua transformação em produtos acabados. Cabe a esse sistema também o gerenciamento dos recursos disponíveis à produção, como por exemplo, capacidade de produção, programa de distribuição, armazenagem dos produtos acabados e da matéria-prima, disponibilidade de mão-de-obra, controle dos níveis de estoque, entre outros. $\mathrm{O}$ PCP opera com estes recursos diariamente, com o objetivo de fornecer produtos e serviços que atendam as exigências dos consumidores.

O gerenciamento adequado destes recursos possibilita uma melhoria na qualidade de seus produtos, proporcionando uma maior satisfação de seus clientes, diminuição dos custos e conseqüentemente maior competitividade e lucro.

O setor de planejamento e controle pode ser dividido hierarquicamente em três níveis: estratégico, tático e operacional (Slack et al., 1997).

Ainda segundo Slack et al.(1997), o planejamento estratégico trata das questões de longo prazo, planejando as necessidades de recursos e quais objetivos financeiros deverão ser alcançados.

Cabe ao planejamento tático executar as metas definidas no planejamento estratégico. Nesse nível é feita a alocação dos recursos necessários e disponíveis à produção, controle dos níveis de estoque, definição do plano mestre de produção (Master Production Schedule) e o planejamento da compra ou manufatura dos itens que irão compor o produto final (Berretta, 1997). O plano mestre de produção define a quantidade e o momento em que os produtos finais devem ser produzidos, com base em previsões de demanda do mercado. 
As decisões de curto prazo referem-se ao planejamento operacional, que envolve as decisões tomadas diariamente. Como por exemplo, alocação de pedidos aos centros de trabalho, compra de componentes e matéria-prima, programação das máquinas, controle de qualidade, definição das rotas de distribuição, entre outras atribuições (Berretta, 1997).

Esse trabalho se concentra nos problemas de planejamento e controle da produção de produtos, que envolvem também o planejamento de itens componentes, os quais também deverão ser produzidos e/ou comprados. Sistemas com esse tipo de estrutura de produtos são chamados de multiestágios. Essas decisões estão situadas no nível do planejamento tático.

Existem vários sistemas que fazem esse gerenciamento, um dos mais utilizados é o MRP (Material Requirements Planning), que surgiu durante a década de 60. Esse sistema tem por objetivo determinar um plano de fabricação dos produtos acabados, assim como a fabricação (ou compra) dos itens componentes. O MRP fornece a quantidade exata ao longo do tempo, a ser produzida (ou comprada) de um determinado item, de modo a atender a sua previsão de demanda.

Embora sejam amplamente utilizados, os sistemas MRP sofrem algumas críticas. Uma delas é que em sua forma básica não leva em conta as limitações dos recursos de produção (Tempelmeier, 1997). Se os recursos são excedidos, deve ser feito um remanejamento de parte da produção ou a adição de capacidade (overtime) na tentativa de ajustar tal plano. Entretanto, esse remanejamento pode causar planos impraticáveis. Alérn disso, a princípio o plano gerado pelo sisterna MRP não fornece um plano de produção no sentido de seu custo ser o menor possível (Berretta, 1997).

O problema de dimensionamento de lotes (lot sizing) trata essencialmente dessas questões, ou seja, seu objetivo é determinar o tamanho dos lotes de produção de forma a minimizar os custos envolvidos, sujeito a um conjunto de restrições. Determina a quantidade e o período para produzir cada item num dado horizonte de tempo de tal modo que a demanda seja atendida. Em sistemas de produção multiestágios o planejamento de cada item ainda depende do planejamento de outros itens, situados em níveis hierárquicos inferiores.

Os custos envolvidos no problema de dimensionamento de lotes podem ser de produção, estoque e ainda um custo de preparação (setup cost), sendo este um custo fixo cobrado quando se decide produzir um determinado lote de um item, num determinado período. Para considerar a utilização dos recursos, podemos levar em conta o gasto por quantidade produzida e o gasto para preparar a produção de um lote de um determinado item (setup time). Em problemas envolvendo limitações de recursos é de fundamental importância considerar o seu consumo na preparação, uma vez que esta pode utilizar uma quantidade considerável de recursos.

Considerar custos e tempos de preparação diferentes de zero, faz com que, matematicamente, o problerna seja modelado como um problema de programação matemática inteiro-misto de dificil resolução, tornando dificil mesrno a obtenção de um plano factível. Entretanto, sua inclusão se faz 
necessária para que se tenha o consumo real dos recursos (Berretta, 1997).

Dada a dificuldade de resolver de forma exata importantes problemas devido à complexidade, recorremos ao uso de algoritmos heurísticos. Esses métodos são muito atraentes do ponto de vista prático, pois além de serem, geralmente, de fácil entendimento, conseguem gerar soluções sem muito esforço computacional, embora sem garantia de obter soluções ótimas.

O objetivo principal desse trabalho é a elaboração de heurísticas, com uso de técnicas mais sofisticadas, denominadas meta-heurísticas, para a resolução do problema de dimensionamento de lotes multiestágio com limitações de capacidade considerando custos e tempos de preparação. As heurísticas envolvem meta-heurísticas do tipo evolutivas e incorporam técnicas de busca local (algoritmos meméticos), uma vez que este tipo de procedimento tem se mostrado eficaz para diversos problemas (MAhomepage, 2000 e Moscato, 1999).

A dissertação está organizada da maneira descrita a seguir.

No Capítulo 1 apresentamos os modelos matemáticos para problemas de dimensionamento de lotes com restrições de capacidade em sistemas monoestágios e multiestágios. Descrevemos também a complexidade computacional envolvida na sua resolução, e ainda uma revisão bibliográfica de alguns artigos que tratam deste problema e das técnicas utilizadas na sua resolução.

A introdução dos conceitos referentes às heurísticas e meta-heurísticas evolutivas é feita no Capítulo 2, mais especificamente algoritmos genéticos e meméticos. Abordamos algumas das dificuldades encontradas na utilização dessas técnicas para o problema de dimensionamento de lotes, juntamente com alguns exemplos de aplicação em problemas de Otimização Combinatória.

No Capítulo 3 descrevemos as heurísticas encontradas em França et al.(1997), que foram utilizadas nas meta-heurísticas evolutivas propostas, inclusive como heurística de busca local nos algoritmos meméticos.

No Capítulo 4 apresentamos as meta-heurísticas que foram implementadas e testadas durante o desenvolvimento desse trabalho. Descrevemos os parâmetros utilizados nos testes, como representação das soluções, tamanho da população, estrutura da população, operadores de reprodução e seleção.

Os experimentos computacionais estão descritos no Capítulo 5. Diferentes estratégias foram testadas e avaliadas através de ajustes nos parâmetros das meta-heurísticas. As meta-heurísticas implementadas foram testadas em conjuntos de exemplos gerados aleatoriamente, segundo parâmetros já encontrados na literatura e os resultados obtidos foram comparados com a heurística encontrada em França et al.(1997).

Finalmente o Capítulo 6 apresenta as conclusões desse trabalho e sugestões para futuras pesquisas. 


\section{CAPÍTULO 1}

\section{FORMULAÇÃO MATEMÁTICA}

\subsection{Introdução}

Nesse capitulo apresentamos os modelos matemáticos para o problema de dimensionamento de lotes com restrições de capacidade em sistemas monoestágios e multiestágios. Embora esse trabalho esteja concentrado no caso de sistemas multiestágios, o modelo monoestágio é apresentado com o intuito de um melhor entendimento do problema em ambiente multiestágio. Para os sistemas multiestágios são apresentadas formulações em estoque convencional e estoque de escalão. Descrevemos também a complexidade computacional envolvida na resolução de tais problemas, e ainda uma revisão bibliográfica de artigos que abordam tanto o problema quanto a metodologia utilizada em sua resolução.

\subsection{Sistemas Monoestágios}

Um sistema é denominado monoestágio quando os itens a serem produzidos são independentes, ou seja, a produção de um item não depende de outros. 
Os custos normalmente considerados são os de produção, estoque e preparação (setup). Podemos impor penalidades (custos adicionais), quando por exemplo, a demanda não é atendida ou temos estoque negativo. Ou ainda custos pela utilização de hora-extra ou pela subutilização de equipamentos.

Os ambientes de produção possuem certas capacidades que deverão ser respeitadas, para que se possa garantir a viabilidade de um determinado plano de produção. Essas capacidades podem ser tempo, recursos financeiros, mão-de-obra, etc. A utilização eficiente destas capacidades, evita uma série de custos decorrentes tanto do uso em excesso quanto da subutilização destes recursos.

A manutenção dos estoques é essencial para que se possa produzir além da demanda de um produto num certo período, ou mesmo não produzir se for o caso, e ainda assim atender a demanda através do excesso de produção acumulado em estoque. Entretanto, devem ser evitados excessos de estoque, em razão dos custos ocasionados por este acúmulo. O estoque pode em algumas situações ser negativo (backorder), embora aqui seja considerado sempre positivo.

O problema de dimensionamento de lotes monoestágio consiste em determinar as quantidades a serem produzidas e os níveis de estoque de $N$ itens, ao longo de um horizonte de planejamento de $T$ períodos, supondo a demanda de cada item conhecida. $\mathrm{O}$ objetivo é minimizar os custos envolvidos, atendendo a demanda e obedecendo as limitações de recursos para produção de cada período.

A demanda e os custos envolvidos podem variar de um período para outro, assim como as limitações de capacidade.

Assim, consideremos os seguintes dados:

$N$ : número de itens a serem produzidos $(i=1, \ldots, N)$

$T$ : número de períodos $(t=1, \ldots, T)$

$c_{i t}$ : custo de produção do item $i$ no período $t$

$h_{i t}$ : custo de estoque do item $i$ no período $t$

$s_{t t}$ : custo de preparação do item $i$ no período $t$

$v_{i t}$ : recurso utilizado na produção do item $i$ no período $t$

$\mathrm{f}_{\text {it }}$ : recurso utilizado na preparação do item $i$ no período $t$

$b_{t}$ : disponibilidade de recursos no período $t$

$M$ : um número suficientemente grande

e as seguintes variáveis:

$x_{i t}:$ quantidade produzida do item $i$ no período $t$

$I_{\text {it }}$ : quantidade estocada do item $i$ no período $t$

$y_{i t}:\left\{\begin{array}{l}1, \text { se houver produção do item } i \text { no período } t \\ 0, \text { c.c. }\end{array}\right.$ 
O modelo matemático, segundo Trigeiro et al.(1989), é o seguinte

$$
\min z=\sum_{i=1}^{N} \sum_{t=1}^{T}\left(c_{i t} x_{i t}+h_{i t} I_{i t}+s_{i t} y_{i t}\right)
$$

sujeito a

$$
\begin{gathered}
I_{i, t-1}+x_{i t}-I_{i t}=d_{i t}, i=1, \ldots, N \text { e } t=1, \ldots, T \\
\sum_{i=1}^{N}\left(\mathrm{v}_{i t} x_{i t}+\mathrm{f}_{i t} y_{i t}\right) \leq b_{t}, t=1, \ldots, T \\
x_{i t} \leq M y_{i t}, i=1, \ldots, N \text { e } t=1, \ldots, T \\
x_{i t}, I_{i t} \geq 0, i=1, \ldots, N \text { e } t=1, \ldots, T \\
y_{i t} \in\{0,1\}, i=1, \ldots, N \text { e } t=1, \ldots, T
\end{gathered}
$$

A função objetivo (1) minimiza a soma dos custos de produção, estoque e de preparação ao longo do horizonte de planejamento. A equações (2) indicam o balanceamento entre produção e estoque, determinando que a demanda de um item será satisfeita pela produção do período mais o estoque do período anterior, e que o excedente ficará estocado. As inequações (3) representam as restrições de capacidade, que limitam a utilização dos recursos pela sua disponibilidade em cada período. As inequações (4) garantem que, se não houver produção de um item no período, então não haverá preparação do mesmo. A positividade das variáveis de estoque e produção estão impostas pelas inequações (5), e as inequações (6) indicam tratar-se de variáveis binárias.

Nas inequações (4), podemos atribuir a $M$ um valor em função da demanda total de um item, durante todo o horizonte de planejamento, isto é, para cada item teríamos $M_{i}=\sum_{i=1}^{T} d_{i t}$.

\subsection{Sistemas Multiestágios}

Um sistema é denominado multiestágio, quando um item final possui itens componentes, ou seja, a produção de um determinado item depende de outros itens, chamados predecessores, para os quais também deverá ser feito um planejamento (produção ou compra). 
Esses itens componentes podem possuir ou não demanda própria, denominada demanda independente. Numa indústria de automóveis, por exemplo, o item farol além de compor o item final automóvel pode ter uma quantidade vendida para lojas de autopeças. Assim precisamos planejar a produção de uma quantidade suficiente para compor o item automóvel mais uma quantidade para atender a demanda independente do item farol.

A estrutura de um determinado item, pode ser representada por um grafo orientado acíclico, sendo que, se o item $i$ é predecessor de $j$ então temos que $i>j$, como mostra a Figura 1.1.

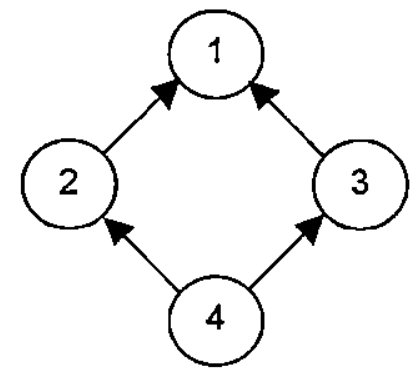

Figura 1.1 Exemplo de uma estrutura de produto.

As estruturas são classificadas de acordo o número de predecessores e sucessores, como descrevemos a seguir.

- Serial: com exceção do primeiro e do último item, todos possuem um único sucessor e um único predecessor.

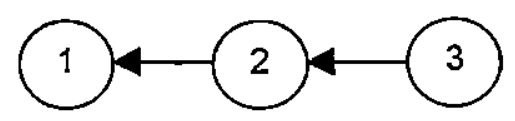

Figura 1.2 Exemplo de uma estrutura serial.

- Montagem: todos os itens possuem um único sucessor, mas não há limites quanto ao número de predecessores.

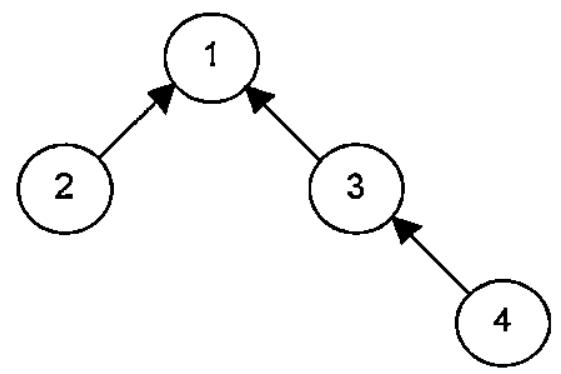

Figura 1.3 Exemplo de uma estrutura montagem. 
- Geral: é a reunião dos casos anteriores, ou seja, não há restrições quanto ao número de predecessores e sucessores.

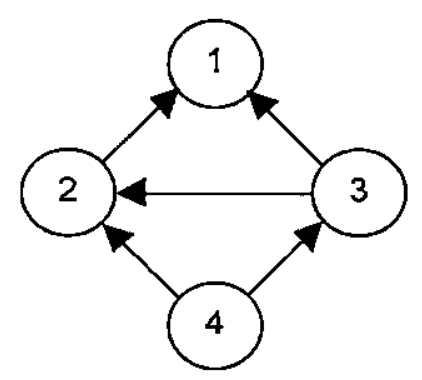

Figura 1.4 Exemplo de uma estrutura geral.

Utilizamos a seguinte notação para representar os conjuntos de itens sucessores e predecessores:

$S(i)$ : conjunto dos itens sucessores imediatos do item $i$;

$P(i)$ : conjunto dos itens predecessores imediatos do item $i$;

$r_{i j}$ : quantidade necessária do item $i$ para compor uma unidade item $j$.

Tomando o exemplo da Figura 1.4, temos

$$
\begin{array}{ll}
S(1)=\emptyset & P(1)=\{2,3\} \\
S(2)=\{1\} & P(2)=\{3,4\} \\
S(3)=\{1,2\} & P(3)=\{4\} \\
S(4)=\{2,3\} & P(4)=\emptyset
\end{array}
$$

Os modelos apresentados em seguida, estão formulados para o caso da estrutura geral, uma vez que as outras representam casos particulares desta. A seguir, as formulações em estoque convencional.

\subsubsection{Formulação em Estoque Convencional}

No caso de sistemas multiestágios, temos que a produção de um item deve ser suficiente para compor os lotes de seus itens sucessores além da sua própria demanda.

O modelo matemático, segundo Billington (1983), é o seguinte 


$$
\min z=\sum_{i=1}^{N} \sum_{i=1}^{T}\left(c_{i t} x_{i t}+h_{i t} I_{i t}+s_{i t} y_{i t}\right)
$$

sujeito a

$$
\begin{gathered}
I_{i, i-1}+x_{i t}-I_{i t}=d_{i t}+\sum_{j \in S(i)} r_{i j} x_{j t}, \quad i=1, \ldots, N \text { e } t=1, \ldots, T \\
\sum_{i=1}^{N}\left(\mathrm{v}_{i t} x_{i t}+\mathrm{f}_{i t} y_{i t}\right) \leq b_{t}, t=1, \ldots, T \\
x_{i t} \leq M y_{i t}, i=1, \ldots, N \text { e } t=1, \ldots, T \\
x_{i t}, I_{i t} \geq 0, i=1, \ldots, N \text { e } t=1, \ldots, T \\
y_{i t} \in\{0,1\}, i=1, \ldots, N \text { e } t=1, \ldots, T
\end{gathered}
$$

Esse modelo é idêntico ao modelo monoestágio (1)-(6), com exceção das equações de balanceamento (8). Tais restrições determinam que a demanda do item mais a quantidade necessária para compor os lotes dos itens sucessores, será satisfeita pela produção do período mais - estoque do período anterior, e que o excedente ficará estocado. Nesse modelo, surge a dependência entre os itens, explicitada pelas equações (8). Essa dependência é imposta pelos múltiplos estágios existentes, onde um item terá outros itens como componentes.

\subsubsection{Formulação em Estoque de Escalão}

Uma formulação que apresenta algumas vantagens em relação a anterior, é obtida quando adotamos o conceito de estoque de escalão. Estoque de escalão de um item é o estoque convencional do item mais a quantidade do item contida no estoque de seus sucessores, ou seja, é a quantidade total do item presente no sistema. Esse conceito foi introduzido por Clark e Scarf (1960) e implementado por Afentakis et al.(1984).

Seja por exemplo, uma indústria de automóveis, e consideremos o item pneu, que tem como único sucessor o item final automóvel. Nesse caso, o estoque de escalão do item pneu é a quantidade de pneus no estoque convencional mais cinco vezes a quantidade de automóveis em estoque (supondo que cada automóvel tenha cinco pneus). 
Assim, definimos o estoque de escalão do item $i$ no período $t$, por

$$
E_{i t}=I_{i t}+\sum_{j \in S(i)} r_{i j} E_{j t}
$$

Exemplo 1.1 Considerando a estrutura da Figura 1.5,

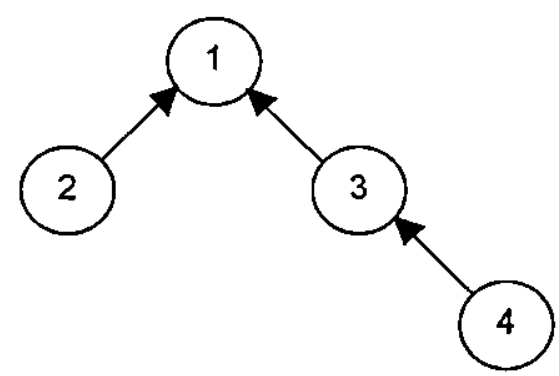

Figura 1.5 Exemplo de uma estrutura montagem.

e aplicando (13) para o item final, temos o seguinte estoque

$$
E_{1 t}=I_{1 t}
$$

Neste caso o estoque convencional coincide com o estoque de escalão, pois o item final não possui sucessores.

O estoque de escalão do item 2 , é o seu estoque convencional mais a quantidade presente em seu item sucessor (1), assim

$$
E_{2 t}=I_{2 t}+r_{21} I_{1 t}
$$

e substituindo (14) na equação anterior,

$$
E_{2 t}=I_{2 t}+r_{21} E_{1 t}
$$

Para o item 3, temos

$$
\begin{aligned}
& E_{3 t}=I_{3 t}+r_{31} I_{1 t} \\
& E_{3 t}=I_{3 t}+r_{31} E_{1 t} .
\end{aligned}
$$

Finalmente para o item 4 , 


$$
\begin{aligned}
& E_{4 t}=I_{4 t}+r_{43} I_{3 t}+r_{43} r_{31} I_{1 t} \\
& E_{4 t}=I_{4 t}+r_{43}\left(I_{3 t}+r_{31} I_{1 t}\right) \\
& E_{4 t}=I_{4 t}+r_{43}\left(I_{3 t}+r_{31} E_{1 t}\right) \\
& E_{4 t}=I_{4 t}+r_{43} E_{3 t} .
\end{aligned}
$$

Definimos também, o custo de estoque de escalão em termos do custo de estoque convencional, de tal modo que a equivalência

$$
\sum_{i=1}^{N} \sum_{i=1}^{T} e_{i t} E_{t}=\sum_{i=1}^{N} \sum_{i=1}^{T} h_{t i} I_{t},
$$

seja mantida. Assim, o custo de estoque de escalão de um item i no período t, é dado por

$$
e_{i t}=h_{i t}-\sum_{j \in P(i)} r_{j i} h_{j t}
$$

Analisando as equações de balanceamento para o item 3 da Figura 1.5, temos

$$
I_{3, t-1}+x_{3 t}-I_{3 t}=d_{3 t}+r_{31} x_{1 t}
$$

sendo $x_{1 t}$ é determinado por

$$
I_{1, t-1}+x_{1 t}-I_{1 t}=d_{1 t} \Rightarrow x_{1 t}=d_{1 t}-I_{1, t-1}+I_{1 t}
$$

Substituindo (17) em (16),

$$
\begin{aligned}
I_{3, t-1}+x_{3 t}-I_{3 t} & =d_{3 t}+r_{31}\left(d_{1 t}-I_{1, t-1}+I_{1 t}\right) \\
I_{3, t-1}+x_{3 t}-I_{3 t} & =d_{3 t}+r_{31} d_{1 t}-r_{31} I_{1, t-1}+r_{31} I_{1 t} \\
I_{3, t-1}+r_{31} I_{1, t-1}+x_{3 t}-I_{3 t}-r_{31} I_{1 t} & =d_{3 t}+r_{31} d_{1 t}
\end{aligned}
$$

logo,

$$
E_{3, t-1}+x_{3 t}-E_{3 t}=d_{3 t}+r_{31} d_{1 t}
$$

Definindo demanda de escalão como sendo, a demanda de um item mais a demanda dos seus sucessores, temos

$$
D_{i t}=d_{i t}+\sum_{j \in S(i)} r_{t j} D_{j t}
$$

Assim, reescrevendo a equação (18), temos a equação do balanceamento em termos do estoque de escalão para o item 3 ,

$$
E_{3, t-1}+x_{3 t}-E_{3 t}=D_{3 t}
$$


E generalizando este resultado, obtemos a equação do balanceamento para um item $i$ num periodo $t$, em termos do estoque de escalão,

$$
E_{i, t-1}+x_{i t}-E_{i t}=D_{i t}
$$

Finalmente, pela definição de estoque de escalão,

$$
E_{i t}=I_{i t}+\sum_{j \in S(i)} r_{i j} E_{j t}
$$

e impondo que o estoque de um item seja maior que zero $\left(I_{i t}>0\right)$, temos

$$
E_{i i} \geq \sum_{j \in S(i)} r_{i j} E_{j t}
$$

Desse modo, podemos apresentar a formulação em estoque de escalão para o problema de dimensionamento de lotes em ambiente multiestágio, que é dada por

$$
\min z=\sum_{i=1}^{N} \sum_{t=1}^{T}\left(c_{i t} x_{i t}+e_{i t} E_{i t}+s_{i t} y_{i t}\right)
$$

sujeito a

$$
\begin{gathered}
E_{i, t-1}+x_{i t}-E_{i t}=D_{i t}, \quad i=1, \ldots, N \text { e } t=1, \ldots, T \\
\sum_{j \in S(i)} r_{i j} E_{j t}-E_{i t} \leq 0, i=1, \ldots, N \text { e } t=1, \ldots, T \\
\sum_{i=1}^{N}\left(\mathrm{v}_{i t} x_{i t}+\mathrm{f}_{i t} y_{i t}\right) \leq b_{t}, t=1, \ldots, T \\
x_{i t} \leq M y_{i t}, i=1, \ldots, N \text { e } t=1, \ldots, T \\
x_{i t}, E_{i t} \geq 0, i=1, \ldots, N \text { e } t=1, \ldots, T \\
y_{i t} \in\{0,1\}, i=1, \ldots, N \text { e } t=1, \ldots, T
\end{gathered}
$$

A equivalência entre essa formulação (22)-(28) e a (7)-(12) é mostrada por Clark e Armentano (1993). Note que nas equações de balanceamento (23), não há dependência entre os itens, como havia no modelo anterior, esta dependência surge agora na inequações (24). $O$ conjunto de inequações (24) garante que o estoque de escalão de um item deve ser suficiente para suprir o 
estoque de escalão dos seus sucessores imediatos.

Embora as formulações sejam equivalentes, o modelo em estoque de escalão apresenta algumas vantagens. Se o conjunto de restrições (24) e (25) forem relaxados, aplicando Relaxação Lagrangiana, por exemplo, obtemos um modelo de dimensionamento de lotes monoestágio não capacitado. Tal modelo pode ser decomposto em $N$ subproblemas, um para cada item, no qual pode ser aplicado o algoritmo de Wagner e Whitin e assim obter um limitante inferior para o problema original.

$O$ algoritmo de Wagner e Whitin (ou, simplesmente WW) é um método de programação dinâmica, que resolve de maneira ótima o problema de dimensionamento de lotes monoestágio sem restrições de capacidade, para um único item ao longo de um horizonte de planejamento. Aplicando o algoritmo de Wagner e Whitin para cada subproblema, referente a um item, separadamente, ao final podemos reunir as soluções encontradas e obter uma solução para o problema original. Esta solução pode ser infactível com relação as restrições relaxadas, sendo necessário neste caso a utilização de algum procedimento para factibilizar esta solução.

A próxima seção, trata das questões referentes a complexidade computacional envolvida na resolução do problema de dimensionamento de lotes.

\subsection{Complexidade Computacional}

Se não forem considerados tempos e custos de preparação no problema de dimensionamento de lotes, mesmo considerando as restrições de capacidade para produção, temos um problema de Programação Linear. Logo pode ser resolvido de maneira ótima se utilizarmos, por exemplo, o método simplex.

Quando as restrições de capacidade não são incorporadas no modelo, mesmo com custos de preparação, o problema monoestágio pode ser resolvido pelo algoritmo ótimo de Wagner e Whitin.

Considerar restrições de capacidade e custos de preparação não nulos tornam o problema da classe NP-Hard (Garey e Johnson, 1979), mesmo com tempos de preparação nulos. Dessa forma, é improvável que exista um algoritmo que encontre a solução ótima do problema em tempo polinomial. Se os tempos de preparação não nulos são considerados no modelo, o problema de factibilidade toma-se NP-Completo (Maes et al., 1991), ou seja, é improvável que exista um algoritmo em tempo polinomial capaz de dizer se existe uma solução factível para um determinado exemplo numérico. 
Devido as dificuldades encontradas na resolução do problema, uma alternativa é o uso de métodos heurísticos, que não garantem encontrar solução ótima, e em alguns casos não garantem obter a factibilidade, rnas podem, no entanto, gerar boas soluções num tempo computacional razoável.

$\mathrm{Na}$ próxima seção apresentamos os principais trabalhos que abordam o problema de dimensionamento de lotes.

\subsection{Revisão Bibliográfica}

Nesta seção descrevemos alguns trabalhos, que tratam do problema de dimensionamento de lotes. Os artigos de Bahl et al.(1987), Billington et al.(1983) e Kuik et al.(1994), fazem uma revisão ampla na área de dimensionamento de lotes.

Billington et al.(1983) apresentam uma revisão para problemas em sistemas multiestágios com restrições de capacidade, incluindo tempos e custos de preparação, lead time (tempo gasto a partir da ordem de produção do item até que ele esteja pronto) e estoque sempre positivo. Classificam os trabalhos de acordo com a estrutura dos produtos: serial, plana, montagem e geral.

Em seu trabalho, Bahl et al.(1987) fazem uma revisão classificando diversos trabalhos de acordo com o ambiente de produção, monoestágio ou multiestágio, e ainda recursos para produção limitados ou ilimitados, comparando a eficiência de diversas técnicas existentes para estes problemas. Os critérios de comparação utilizados são esforço computacional, generalização, otimalidade e simplicidade.

O artigo de Kuik et al.(1994) apresenta estruturas e modelos de decisão para o problema de dimensionamento de lotes. Fazem uma categorização da estrutura de decisão em três níveis hierarquicamente inter-relacionados, que são: escolha/projeto do processo, planejamento da atividade e controle da atividade.

A apresentação dos artigos a seguir está dividida de acordo com o sistema de produção.

\section{Sistemas Monoestágios}

Para o problema de dimensionamento de lotes monoestágio com restrições de capacidade, além 
dos artigos de Bahl et al.(1987) e Kuik et al.(1994) podemos citar os artigos de Diaby et al.(1992a,1992b) e Trigeiro et al.(1989) que fazem revisões nesta área. Além desses, os trabalhos de Haase e Kohlmorgen (1998) e Özdamar e Birbil (1998) que utilizam algoritmos genéticos. Todos considerando custos e tempos de preparação.

Quando as limitações de recursos não são consideradas, podemos decompor o problema em N subproblemas independentes, e resolvê-lo de maneira ótima utilizando o algoritmo de programação dinâmica proposto por Wagner e Whitin (WW).

O trabalho de Diaby et al.(1992a) utiliza Relaxação Lagrangiana com otimização por subgradiente para a geração de limitantes superiores, que são utilizados num Branch and Bound para localização de soluções ótimas, considerando o problema com uma única restrição de capacidade. Obtêm soluçð̃es a $1 \%$ do ótimo, para exemplos de até 8 itens e 8 períodos. Diaby $e t$ al.(1992b) utilizam a mesma técnica só que para problemas de grande porte, obtendo soluções excelentes para exemplos com até 5000 itens e 30 períodos.

Trigeiro et al.(1989) consideram também o problema com restrições de capacidade. Eles utilizam Relaxação Lagrangiana nas restrições de recursos, para decompor o problema em subproblemas monoestágios não capacitados com um único item, os quais são resolvidos pelo algoritmo de Wagner e Whitin. Um procedimento heurístico então é utilizado, caso necessário, para factibilizar os planos de produção obtidos.

Os artigos de Haase e Kohlmorgen (1998) e Özdamar e Birbil (1998) foram trabalhos encontrados que utilizam estratégias de resolução baseadas em algoritmos genéticos, para o problema de dimensionamento de lotes monoestágio.

Haase e Kohlmorgen (1998) apresentam um algoritmo genético que utiliza processadores paralelos, para a resolução o problema de dimensionamento de lotes capacitado monoestágio. $\mathrm{O}$ algoritmo é testado num conjunto de exemplos numéricos com 50 itens e 20 períodos, 20 itens e 20 períodos e 8 itens e 50 períodos, num total de 120 exemplos. Os resultados obtidos são comparados com a heurística de Dixon e Silver (1981) e a de Kirca e Kökten (1994). O algoritmo genético obteve os melhores resultados para os problemas com 8 e 50 itens, perdendo na média para o algoritmo de Kirca e Kökten (1994). Em geral o algoritmo consegue obter bons resultados, embora o tempo computacional envolvido na resolução seja alto.

O artigo de Ozdamar e Birbil (1998) apresenta uma heurística híbrida para o problema de dimensionamento de lotes, com decisões de hora-extra, juntamente com o problema de carregamento. As decisões de carregamento dizem respeito a designação de lotes de famílias de produtos às máquinas, onde existem máquinas paralelas no estágio de produção. Desenvolveram uma heurística usando algoritmos genéticos, que utiliza um procedimento de busca local baseado em Busca Tabu e Simulated Annealing. Os resultados são comparados com a solução ótima de 
108 problemas testes pequenos e 36 de tamanho grande, gerados aleatoriamente, obtendo resultados melhores do que outras técnicas reportadas no artigo.

\section{Sistemas Multiestágios}

Para o problema de dimensionamento de lotes em sistemas multiestágios, os artigos foram divididos de acordo com fato de considerarem ou não custos e tempos de preparação. Sendo dada maior ênfase ao caso que inclui custos e tempos de preparação, por se tratar do tema central desta pesquisa.

\section{Incluindo Custos de Preparação e Tempos de Preparação Nulos}

Artigos que apresentam uma abordagem ótima para este problema são em número reduzido, entre eles o de Lambrecht e Vandervecken (1978), Gabbay (1979) e Steinberg e Napier (1980). Em seu artigo, Lambrecht e Vandervecken (1978) estudam o problema para o caso da estrutura serial, considerando restrições de capacidade somente para o item final. Gabbay (1979) considera restrições de recursos em cada nível e propôs um algoritmo de programação dinâmica, utilizando uma formulação para o problema com múltiplos itens na estrutura serial. Steinberg e Napier (1980) usaram técnicas de modelagem em redes, para a estrutura geral. Apesar de ótimo, o método é computacionalmente inviável para problemas de médio e grande porte. Foram testados exemplos de 3 itens, 4 estágios e 20 períodos.

Abordagens heurísticas são encontradas em urn núrnero maior de artigos, como os trabalhos de Blackburn e Millen (1984), Maes et al.(1991), Roll e Kami (1991) e Kuik et al. (1993).

Para a estrutura montagem, Blackburn e Millen (1984) usam urna técnica para modificação de custos na função objetivo, para considerar os efeitos das limitações de capacidade em diferentes estágios. Em seguinda utilizam urn método monoestágio, a partir do item final.

O artigo de Maes et al.(1991) utiliza três heurísticas baseadas em Relaxação Linear. As heurísticas tem sua performance testada para uma grande quantidade de problemas testes de pequeno porte, gerados aleatoriamente, obtendo um bom desempenho.

O trabalho de Roll e Karni (1991) apresenta uma heurística, que parte de uma solução gerada pelo algoritmo de Wagner e Whitin item a item, sem as restrições de capacidade. Se a solução obtida é infactível, é aplicado urn novo procedimento baseado em transferências de produção, para eliminar a infactibilidade. Em seguida são aplicados procedimentos de melhoria nesta solução. 
Kuik et al.(1993) comparam heurísticas baseadas em Programação Linear com heurísticas que utilizam Simulated Annealing e Busca Tabu, para as estruturas serial e montagem. Foram testados exemplos com 6 e 7 itens, até 3 estágios e 12 períodos. Eles concluiram que as heurísticas que combinam Programação Linear com Simulated Annealing e Busca Tabu, conseguem melhores resultados do que as que utilizam somente Programação Linear.

\section{Incluindo Custos e Tempos de Preparação}

Trabalhos que consideram o problema com custos e tempos de preparação são poucos, devido à complexidade envolvida e, em geral, são heurísticas para casos especiais (Billington et al.(1986), Toklu e Wilson (1992,1995), Harrison e Lewis (1996)). Para casos mais gerais podemos citar os trabalhos de Clark e Armentano (1993,1995), Tempelmeier e Derstroff (1996), Tempelmeier (1997), França et al.(1997), Berretta (1997) e Katok et al.(1998). Artigos que utilizam algoritmos genéticos para problema de dimensionamento de lotes multiestágio, são os trabalhos de Helber (1995) e Kimms (1997), sendo este último para o problema de dimensionamento de lotes juntamente com o problema de seqüenciamento.

Billington et al.(1986) consideram limites de capacidade em apenas um estágio da estrutura, supondo a existência de uma máquina gargalo neste nível. Apresentam uma heurística baseada em Relaxação Lagrangiana, utilizando a metodologia Branch and Bound. Relaxam e incorporam as restrições de capacidade e balanceamento na função objetivo, e resolvem heuristicamente o problema lagrangiano resultante item a item. Caso necessário, uma heurística de factibilização baseada em transferências de produção é aplicada. Considerando estruturas serial e montagem, exemplos com 5 itens em série mostram gap de $29 \%$ a $62 \%$, comparando a solução da heurística com o limitante inferior obtido pela Relaxação Lagrangiana. Sendo que, em 8 exemplos a solução obtida esteve a $1 \%$ do ótimo.

O artigo de Toklu e Wilson (1992) propõe uma heurística gulosa para casos especiais do modelo apresentado por Billington (1986). A heurística divide os itens em itens finais e não finais, impondo restrições de capacidade somente aos itens finais. Utilizam a política EOQ (Economic Order Quantity) para os itens não finais, supondo demanda constante. Tomando os mesmos exemplos que foram adotados por Billington (1986), mostram gap entre $20 \%$ e $36 \%$, comparando a soluçăo da heurística com a do problema linear relaxado. Toklu e Wilson (1995) substituem a política EOQ pela heurística de Silver-Meal, obtendo melhores resultados.

Harrison e Lewis (1996) não consideram custos de preparação, mas levam em conta os recursos utilizados na preparação. Através da relaxação da restrição de capacidade, transformam o 
problema num problema de programação linear, o qual é resolvido várias vezes. Conseguiram obter melhores soluções, quando comparado com o pacote de otimização OSL (Optimization Subrotines Library) com tempo de processamento limitado.

Em seu trabalho, Clark e Armentano (1993) utilizam o conceito de estoque de escalão, apresentando um modelo matemático baseado no de Billington et al.(1983). Em outro trabalho, Clark e Armentano (1995) propõem uma heurística para a resolução do modelo anterior. A heurística é iniciada com uma solução obtida pela aplicação seqüencial do algoritmo de Wagner e Whitin. A seguir, tenta factibilizar essa solução através de transferências de produção entre os períodos. Para 20 exemplos com 40 itens, 12 períodos e 2 recursos, obtiveram um gap médio de $3.7 \%$ (custo de preparação baixo) e $25.5 \%$ (custo de preparação alto) para a estrutura geral. Para a estrutura plana, conseguiram um gap médio de $1.1 \%$ (custo de preparação baixo) e de $13.2 \%$ (custo de preparação alto). Comparando as soluções encontradas com o limitante inferior obtido pela aplicação de Relaxação Lagrangiana. Para exemplos com 5 itens, os gaps obtidos foram $4.9 \%$ com relação ao valor ótimo e $25.1 \%$ em relação ao limitante inferior, indicando um gap de dualidade de $19 \%$. Por esta razão, os autores acreditam que os resultados obtidos nos problemas maiores sejam melhores do que aparentam.

O trabalho de Tempelmeier e Derstroff (1996) considera limitações de capacidade em todas as operações, e não somente numa máquina gargalo como Billington et al.(1986). Por meio da aplicação de Relaxação Lagrangiana nas restrições de capacidade e de balanceamento, encontram um limitante inferior. Em seguida, um procedimento de factibilização é aplicado. As diferenças entre esta heurística e a de Billington et al.(1986) é que esta resolve de maneira ótima a Relaxação Lagrangiana e o procedimento de factibilização é mais elaborado. Foram testados exemplos com 40 itens, obtendo soluções que estão a 16\% do limite obtido pela Relaxação Lagrangiana.

Tempelmeier (1997) considera o problema de dimensionamento de lotes para a estrutura geral de produtos. Apresenta as principais deficiências dos sistemas $M R P$, enfatizando o fato de não considerar as restrições de capacidade. Com a ajuda de um pequeno exemplo numérico, mostra que a técnica item-por-item e a aplicação de um algoritmo dinâmico exato para um único item, resulta num plano de produção infactível com relação as restrições de capacidade. Mostra ainda, que somente uma técnica dinâmica, para o problema de dimensionamento de lotes capacitado em sistemas multiestágio com tempos de preparação, conduz a planos de produção factíveis. Basicamente sua proposta consiste na substituição da técnica item-por-item utilizada no $M R P$ padrão por esta heurística de resolução, obtendo assim o então denominado $M R P-r c$.

França et al.(1997) apresentam uma heurística baseada na desenvolvida por Clark e Armentano (1995), mas considerando lead times nulos. A heurística parte de uma solução inicial, geralmente infactível, e procedimentos distintos são aplicados com objetivo de factibilizar a 
solução e melhorar sua qualidade. Seus resultados mostram que o método consegue obter soluções factíveis em $78 \%$ dos exemplos testados, enquanto que a heurística de Clark e Armentano (1995) consegue em apenas $22 \%$, sobre os mesmos exemplos. As soluções encontradas são avaliadas através de limitantes inferiores lagrangianos e conseguiram atingir gaps com valores de $4 \%$ (estrutura plana), $18 \%$ (estrutura serial) e 10\% em média.

O trabalho de Berretta (1997) considera lead times não nulos, apresentando heurísticas com o objetivo de encontrar soluções factíveis com maior eficiência e soluções de melhor qualidade. Esse trabalho é a continuação do apresentado em França et al.(1997), mas incorporando Busca Tabu e Simulated Annealing. Seus resultados, indicaram um aumento expressivo no número de exemplos em que foi possivel obter solução factível, quando comparado ao trabalho inicial de Clark e Armentano (1995). Além disso, a qualidade das soluções foram melhoradas com a inclusão das meta-heurísticas Busca Tabu e Simulated Annealing.

Em um trabalho recente, Katok et al.(1998) apresentam um método heurístico para o caso da estrutura geral, considerando múltiplas restrições de recursos, baseando-se no trabalho de Harrison e Lewis (1995). Para problemas de pequeno porte, gerados aleatoriamente, em média as soluções encontradas pela heurística ficaram a $4 \%$ do ótimo, em menos de $1 \%$ do tempo requerido pelo OSL. Para problemas de médio porte, também gerados aleatoriamente, as soluções ficaram em média $26 \%$ melhores do que as soluções obtidas pelo OSL (com tempo limitado de execução), sendo que as soluções heurísticas foram obtidas em aproximadamente $10 \%$ do tempo requerido pelo OSL.

Helber (1995) descreve a estrutura hierárquica de um PCP considerando capacidade de produção em cada estágio do processo de planejamento. Compara vários procedimentos para resolução do problema de dimensionamento de lotes multiestágio capacitado, considerando custos e tempos de preparação e lead times diferentes de zero. Propõe uma técnica de decomposição baseada na heurística de Dixon (Dixon e Silver, 1981) e utiliza uma estratégia evolutiva descrita em Helber (1994). Extendeu para este problema a proposta baseada em Simulated Annealing de Kuik e Salomon (1990) e a que utiliza Busca Tabu de Salomon (1991). Finalmente, o procedimento baseado em Relaxação Lagrangiana proposto por Tempelmeier e Derstroff (1993). O autor, por meio de diversas combinações destes procedimentos, avalia sua eficácia em três classes de problemas (exemplos com 20, 40 e 80 itens). Através desses experimentos, o autor concluiu que a heurística proposta por Tempelmeier e Derstroff (1993) conseguem melhores resultados. A heurística baseada em algoritmos genéticos não apresentou bom desempenho, principalmente com relação ao tempo computacional envolvido. Acreditamos que o mau desempenho pode ser atribuído a uma representação que utiliza apenas as variáveis binárias de preparação, embora maiores detalhes dos procedimentos usados neste algoritmo não tenham sido 
reportados neste trabalho.

Kimms (1999) apresenta um algoritmo genético para resolução do problema de dimensionamento de lotes multiestágio capacitado, com múltiplas máquinas juntamente com o problema de seqüenciamento (scheduling problem). A eficiência do algoritmo é atribuida à representação da solução que usa uma matriz bidimensional com valores inteiros. $O$ procedimento é extremamente rápido quando comparado às técnicas baseadas em Busca Tabu, competindo também com estas técnicas no que se refere a capacidade de encontrar soluções factíveis.

Com relação a outras meta-heurísticas, podemos citar ainda o trabalho de Adenso-Díaz e Laguna (1997) que utiliza Busca Tabu, e o de Kuik e Salomon (1990) utilizando Simulated Annealing, ambos para problema de dimensionamento de lotes em sistemas multiestágio, sendo o de Kuik e Salomon (1990) para o problema não capacitado.

Em seu trabalho, Adenso-Díaz e Laguna (1997) com base na principal deficiência de um $M R P$, ou seja, o fato de não considerar as restrições de capacidade, apresentam uma técnica de busca para encontrar planos de produção factíveis minimizando o total de horas-extras. Esta técnica é baseada numa modificação do método POQ (periodic-order-quantity) utilizando Busca Tabu. Os autores através de experimentos computacionais mostram que é a técnica é robusta no sentido de solucionar as violações de capacidade provocadas pelo $M R P$, isto é, consegue factibilizar planos de produção obtidos pelo $M R P$ com eficiência.

No próximo capítulo, descrevemos os conceitos básicos das meta-heurísticas evolutivas, com um breve histórico a respeito do surgimento das heurísticas e meta-heurísticas. 


\section{CAPÍTULO 2}

\section{META-HEURÍSTICAS EVOLUTIVAS}

\subsection{Introdução}

Nesse capítulo apresentamos inicialmente conceitos básicos referentes à métodos heurísticos e meta-heurísticos. Descrevemos os fundamentos básicos de algoritmos genéticos, como representação da solução, estrutura populacional, tipos de operadores de reprodução mais comumente utilizados, juntamente com alguns exemplos de aplicação à problemas reais. Em seguida, os algoritmos meméticos são descritos.

\subsection{Heurísticas e Meta-Heurísticas}

Devido a dificuldade prática de se resolver de forma exata um grande número de problemas de otimização combinatória, como o dimensionamento de lotes envolvendo custos e tempos de preparação, começaram a surgir algoritmos que forneciam soluções satisfatórias num tempo de cálculo razoável. A estes algoritmos denominam-se heurísticas, do grego heuriskein que significa encontrar ou descobrir. Embora não tenham sido bem vistas no meio acadêmico num primeiro 
instante, acusadas de ter pouco rigor matemático. Com a proliferação dos resultados obtidos na área de complexidade computacional em meados dos anos 70 , estes métodos foram ganhando maior importância segundo Diaz et al.(1996). Nas últimas décadas uma grande quantidade de trabalhos que utilizam heurísticas foram publicados, Zanakis et al.(1989), por exemplo, listaram mais de 400 artigos que fazem uso destas técnicas.

Zanakis e Evans (1981) definem estes métodos como "procedimentos simples, baseados num sentido comum, que se supõe oferecer uma boa solução, ainda que não necessariamente a ótima, a problemas dificeis de um modo fácil e rápido". Ou ainda, segundo Reeves (1993), "uma heurística é uma técnica que procura boas soluções (isto é, próximas da ótima) com um custo computacional razoável, embora sem garantia de factibilidade ou otimalidade, ou mesmo afirmar quão próximo da ótima está uma solução em particular".

Uma das vantagens das heuristicas em relação às técnicas exatas, é que normalmente, elas permitem uma maior flexibilização das características do problema, além do que em geral são de fácil entendimento.

Um dos problemas desses métodos, diz repeito à qualidade da solução, ou seja, dada uma solução $\left(x_{h e u}\right)$, dizer quão próxima ela está do ótimo $\left(x^{*}\right)$. Num problema de minimização (minf), o único fato conhecido é que $f\left(x^{*}\right) \leq f\left(x_{h e u}\right)$. Uma maneira de contornar esta dificuldade, é a aplicação da heurística em problemas para os quais a solução ótima é conhecida, e assim a qualidade da heurística pode ser avaliada.

Silver et al.(1980) fazem uma classificação das heurísticas de acordo com o modo em que buscam e constroem soluções, obtendo a seguinte divisão:

\section{- Métodos Construtivos}

Esses métodos constroem uma solução passo a passo, sendo geralmente utilizados para fornecer uma solução inicial para a aplicação de outros tipos de métodos.

\section{- Métodos de Decomposição}

Dividem o problema em subproblemas menores, sendo a saída de um a entrada do seguinte, de modo que, ao resolver todos os subproblemas tem-se a solução do problema original. Alguns autores dividem ainda esta classe em métodos de decomposição (quando os subproblemas são dependentes) e de partição (quando os subproblemas são independentes entre si).

\section{- Métodos de Redução}

Simplificam o problema, identificando alguma característica que presumidamente a solução ótima possui, com isso conseguem, por exemplo, fixar o valor de alguma variável do problema. 


\section{- Manipulação do Modelo}

Modificam a estrutura do modelo a fim de se obter um modelo mais simples de resolver, deduzindo, a partir desta solução, a solução do modelo original. Podem, por exemplo, aumentar ou diminuir o número de restrições, baseando-se no comportamento esperado da solução ótima.

\section{- Métodos de Busca em Vizinhanças}

Esses métodos partem de uma solução inicial, e iterativamente através de alterações dessa solução, vão passando para outras de sua vizinhança, em busca de melhores soluções, até que um critério de parada seja satisfeito ou até que não haja mais possibilidades de busca.

Um conceito fundamental destes métodos é como passar de uma solução factível para outra. Para isso, define-se $N(s)$ como sendo a vizinhança da solução $s$, que é o conjunto de soluções, para as quais é possível, obter uma solução $s^{\prime} \in N(s)$, com apenas uma operação elementar, chamada movimento sobre $s$. Em geral, esses métodos buscam entre os elementos da vizinhança, algum que tenha um melhor valor do que a solução atual, e repetem este processo até que não existam melhores soluções no conjunto ou algum critério de parada seja satisfeito.

Para exemplificar esses conceitos, apresentamos a seguir um pequeno exemplo de um problema de seqüenciamento de tarefas numa máquina. $\mathrm{O}$ problema de seqüenciamento consiste em determinar qual a melhor seqüência para processar um conjunto de tarefas num conjunto de máquinas, de modo a otimizar algum objetivo, como por exemplo, minimizar o atraso ou o tempo de processamento das tarefas.

Exemplo 3.1 Como exemplo de busca local, consideremos o problema de seqüenciar 4 tarefas numa máquina, com o objetivo de minimizar o atraso. Sejam os seguintes dados

\begin{tabular}{|c|c|c|c|c|}
\hline tarefas & 1 & 2 & 3 & 4 \\
\hline tempos de produção & 8 & 4 & 6 & 2 \\
\hline datas de entrega & 6 & 12 & 14 & 8 \\
\hline
\end{tabular}

Seja a solução $s=(1243)$, construída ao acaso. Calculando o valor da função atraso, temos $f(s)=2+0+6+6=14$. Definindo a troca da tarefa i com a j, como movimento sobre $s$, obtemos sua vizinhança. 


\begin{tabular}{|c|c|c|}
\hline troca & $s^{\prime}$ & $f\left(s^{\prime}\right)$ \\
\hline$(1,2)$ & $(2143)$ & 18 \\
$(1,3)$ & $(3241)$ & 18 \\
$(1,4)$ & $(4213)$ & 14 \\
$(2,3)$ & $(1342)$ & 18 \\
$(2,4)$ & $(1423)$ & 12 \\
$(3,4)$ & $(1234)$ & 18 \\
\hline
\end{tabular}

Um procedimento de busca local na vizinhança de $s$ pode ser definido por: analise todas as soluções vizinhas e escolha a que possui menor atraso.

Assim, a nova solução é $s=(1423)$ com um atraso de 12. Repetindo este processo para a nova solução, temos

\begin{tabular}{|c|c|c|}
\hline troca & $s^{\prime}$ & $f\left(s^{\prime}\right)$ \\
\hline$(1,2)$ & $(2413)$ & 14 \\
$(1,3)$ & $(3421)$ & 14 \\
$(1,4)$ & $(4123)$ & 12 \\
$(2,3)$ & $(1432)$ & 14 \\
$(2,4)$ & $(1243)$ & 14 \\
$(3,4)$ & $(1324)$ & 20 \\
\hline
\end{tabular}

Nesse ponto, a busca é interrompida, pois não há na vizinhança de $s$ uma solução com melhor valor, isto é, com atraso menor que 12. Isto ocorre porque a busca fica estagnada num ótimo local, não conseguindo atingir diferentes ótimos locais. Se alterarmos o critério de busca, de modo a aceitar soluções com custo igual a solução atual, então a nova solução será $s=(4123)$. E sua vizinhança dada por

\begin{tabular}{|c|c|c|}
\hline troca & $s^{\prime}$ & $f\left(s^{\prime}\right)$ \\
\hline$(1,2)$ & $(4213)$ & 14 \\
$(1,3)$ & $(4321)$ & 14 \\
$(1,4)$ & $(1423)$ & 12 \\
$(2,3)$ & $(4132)$ & 14 \\
$(2,4)$ & $(2143)$ & 18 \\
$(3,4)$ & $(3124)$ & 26 \\
\hline
\end{tabular}

Nesse momento a busca entra em "ciclagem", isto é, a nova solução é exatamente igual a uma das soluções anteriores e se continuarmos com o processo, não haverá alterações no espaço de busca indefinidamente. 
Um dos grandes inconvenientes dessas técnicas é a existência de diversos ótimos locais em diferentes regiōes. Dependendo do modo como a heurística foi construída, a busca pode ficar estagnada, o que acarreta a impossibilidade de atingir diferentes ótimos locais, como ocorreu no exemplo anterior.

Uma maneira de melhorar o desempenho das heurísticas, tentando eliminar suas possíveis falhas e limitações é utilizar as chamadas meta-heurísticas (Reeves, 1993 e Diaz et al., 1996). Meta-heurística é um guia para as heurísticas, que tem como objetivo direcionar seus movimentos permitindo a exploração de diferentes regiões, tentando alcançar diferentes ótimos locais, através de uma busca mais eficiente.

Algumas das meta-heurísticas mais utilizadas em otimização são Busca Tabu, Simulated Annealing, Algoritmos Genéticos e Meméticos. As meta-heurísticas seguem diferentes estratégias para evitar mínimos locais. Simulated Annealing (Kirkpatrick et al., 1983) é baseado num processo físico em metalurgia e permite com certa probabilidade a aceitação de soluções piores com o objetivo de escapar de ótimos locais. Em Busca Tabu (Glover e Laguna, 1997), a idéia é a utilização de mecanismos que manipulam o uso de memória, minimizando o uso de estratégias aleatórias. Algoritmos Genéticos (Holland, 1975 e Goldberg, 1989) imitam o processo biológico da reprodução e evolução, como será visto mais detalhadamente na próxima seção. Algoritmos Meméticos (Moscato, 1989), que também será discutido na seção seguinte, é uma meta-heurística do tipo evolutiva, como algoritmos genéticos, que incorpora todo e qualquer tipo de conhecimento existente em relação à resolução do problema estudado, tentando obter uma evolução "cultural" das soluções.

\subsection{Algoritmos Genéticos}

O nome "algoritmos genéticos" se originou da analogia entre a representação complexa da estrutura genética de um cromossomo, por meio de um vetor de componentes. Segundo Goldberg (1989) os algoritmos genéticos são "técnicas de busca baseadas no mecanismo de seleção natural e da genética".

A evolução na natureza, em particular dos seres vivos, motivaram John Holland a iniciar em meados da década de setenta uma linha de pesquisa, que hoje é conhecida como Algoritmos Genéticos. Os algoritmos desenvolvidos inicialmente por Holland eram simples, mas conseguiram soluções satisfatórias para problemas considerados dificeis naquela época. Desde então esses 
algoritmos vêm incorporando mecanismos cada vez mais sofisticados, devido a necessidade de se resolver de modo aproximado, uma grande variedade de problemas.

$\mathrm{Na}$ natureza, vários organismos vivos se agrupam formando uma população, e aqueles indivíduos com maior capacidade de adaptação são os que maiores chances possuem de sobreviver e se reproduzir. Esses indivíduos selecionados pela natureza vão produzir uma nova geração de organismos. As características hereditárias de uma espécie são passadas para outras gerações através do cruzamento entre os indivíduos, de modo a preservar suas qualidades.

Desse modo, podemos estabelecer uma analogia entre os componentes de um indivíduo na população e a representação das características de um problema de otimização combinatória. Cada indivíduo na população, que também é chamado de cromossomo, representa uma solução do problema codificado. Os valores que compõem um indivíduo são denominados genes. A posição de cada gene no indivíduo recebe o nome de locus. Tais genes podem ainda sofrer alterações de uma geração para outra, denominadas mutações.

A principal diferença entre os algoritmos genéticos e as meta-heurísticas em geral, é que estas geram uma única solução em cada iteração, enquanto os algoritmos genéticos geram uma população de soluções. Uma outra característica importante é que os algoritmos genéticos não utilizam necessariamente informações a respeito do problema durante o processo evolutivo, ou seja, uma vez codificada a solução através de um indivíduo, o processo de melhoria dessa solução é um problema independente do problema original.

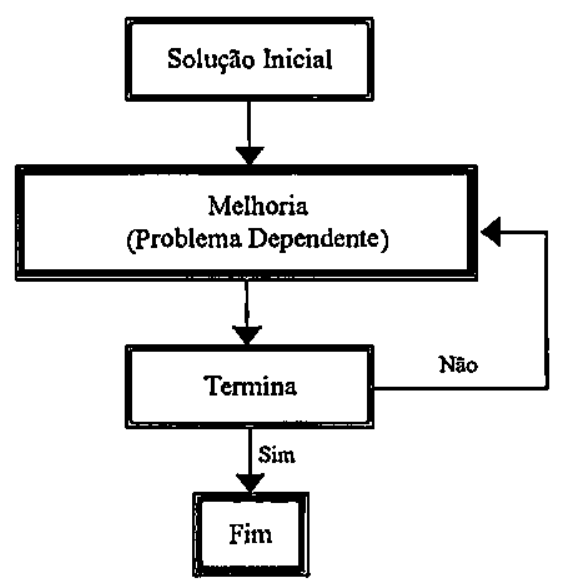

Métodos Convencionais

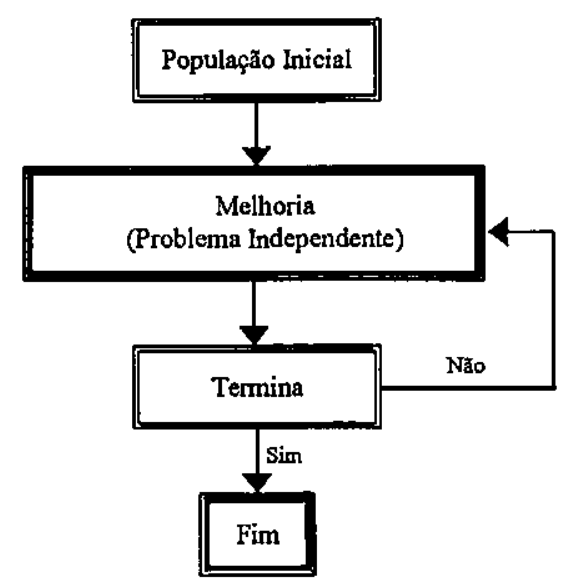

Algoritmos Genéticos

Figura 2.1 Métodos Convencionais e Algoritmos Genéticos (Gen e Cheng, 1997).

No contexto de encontrar a solução ótima de um problema de otimização de grande escala, um algoritmo genético padrão funciona do modo descrito a seguir.

Seja um conjunto de indivíduos, chamado de população inicial. Em geral, esta população é 
construida aleatoriamente. A cada elemento desta população é atribuído um valor de fitness, normalmente relacionado com o valor da solução na função objetivo. Desse modo, cada indivíduo representa um ponto do espaço de busca do problema de otimização. Através de mecanismos de seleção, dois indivíduos são escolhidos na população para dar origem, por meio dos operadores de reprodução (cruzamento e mutação) a um novo indivíduo. Um mecanismo de seleção, pode ser baseado no valor de fitness do indivíduo. Aplicações sucessivas deste processo, irão formar um novo conjunto de individuos, que substituirá a anterior através de algum critério pré-estabelecido. Ocorrendo assim, a "morte" de uma população e o "nascimento" de outra, a princípio mais evoluída, pois este é um modelo de evolução que incorpora os conceitos de sobrevivência e seleção do mais forte.

A estrutura geral de um algoritmo genético é dada a seguir.

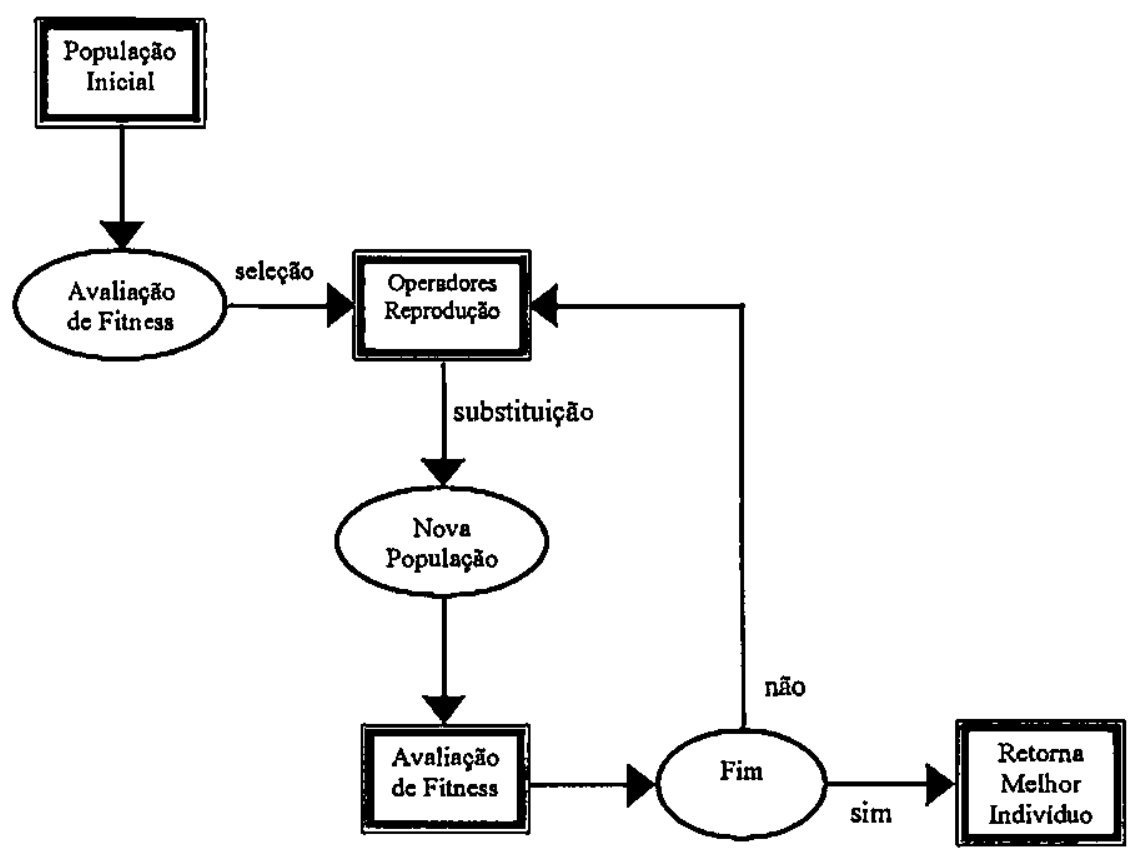

Figura 2.2 Estrutura de um Algoritmo Genético.

A medida que as pesquisas foram avançando, surgiram outras estratégias mais específicas para cada área de aplicação, inclusive para manipulação de variáveis não binárias.

Os algoritmos genéticos tem encontrado aplicação em problemas das mais variadas áreas. Em áreas específicas da Inteligência Artificial, problemas combinatórios como por exemplo, o problema do caixeiro viajante, problema da mochila, cobrimento de conjuntos (set covering), e ainda problemas de programação não-linear, coloração de grafos, scheduling e em áreas como Biofísica, Geofisica e Fisicoquímica.

A seguir descrevemos separadamente e em maiores detalhes os aspectos mais importantes à 
implementação de um algoritmo genético.

\section{Representação da Solução}

Uma das primeiras questões que surgem na implementação de um algoritmo genético, é como representar as características de uma solução através de um indivíduo (cromossomo).

Originalmente, os individuos eram representados por valores binários. Este tipo de codificação pode ser utilizado eficientemente em muitos problemas. Como por exemplo, o problema da mochila, que consiste em dados $n$ itens determinar quais serão colocados na mochila, de modo a maximizar a função objetivo, que representa os valores dos itens na mochila. Assim, uma representação eficiente para uma solução pode ser dada por $c=(11001)$, indicando que somente os itens 1, 2 e 5 estão na mochila. Ou ainda, de modo mais genérico, o valor 1 na i-ésima posição indica que o item i está na mochila e o valor 0 , caso contrário.

No entanto, para outros problemas esta representação pode causar alguns inconvenientes. Suponha por exemplo, que a solução ótima de um problema qualquer é 16. Usando uma codificação binária (ou seja, utilizando a representação binária em vez da decimal) com 5 bits, a representação dessa solução é $c^{*}=(10000)$. Uma razoável aproximação para a solução ótima seria 15 , que é representado por $c_{1}=(01111)$, enquanto que o valor 0 é representado por $c_{3}=(00000)$. Comparando os indivíduos, temos uma alta semelhança entre $c^{*}$ e $c_{2}$, pois diferem em apenas um dígito, enquanto $c_{1}$ difere totalmente da solução. Ou seja, essa codificação não representa de modo eficiente as características do problema. A dificuldade está em encontrar um significado relevante para esta representação com relação a um grande número de problemas importantes, daí a necessidade de estendê-la para valores reais.

Uma vez escolhida a representação, é preciso caracterizar estas soluções de acordo com suas qualidades, ou seja, de acordo com sua importância para o problema. Isso é feito a seguir.

\section{Função de Avaliação}

A cada indivíduo na população é atribuído um valor definido pela função de avaliação, denominado fitness, que está relacionado com o valor da solução na função objetivo.

Uma idéia natural que surge é a utilização do próprio valor da função objetivo para a função de avaliação. No entanto, o uso de valores muito próximos pode provocar a convergência da população para um conjunto altamente homogêneo, dificultando a identificação dos melhores 
indivíduos. Uma outra possibilidade ocorre quando há indivíduos com valores muito discrepantes em relação aos demais, ocasionando uma convergência prematura para um ponto de ótimo local. É importante ressaltar que o sucesso destes métodos está no equilíbrio entre uma busca rápida e diversificada, evitando assim uma convergência prematura.

A função utilizada para designar os valores de fitness aos membros da população, deverá portanto, ocasionar uma boa discriminação entre os indivíduos bons e os ruins. Se o valor de fitness de um indivíduo que representa uma boa solução e um que representa uma solução ruim estiverem muito próximos, será necessário muito tempo para que os descendentes do bom indivíduo influenciem mais que os descendentes do ruim. Por esta razão, muitas implementações usam um processo de normalização, para destacar os melhores indivíduos, no intuito de acelerar o processo de busca da melhor solução.

Ao escolher uma função de avaliação, é muito importante levar em conta as restrições do problema, seja criando decodificadores para a representação ou impondo penalidades a indivíduos que violam as restrições, evitando gerar indivíduos infactíveis. Uma função que incorpora o termo de penalidade, tem a seguinte forma

$$
\text { fitness }=\text { ValorObjetivoNormalizado }- \text { Penalização } * \text { MedidaInfactibilidade, }
$$

supondo que o melhor individuo possui maior valor de fitness.

Uma vez avaliado o fitness de um individuo, fazemos um teste para comparar seu fitness com aquele associado ao melhor indivíduo criado pelo processo até então. Se o indivíduo possui melhor valor de fitness, ele é armazenado na memória, para que ao final do processo o melhor indivíduo conste na memória, sem a necessidade de estar presente na população final.

Estabelecida esta função podemos agrupar um conjunto de individuos na forma de uma população.

\section{População Inicial}

A criação da população inicial de um algoritmo genético pode ser feita de várias maneiras. Pode-se inicializar com uma população criada de modo aleatório, e fazer evoluções até que se obtenha uma população satisfatória, ou seja, soluções aproximadas para o problema. Este tipo de inicialização é indicado para testar a eficiência dos operadores de reprodução de um algoritmo genético, uma vez que, as características essenciais da solução final devem ser consequêencia do processo evolutivo e não depender dos métodos usados para gerar a população inicial. Em problemas mais complexos, pode ser conveniente o uso de métodos mais diretos, com o objetivo 
de ajudar a encontrar melhores soluções mais rapidamente. Por exemplo, técnicas de perturbação da saída de algum algoritmo guloso, ou pela perturbação de uma solução gerada por algum método especialista no problema. Entretanto, há a possibilidade deste tipo de procedimento aumentar as chances de uma convergência prematura.

Uma outra questão importante referente à população inicial, diz respeito ao tamanho da população e sua influência no desempenho do algoritmo. Populações muito pequenas podem reduzir sensivelmente o espaço de busca, diminuindo as possibilidades de atingir o ótimo global. Enquanto que populações muito grandes provocam sérios problemas relacionados aos recursos computacionais necessários.

Alguns estudos teóricos indicam que o tamanho ótimo da população cresce exponencialmente com o valor de $n$ que é o tamanho da solução, o que implicaria na necessidade de populações muito grandes para a maioria dos problemas reais. No entanto, resultados empíricos de muitos pesquisadores sugerem que um tamanho pequeno, é adequado em muitos casos.

\section{Mecanismos de Seleção dos Pais}

Definidos os critérios para a formação da população inicial, é necessário estabelecer critérios para seleção dos indivíduos, que combinados através dos operadores de reprodução, irão gerar novos individuos, e ainda, como estes serão inseridos na população.

$\mathrm{O}$ intuito dessa seleção é aumentar as chances de reprodução dos melhores indivíduos, e conseqüentemente produzir melhores gerações. A escolha dos pais para aplicação dos operadores de reprodução, pode ser feita com base no valor de fitness do indivíduo, assim quanto maior o valor de fitness maior a probabilidade do elemento ser selecionado. Um outro critério é o sorteio aleatório dos pais na população, ou ainda uma combinação destes dois, como foi utilizado por Holland inicialmente.

O objetivo da seleção dos pais baseado em seu valor de fitness é aumentar a probabilidade de reproduzir membros da população que representam boas soluções para o problema, e o da escolha aleatória é proporcionar uma certa diversidade.

Os filhos gerados pela aplicação dos operadores de reprodução, poderão constituir uma nova população que substituirá a anterior, ou podem ser inseridos no lugar dos pais, ou ainda no lugar de indivíduos com baixo valor de fitness. Segundo Reeves, vários estudos analisam a performance dos algoritmos genéticos com relação ao modelo de substituição adotado, como o trabalho de Davis (1991), De Jong (1975) e Whitley (1989). 


\section{Estratégia de Reprodução}

A estratégia de reprodução é um dos aspectos mais importantes de um algoritmo genético, pois toda convergência do processo evolutivo dependerá dessa estratégia.

O cruzamento (crossover) é um procedimento no qual os indivíduos recombinam seu material genético para gerar novos indivíduos. A tendência desse operador é provocar a convergência da população ao longo das gerações, pois tenta combinar as melhores qualidades de cada indivíduo a fim de se obter gerações mais evoluídas. Um outro tipo de operador que também é utilizado, com o intuito de aumentar a diversidade da população para escapar de regiões com ótimos locais, é o denominado mutação. A mutação geralmente tem sua aplicação condicionada a uma função de probabilidade. No caso da representação binária, são escolhidos pontos aleatórios de uma solução, trocando o valor deste gene para zero ou um, dependendo do caso, sujeito sempre a uma certa probabilidade.

A seguir são descritos alguns dos principais operadores de cruzamento utilizados em algoritmos genéticos.

O operador inicialmente usado em algoritmos genéticos é denominado one-point crossover. Escolhemos aleatoriamente um ponto de cruzamento, de modo que o material além deste ponto é trocado entre os pais. Por exemplo, consideremos os pais $p_{1}=(011100)$ e $p_{2}=(100011)$. Ao escolhermos o ponto 3 para cruzamento, são gerados os filhos $f_{1}=(011011)$ e $f_{2}=(100100)$, trocando os valores após o ponto escolhido.

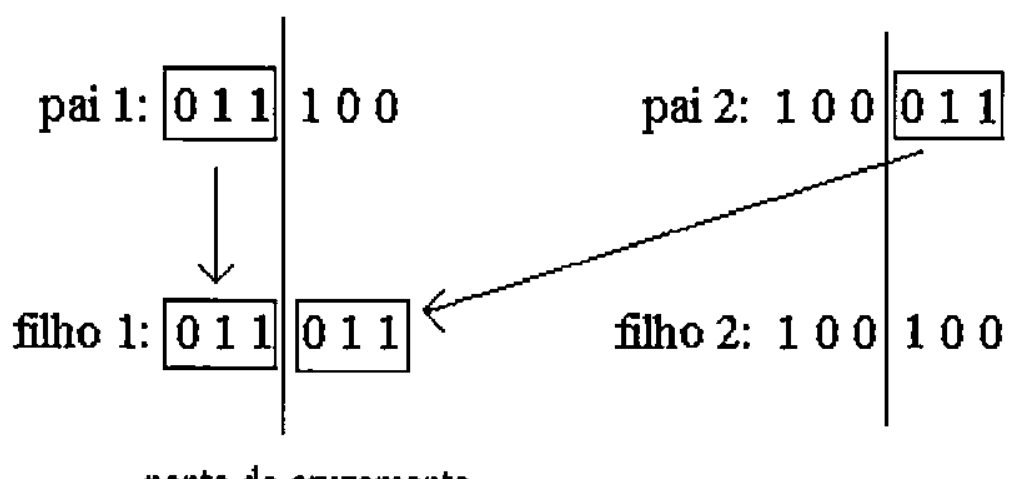

ponto de cruzamento

Figura 2.3 Exemplo de one-point crossover.

Uma outra estratégia, utiliza dois pontos de cruzamento (two-point crossover), que são escolhidos também aleatoriamente, efetuando-se a troca do material genético entre estes pontos. 
Assim considerando o exemplo anterior, ou seja, $p_{1}=(011100)$ e $p_{2}=(100011)$. Escolhendo ao acaso os pontos 2 e 4 para o cruzamento, são gerados os filhos $f_{1}=(010100)$ e $f_{2}=(101111)$.

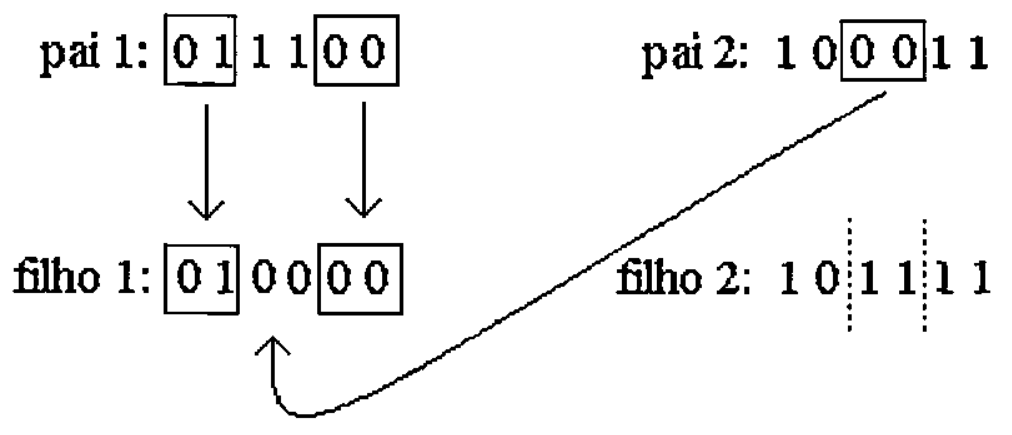

Figura 2.4 Exemplo de two-point crossover.

Quando a representação utilizada da solução não é binária, um exemplo de operador é o PMX (Partially-Matched Crossover), usado no problema do caixeiro viajante. O problema do caixeiro viajante consiste em fornecer a ordem na qual um número de cidades serão visitadas de modo que

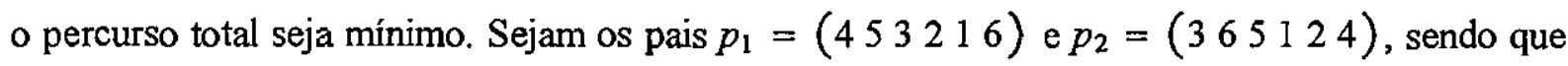
o número representa a ordem em que as cidades serão visitadas. Fixando os elementos das posições 3 e 4 em $p_{1}$, completa-se a nova solução com os elementos de $p_{2}$, e assim,

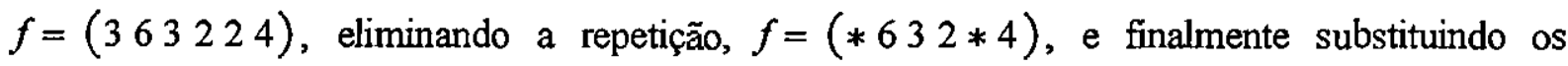
elementos que estavam faltando, temos $f=\left(\begin{array}{lllll}5 & 6 & 3 & 2 & 1\end{array}\right)$.

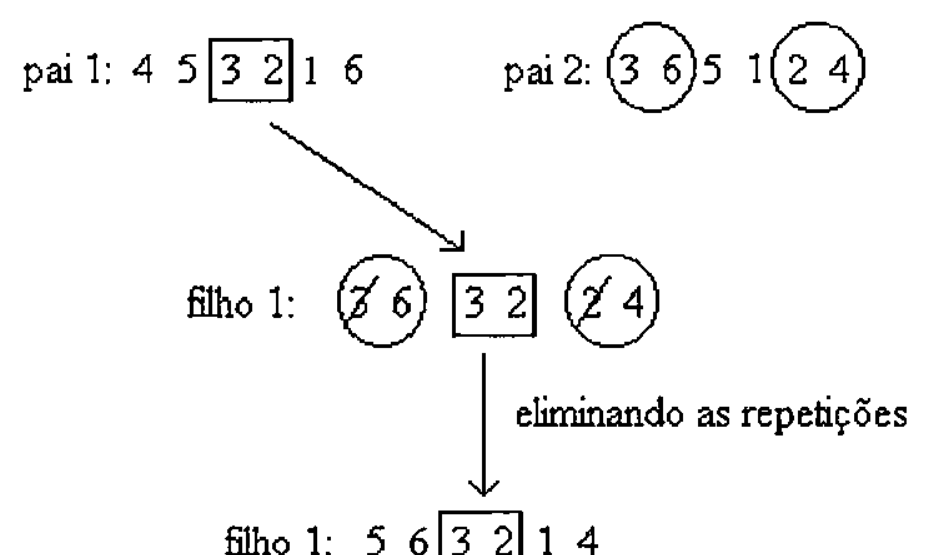

Figura 2.5 Exemplo de Partially-Matched Crossover.

A seguir apresentamos um exemplo de operador de cruzamento e mutação também para 
variáveis inteiras, aplicado ao problema de dimensionamento de lotes.

\subsubsection{Um Algoritmo Genético para o Problema de Dimensionamento de Lotes Monoestágio}

Geralmente em problemas muito restritos, dependendo do tipo de cruzamento aplicado, os filhos gerados não preservam certas características das soluções, tomando-as infactíveis. Quando isso acontece é preciso aplicar um novo operador, na tentativa de reestabecer estas propriedades. No caso do problema de dimensionamento de lotes, devido ao número acentuado de restrições, é extremamente complicado obter um operador de cruzamento que preserve a factibilidade.

Ozdamar e Birbil (1998) desenvolveram uma heurística usando algonitmos genéticos para o problema monoestágio capacitado juntamente com o problema de carregamento. Eles utilizaram procedimentos de busca local baseados em Busca Tabu e Simulated Annealing. Dividiram os procedimentos em dois tipos, um que preserva a factibilidade da solução inicial durante a busca e o outro que não preserva. Foram testadas três tipos de populações iniciais: geradas aleatoriamente, parte gerada aleatoriamente e parte composta por soluções factíveis (geradas por um procedimento de busca local), e ainda o processamento simultâneo de populações paralelas independentes. Para o operador de cruzamento foi utilizado um operador two-point, e para a mutação utilizou-se a idéia de transferência de produção entre os períodos, em uma dada solução.

A seguir são descritos operadores de cruzamento e mutação que foram utilizados por Özdamar e Birbil (1998).

Sejam por exemplo, as seguintes soluções:

$\begin{array}{lcccclcccc}\text { Período } & 1 & 2 & 3 & 4 & \text { Período } & 1 & 2 & 3 & 4 \\ \text { Demanda } & 30 & 20 & 10 & 40 & & & & & \\ \text { Pai 1 } & & & & & \text { Pai 2 } & & & & \\ \text { Lote } & 50 & 0 & 50 & 0 & \text { Lote } & 30 & 20 & 50 & 0 \\ \text { Estoque } & 20 & 0 & 40 & 0 & \text { Estoque } & 0 & 0 & 40 & 0\end{array}$

O operador de cruzamento consiste basicamente em fixar dois períodos na solução de modo aleatório, e efetuar a troca dos valores dos lotes entre esses períodos, gerando assim dois filhos. Logo, fixando os períodos 1 e 4 , tem-se 


$\begin{array}{lcccclcccc}\text { Periodo } & 1 & 2 & 3 & 4 & \text { Período } & 1 & 2 & 3 & 4 \\ \text { Demanda } & 30 & 20 & 10 & 40 & & & & & \\ \text { Filho 1 } & & & & & \text { Filho } 2 & & & & \\ \text { Lote } & 50 & 20 & 50 & 0 & \text { Lote } & 30 & 0 & 50 & 0 \\ \text { Estoque } & 0 & 20 & 60 & 20 & \text { Estoque } & 0 & -20 & 20 & -20\end{array}$

Como podemos notar, a solução Filho 1 tem excesso de produção, e a solução Filho 2 não atende a demanda em todos os períodos, ou seja, é infactível. Esta é uma das grandes dificuldades na elaboração de um operador de cruzamento para este tipo de problema. Uma alternativa neste caso, seria reduzir ou aumentar as quantidades produzidas, em determinados períodos, para a correção de excesso ou falta de produção.

Para o operador de mutação, seleciona-se aleatoriamente uma solução na população. Uma quantidade aleatória, que não excede nem o tamanho do lote nem o estoque, é deduzida de um período, também escolhido aleatoriamente. Essa mesma quantidade é adicionada ao período seguinte. Desse modo, considere a solução a seguir.

$\begin{array}{lcccc}\text { Período } & 1 & 2 & 3 & 4 \\ \text { Demanda } & 30 & 20 & 10 & 40 \\ \text { Lote } & 60 & 0 & 0 & 40 \\ \text { Estoque } & 30 & 10 & 0 & 0\end{array}$

Se o período 1 é escolhido deduzindo-se uma quantidade aleatória $x=20 \leq \min \{30,60\}$, e adicionando-a ao período 2 , temos

$\begin{array}{lcccc}\text { Período } & 1 & 2 & 3 & 4 \\ \text { Demanda } & 30 & 20 & 10 & 40 \\ \text { Lote } & 40 & 20 & 0 & 40 \\ \text { Estoque } & 10 & 10 & 0 & 0\end{array}$

Neste caso a factibilidade é preservada, pois não é permitada a transferência de uma quantidade maior do que o lote ou o estoque disponível.

Como podemos observar, uma grande dificuldade de resolução de alguns problemas combinatórios, em particular o de dimensionamento de lotes, está no número elevado de restrições. O que dificulta desde a criação da codificação adequada da solução até a manipulação eficiente 
destas variáveis.

Para o problema multiestágio, ainda há o fator complicador da dependência existente entre os itens. A maior dificuldade está em estabelecer um operador de reprodução que consiga respeitar a factibilidade entre os níveis na estrutura do produto.

A seguir descrevemos os algoritmos meméticos.

\subsection{Algoritmos Meméticos}

A incorporação de estratégias de busca local tem obtido êxito na resolução de diversos tipos de problemas combinatórios, principalmente nos mais complexos. Dentre essas técnicas, a que mais se destaca é a denominada Algoritmos Meméticos (Memetic Algorithms), desenvolvida por Moscato e Norman em 1992 (MAhomepage, 2000 e Moscato, 1999). Basicamente combina heurísticas de busca local com operadores de cruzamento. Por esta razão alguns pesquisadores chamam de Algoritmos Genéticos Híbridos (Hybrid Genetic Algorithm), Algoritmos Genéticos Paralelos (Parallel Genetic Algorithm) ou ainda Busca Local Genética (Genetic Local Search). Segundo Moscato (1999) o termo "memético" surgiu depois que Richard Dawkins introduziu o termo "meme", para denotar gene no campo da evolução cultural.

Nos algoritmos meméticos, os agentes (ou indivíduos) são criados a partir de outros altamente desenvolvidos. O desenvolvimento desses indivíduos na população, é feito através do uso de conhecimentos prévios do problema. Tais conhecimentos podem, por exemplo, ser propriedades que a solução ótima possui, uso de heurísticas, algoritmos construtivos ou métodos exatos truncados.

Nesse caso, os cromossomos ou indivíduos recebem a denominação de agentes, pois possuem informações a respeito do problema. Assim, a população é formada por um grupo de agentes com conhecimentos do problema. Diferentemente dos algoritmos genéticos, os meméticos possuem pouca relação com o processo biológico.

Nessa técnica, os elementos selecionados iniciam um processo de competição e cooperação, ou seja, competindo com os elementos vizinhos e cooperando com os mais distantes. A cooperação se dá através do processo de cruzamento, no qual um indivíduo cede parte de suas características para gerar um novo indivíduo. A competição ocorre através de uma luta pela sobrevivência na população, ou seja, um elemento elimina o outro, que pode ser de acordo com uma certa distribuição de probabilidade. Estas fases se alternam, até que a diversidade da população se torne 
muito baixa.

A seguir, descrevemos as etapas necessárias à implementação de um algoritmo memético, sendo muito semelhantes às fases necessárias a implementação de um algoritmo genético.

É preciso definir como as soluções serão codificadas em agentes e uma função de avaliação que atribuirá a cada agente um valor de fitness. Assim como num algoritmo genético, a eficiência desse algoritmo dependerá muito da representação adotada, ou seja, como as características de uma solução do problema serão codificadas através de um agente na população. Estabelecer um método para construção da população inicial, uma vez que o uso de algoritmos específicos produzirá melhores soluções do que a geração aleatória. Definir os operadores de recombinação (cruzamento) e mutação, semelhantes aos utilizados nos algoritmos genéticos. $\mathrm{E}$ ainda, encontrar um algoritmo de busca local eficiente, pois esta será a mais potente ferramenta deste algoritmo em relação ao genético.

O procedimento de recombinação num algoritmo memético tem um caráter mais geral do que o operador de cruzamento dos genéticos. $\mathrm{O}$ operador de recombinação pode envolver $k$ indivíduos $(k \geq 2)$ na geração de um filho, enquanto no cruzamento somente dois indivíduos são usados para gerar um filho. Além disso, o operador de recombinação pode embutir conhecimentos a respeito do problema, embora nesse trabalho, consideremos semelhantes esses operadores.

A seguir apresentamos a estrutura geral de um algoritmo memético. 


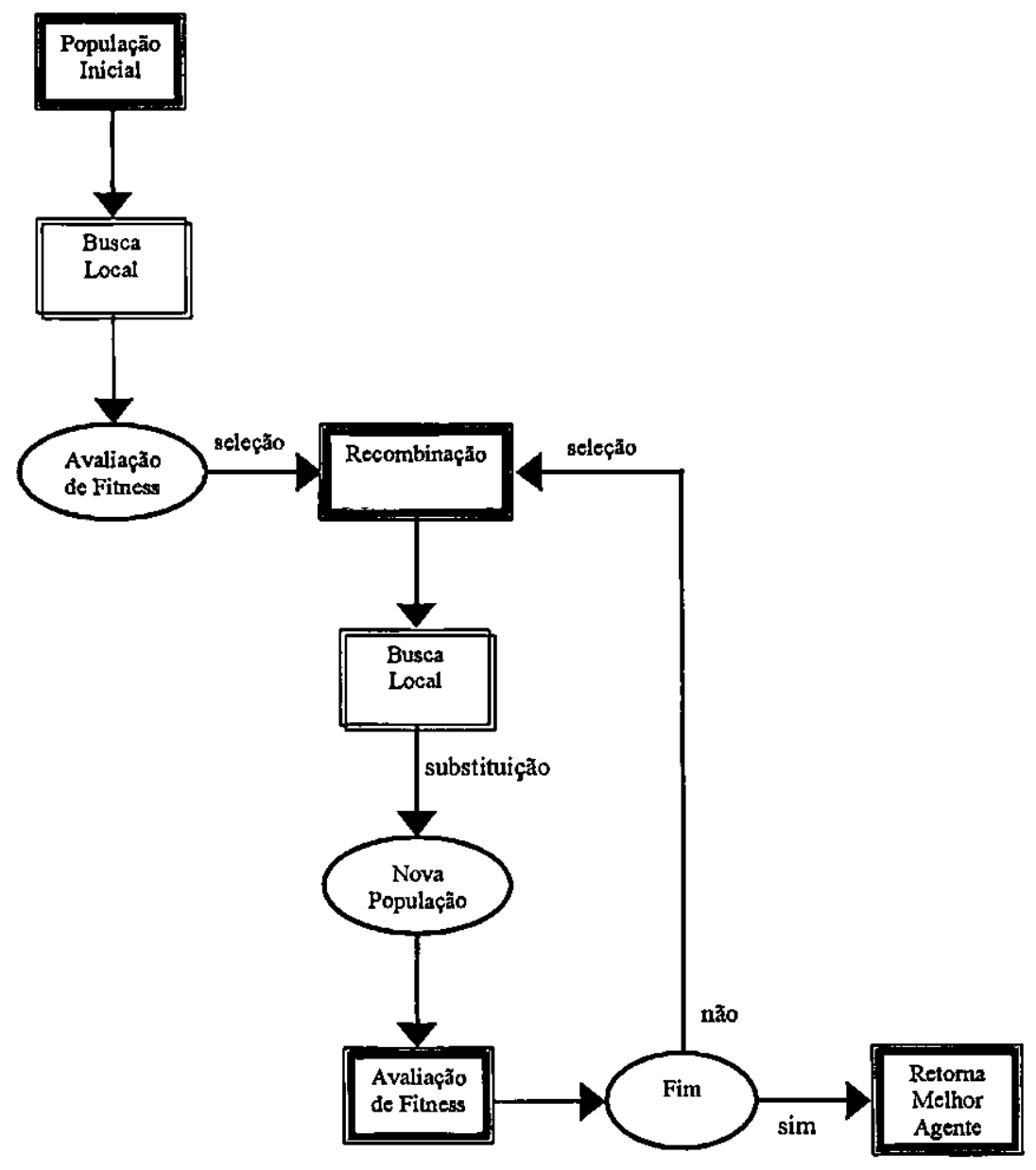

Figura 2.6 Estrutura geral de um algoritmo memético

Como podemos observar pela Figura 2.6, cada agente da população passa por um processo de melhoria através de uma busca local, que ocorre durante as gerações. O intuito desta busca é provocar uma evolução "cultural" desses agentes, uma vez que esta busca possui conhecimento ou de certa forma, cultura a respeito do problema. Alguns aspectos dos algoritmos meméticos que não foram mencionados aqui, serão tratados no capítulo seguinte.

No próximo capítulo apresentamos uma descrição detalhada dos procedimentos propostos por França et al.(1997) e que foram utilizados nesse trabalho. 


\section{CAPÍTULO 3}

\section{A HEURÍSTICA DE FRANÇA ET AL.(1997)}

\subsection{Introdução}

Nesse capítulo descrevemos a heurística encontrada em França et al.(1997), que é utilizada como base para a nossa heurística evolutiva a ser apresentada no próximo capítulo. Essa heurística é composta por quatro procedimentos, os quais apresentamos separadamente a seguir.

\subsection{Procedimento para Obtenção de uma Solução Inicial - P1}

Inicialmente precisamos estabelecer como uma solução inicial será obtida. Por tratar-se de um problema altamente restrito, utilizamos um procedimento baseado num algoritmo conhecido para $o$ problema de dimensionamento de lotes monoestágio, que é o algoritmo de Wagner-Whitin.

Desse modo, o procedimento utilizado na obtenção de uma solução inicial é um algoritmo de 
construção, que gera uma solução a partir da aplicação seqüencial do algoritmo de Wagner-Whitin.

$\mathrm{O}$ algoritmo de Wagner-Whitin consiste num método de programação dinâmica, que resolve de maneira ótima o problema de dimensionamento de lotes monoestágio para um único item, sem as restrições de capacidade ao longo de um horizonte de planejamento.

O procedimento consiste, basicamente, em ignorar as restrições de capacidade do modelo em estoque convencional (7)-(12) e aplicar o algoritmo para os itens finais (itens que não possuem sucessores) separadamente. Esta ordem de aplicação é estabelecida a fim de preservar a factibilidade entre os estoques.

A seguir a demanda é recalculada para os seus predecessores imediatos, com base na solução obtida anteriormente, que é dada por

$$
d_{i t}^{*}=d_{i t}+\sum_{j \in S(i)} r_{i j} x_{j t}
$$

Em seguida o algoritmo é aplicado novamente para esses itens. Após $N$ aplicações do método, e reunindo as soluções encontradas, obtemos uma solução inicial para o problema original.

Como as restrições de capacidade foram ignoradas, a solução provavelmente será infactível com relação a capacidade. Ou seja,

$$
\sum_{i=1}^{N}\left(\mathrm{v}_{i t} x_{i t}+\mathrm{f}_{i t} y_{i t}\right)>b_{t}
$$

para algum $t(t=1, \ldots, T)$. Nesse trabalho, o termo solução infactível, será utilizado para se referir à infactibilidade com relação à capacidade.

Uma medida da infactibilidade de uma solução em cada período, é dada pela função $\operatorname{Excesso}(t)$, que contabiliza o excedente de recursos utilizados em relação à capacidade disponível no período. Assim,

$$
\operatorname{Excesso}(t)=\left[\frac{\sum_{i=1}^{N}\left(\mathrm{v}_{i t} x_{i t}+\mathrm{f}_{i t} y_{i t}\right)-b_{t}}{b_{t}}\right]^{+},
$$

sendo $[a]^{+}=\left\{\begin{array}{l}0, \text { se } a \leq 0 \\ a, \text { se } a>0\end{array}\right.$.

Note que a função $\operatorname{Excesso}(t)$ não informa se há sobras de recursos no período, pois quando isso ocorre a função assume valor nulo.

Se a solução obtida por esse procedimento for infactível, aplicamos então um procedimento de factibilização baseado em transferências de produção entre os períodos. $O$ conceito de transferências de produção fundamenta, não somente o procedimento de factibilização, mas 
também os procedimentos de melhoria e alteração que serão descritos mais a frente. Por essa razão apresentamos primeiramente as características dessas transferências, para que em seguida, os respectivos procedimentos possam ser descritos.

\subsection{Características das Transferências}

Uma transferência de produção de um período para outro, é caracterizada pela quantidade $(q)$ a ser transferida, pelo item $(i)$ do qual esta quantidade está sendo transferida, pelo período de origem $(t)$ e o período destino $(\tau)$.

Para que possamos efetuar uma transferência, precisamos determinar qual a quantidade máxima que pode ser transferida de um período para outro sem causar infactibilidade inter-escalão, e qual a quantidade necessária para eliminar o excesso num periodo. A partir disso, precisamos ainda de um mecanismo para avaliar dentre as possíveis transferências, qual a mais indicada. Esses tópicos são apresentados a seguir.

\section{Quantidade Máxima a ser Transferida - $\mathbf{M}_{i t \tau}$}

A quantidade máxima do item $i$, que pode ser transferida de um período $t$ para um outro período $\tau$, sem violar as restrições

$$
\begin{aligned}
E_{i, t-1}+x_{i t}-E_{i t} & =D_{i t} \\
\sum_{j \in S(i)} r_{i j} E_{j t}-E_{i t} & \leq 0,
\end{aligned}
$$

será representada por $M_{i t r}$.

$O$ período destino $\tau$ pode ser anterior ou posterior ao período $t$, vejamos cada caso separadamente.

\section{- Transferência para um período posterior}

Para deduzirmos o valor de $M_{i t r}$, suponha que se deseja transferir um quantidade $q$ da produção do item $i$, do período $t$ para o período $\tau$, sendo $\tau>t$.

Analisando a equação do balanceamento de estoque, dada por 


$$
E_{i, t-1}+x_{i t}-E_{i t}=D_{i t},
$$

temos que ao deduzir $q$ unidades do lote $\left(x_{i t}\right)$, o estoque de escalão do item também deverá ser atualizado.

Como estamos transferindo uma quantidade $q$ para um periodo posterior a $t$, devemos deduzir esta quantidade do estoque de escalão deste item do período $t$ ao $\tau-1$. No entanto, o estoque de escalão do item $i$ ainda deverá ser suficiente para atender as necessidades dos seus sucessores imediatos. Logo, o valor de $q$ será então limitado pela inequação

$$
\sum_{j \in S(i)} r_{i j} E_{j \delta}-E_{i \delta} \leq 0, \quad \delta=t, \ldots, \tau-1
$$

que pode ser reescrita como

$$
E_{i \delta} \geq \sum_{j \in S(i)} r_{i j} E_{j \delta}
$$

e, deduzindo a quantidade transferida, temos

$$
E_{i \delta}-q \geq \sum_{j \in S(i)} r_{i j} E_{j \delta}
$$

Isolando o termo $q$, temos que a quantidade máxima permitida para transferência do item $i$, do período $t$ ao $\tau$ é dada por

$$
q \leq M_{i t \tau}=\min \left\{\min _{\delta=1, \ldots, \tau-1}\left\{E_{i \delta}-\sum_{j \in S(i)} r_{i j} E_{j \delta}\right\}, x_{i t}\right\} .
$$

Garantimos assim que após a transferência, a factibilidade inter-escalão será preservada, ou seja, o estoque de escalão do item será suficiente para suprir o estoque de escalão dos seus sucessores imediatos. Além disso, a quantidade transferida não pode ser superior à produção do periodo.

A expressão recursiva para calcular o valor de $M_{i t \tau}$ é

$$
M_{i t \tau}=\left\{\begin{array}{l}
\min \left\{M_{i, t, \tau-1}, E_{i, \tau-1}-\sum_{j \in S(t)} r_{i j} E_{j, \tau-1}\right\}, \text { se } \tau>t \\
x_{i t}, \text { se } \tau=t
\end{array}\right.
$$

Pela expressão anterior, podem existir períodos em que a quantidade máxima permitida para transferência é zero, ou seja, não é permitida nenhuma transferência. 


\section{- Transferência para um período anterior}

Analogamente, suponhamos que uma quantidade $q$ da produção do item $i$ seja transferida do período $t$ para o período $\tau$, sendo $\tau<t$.

Novamente, analisando a equação do balanceamento, dada por

$$
E_{i, t-1}+x_{i t}-E_{i t}=D_{i t}
$$

temos que ao deduzir $q$ unidades do lote $\left(x_{i t}\right)$, o estoque de escalão do item também deverá ser atualizado.

Neste caso, como estamos transferindo uma quantidade para um período anterior a $t$, devemos acrescentar esta mesma quantidade ao estoque de escalão do item do período $\tau$ ao $t-1$. Entretanto, como estamos aumentando o estoque de escalão do item $i$, é preciso verificar se o estoque de escalão dos seus predecessores imediatos continuarão sendo suficientes para prover o seu estoque de escalão. Desse modo, precisamos analisar a inequação

$$
E_{j \delta} \geq \sum_{m \in S(j)} r_{j m} E_{m \delta}+r_{j l} q, \delta=\tau, \ldots, t-1(\delta \leq T)
$$

para todos os predecessores do item $\mathrm{i}$, ou seja, $j \in P(i)$.

Isolando-se $q$ na inequação anterior, temos

$$
\begin{aligned}
r_{j i} q & \leq E_{j \delta}-\sum_{m \in S(j)} r_{j m} E_{m \delta}, \delta=\tau, \ldots, t-1(\delta \leq T) \\
q & \leq \frac{\left[E_{j \delta}-\sum_{m \in S(j)} r_{j m} E_{m \delta}\right]}{r_{j i}}, \delta=\tau, \ldots, t-1(\delta \leq T) .
\end{aligned}
$$

Novamente analisando as inequações para todo $j \in P(i)$,

$$
q \leq M_{i t \tau}=\min \left\{\min _{\substack{\delta=1, \ldots, t-1 \\ j \in P(t) \\ \delta \leq T}}\left\{\frac{\left[E_{j \delta}-\sum_{m \in S(j)} r_{j m} E_{m \delta}\right]}{r_{j t}}, x_{i t}\right\}\right\}
$$

Assim, mais uma vez temos preservada a factibilidade inter-escalão. Além disso, como no caso anterior, a quantidade transferida não pode ser maior que a produção do item $i$ período no período $t$.

A fórmula recursiva para esta expressão é dada em seguida. 


$$
M_{i t \tau}=\left\{\begin{array}{l}
\min \left\{M_{i, t, \tau+1}, \min _{\substack{j \in P(i) \\
\tau \leq T}}\left\{N_{i j \tau}\right\}\right\}, \text { se } \tau<t \\
x_{i t}, \operatorname{se} \tau=t
\end{array},\right.
$$

sendo

$$
N_{i j \tau}=\frac{E_{j \tau}-\sum_{m \in S(j)} r_{j m} E_{m \tau}}{r_{j i}} .
$$

Pela expressão (32), em períodos em que há produção de todos os itens, sempre existe uma quantidade de pelo menos um item que pode ser transferida. A limitação ocorre para itens que possuem predecessores, mas existe sempre pelo menos um item que não possui predecessor.

As expressões (31) e (32) indicam qual o valor máximo a ser transferido de um período para outro, sem perda da factibilidade inter-escalão.

Uma questão importante é se existe uma quantidade, menor que $M_{i t}$, que se transferida do período $t$ elimina o excesso neste período. Apresentamos essa análise a seguir.

\section{Quantidade para eliminar o excesso - $Q_{i t}$}

Suponhamos que Excesso $(t)>0$, para algum $t$. Seja $Q_{i t}$ a quantidade exata da produção de $x_{i t}$, que se transferida do período $t$, reduziria a zero o excesso referente a parcela deste item em $\operatorname{Excesso}(t)$. Assim

$$
\mathrm{Q}_{i t}=\frac{\left[\sum_{j=1}^{N}\left(\mathrm{f}_{j t} y_{j t}+\mathrm{v}_{j t} x_{j t}\right)-b_{t}\right]^{+}}{\mathrm{v}_{i t}}, \text { se } \mathrm{Q}_{i t}<M_{i t t}
$$

sendo $[a]^{+}=\left\{\begin{array}{l}0, \text { se } a \leq 0 \\ a, \text { se } a>0\end{array}\right.$.

Podemos notar que $\mathrm{Q}_{i t}$ indica se existe uma quantidade menor do que $M_{i t \tau}$ capaz de reduzir a zero a parcela do recurso deste item em $\operatorname{Excesso}(t)$, sem que haja sobra de recursos no período.

Apresentamos a seguir um mecanismo para escolha, dentre as possiveis transferências, qual a melhor candidata. 


\section{Teste da Razão}

Esse teste é usado para avaliar uma transferência, atribuindo a ela um valor, chamado Razão, de forma a auxiliar no processo de escolha entre várias transferências possíveis. Dada uma transferência $(q, i, t, \tau)$, calculamos a Razão associada da seguinte maneira:

$$
\text { Razão }=\frac{\Delta \text { custo }+\beta \text {.penalidade }}{\Delta \text { excesso }} .
$$

Sendo a variação no custo que uma determinada transferência causa, dada em termos percentuais por

$$
\Delta \text { custo }=\frac{\Delta \text { custo produção }+\Delta \text { custo_estoque }+\Delta \text { custo_preparação }}{\text { custo_total }},
$$

sendo

$$
\begin{gathered}
\Delta \text { custo_produção }=q\left(c_{i \tau}-c_{i t}\right) \\
\Delta \text { custo_estoque }=\left\{\begin{array}{l}
+q \sum_{\delta=\tau}^{t-1} e_{i \delta}, \text { para } \tau<t \\
-q \sum_{\delta=t}^{\tau-1} e_{i \delta}, \text { para } \tau>t
\end{array}\right. \\
\Delta \text { custo_preparação }=\Delta \mathrm{S} 1-\Delta \mathrm{S} 2,
\end{gathered}
$$

onde

$$
\left\{\begin{array}{l}
\Delta \mathrm{S} 1=\left\{\begin{array}{l}
s_{i \pi}, \text { se } x_{i \tau}=0 \\
0, \text { caso contrário }
\end{array}\right. \\
\Delta \mathrm{S} 2=\left\{\begin{array}{l}
s_{i t}, \text { se } q=x_{i t} \\
0, \text { caso contrário }
\end{array}\right.
\end{array}\right.
$$

A variação no custo de preparação dependerá do lote ser todo transferido, ou da existência ou não, de produção do item no período destino. Em geral, transferências para períodos posteriores fazem com que a variação do custo seja negativa, enquanto que para períodos anteriores a variação é positiva. No entanto, esta variação dependerá em grande parte dos custos de preparação.

A penalidade é um acréscimo feito à Razão, que depende dos excessos nos períodos de origem e destino da transferência. Desse modo, 


$$
\text { Penalidade }=E x c \_d e p o i s(t)+\left[E x c \_d e p o i s(\tau)-E x c \_ \text {antes }(\tau)\right],
$$

sendo

$\operatorname{Exc}$ _antes $(t)=\operatorname{Excesso}(t)$ usando a solução anterior à transferência

Exc_depois $(t)=\operatorname{Excesso}(t)$ supondo que a transferência tenha sido feita.

Lembrando que a função Excesso $(t)$ contabiliza somente o excessos da capacidade, não sendo consideradas as folgas. Além disso,

$$
\text { Exc_depois }(\tau) \geq E x c \_a n t e s(\tau)
$$

pois há sempre acréscimo de produção no período $\tau$ e, portanto, Penalidade é sempre positiva.

A soma ponderada da variação do custo e da penalidade é feita para que se possa dar maior importância, ou para a variação de custo ou para variação do excesso.

Finalmente, a variação de excesso é dada por

$$
\Delta \text { excesso }=E x c \_ \text {antes }(t)-E x c \_ \text {depois }(t)
$$

Quando as soluções são factíveis, temos em Razão a variação no custo que uma determinada transferência causa. No entanto, quando a solução antes e/ou depois da transferência é infactível, a Razão contabiliza um custo penalizado que leva em conta a variação no consumo dos recursos em excesso.

Com base nesses conceitos, apresentamos a seguir o procedimento de factibilização.

\subsection{Procedimento de Factibilização - P2}

A partir de uma solução infactivel, esse procedimento através de transferências de produção entre períodos tenta encontrar uma solução factível. O procedimento está dividido nos passos Progressivo e Regressivo.

No passo Regressivo os períodos são analisados de trás para frente (isto é, $t=T, T-1, \ldots, 2$ ), e a cada periodo $t$ infactível são feitas tentativas de transferências. Sendo consideradas todas as transferências $(q, i, t, \tau)$, sendo 
$q=$ quantidades $\mathrm{M}_{i t \tau}$ e $\mathrm{Q}_{i t}$

$i=$ itens que possuem produção no período $t$

$\tau=t-1, \ldots, \delta$

$\delta=\left\{\begin{array}{l}\text { primeiro período anterior a } t \text { com produção do item } i \text { ou l, caso } \\ \text { não existam períodos anteriores com produção }\end{array}\right.$

Para cada uma das transferências possíveis, a que apresentar menor Razão será efetuada. As transferências são efetuadas até que o período se torne factível ou até que não existam mais transferências possíveis. Quando isso ocorre, o periodo anterior é então analisado. Se ao final deste processo (isto é, $t=2$ ) a solução for infactível, então o passo Progressivo é executado.

No passo Progressivo os períodos $t=1,2, \ldots, T-1$, são analisados nesta ordem. Novamente para cada periodo $t$ infactível são feitas tentativas de transferências. Isso ocorre até que o período se torne factivel ou que não existam mais transferências possíveis.

Os dois passos são executados até que uma solução factível seja encontrada ou o número de passos exceda um limite pré-estabelecido. Neste último caso, o método falha.

A soma ponderada no cálculo da Razão, é feita de forma a aumentar o peso da variação do excesso em relação ao peso da variação do custo, ao longo da aplicação dos passos regressivo e progressivo. Dessa forma, $\beta=n$, sendo $n=$ número do ciclo, ou seja, número de vezes que os passos regressivo e progressivo foram aplicados. Assim, quanto maior número de aplicações do passos, maior a dificuldade de encontrar uma solução factível.

A seguir, apresentamos os pseudo-códigos dos passos regressivo e progressivo. 


\section{- PASSO REGRESSIVO DE FACTIBILIZAÇÃO}

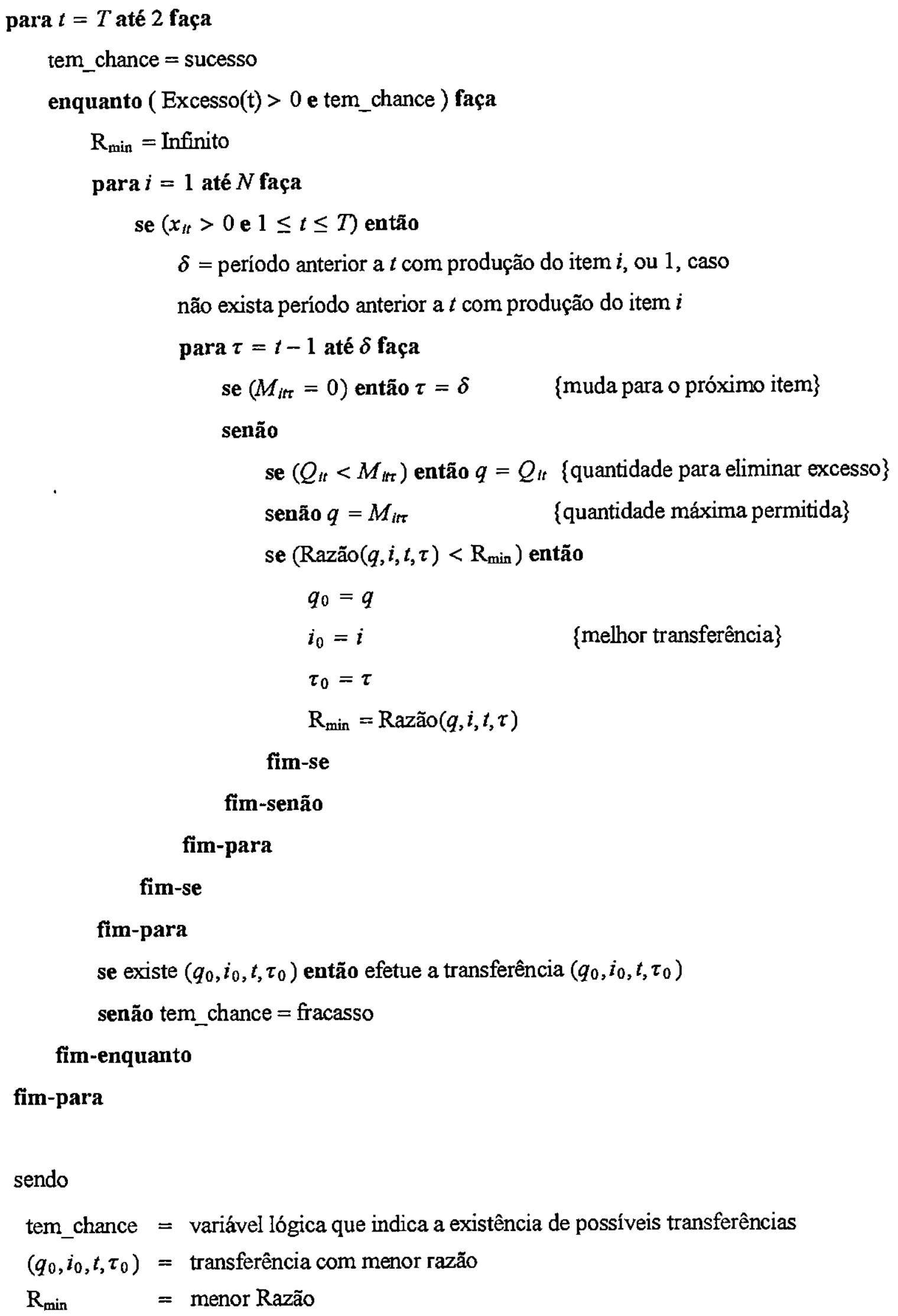




\section{- PASSO PROGRESSIVO DE FACTIBILIZAÇÃo}

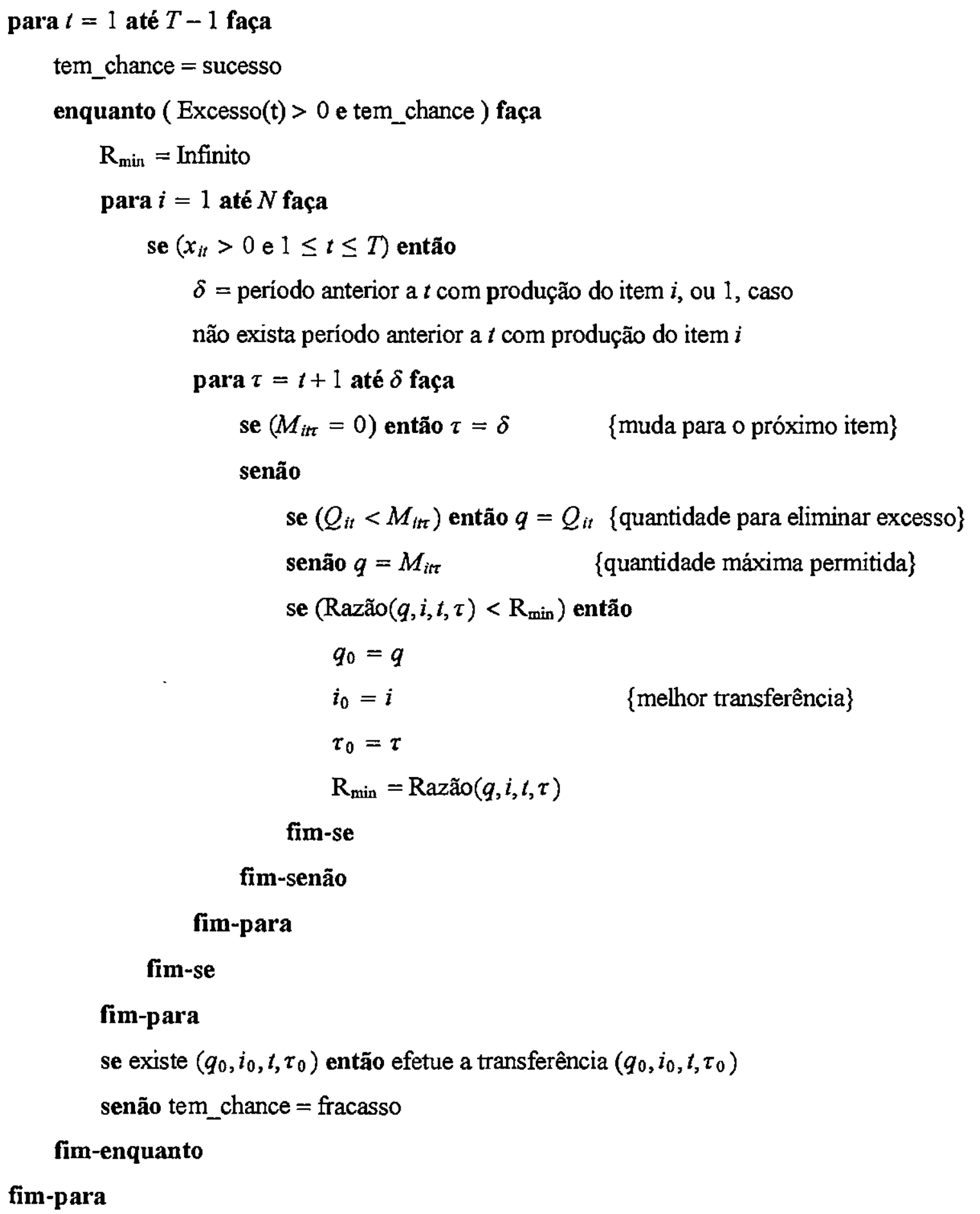

As transferências para trás tendem geralmente a causar um aumento no custo total, quando há transferência parcial do lote, pois neste caso podem implicar em custos adicionais de estoque e preparação, sem reduzir custos de preparação. Já no passo progressivo há uma probabilidade 
maior de ocorrer redução nos custos, pois existe a possibilidade de redução dos custos de estocagem.

Obtida uma solução factível, o procedimento seguinte trabalha com o objetivo de encontrar uma solução com menor custo, também efetuando transferências de produção entre períodos.

\subsection{Procedimento de Melhoria - P3}

Esse procedimento, assim como o anterior, é baseado em mecanismos de transferências de produção entre períodos. A diferença é que esse procedimento realiza somente transferências que melhorem o valor da função objetivo.

Dessa forma, esse procedimento pode ser visto como uma busca local, pois parte de uma solução factível, e através de movimentos tenta atingir soluções com menor custo. Uma transferência de produção pode ser vista como um movimento, pois ao efetuarmos uma transferência estamos passando de uma solução para outra de sua vizinhança. Neste caso, por exemplo, a vizinhança de uma solução qualquer é composta por todas as soluções que podem ser obtidas a partir desta, através de uma única transferência de produção entre períodos. Como o procedimento analisa dentre as possíveis transferências, ou seja, dentre os possíveis movimentos qual o melhor através da Razão, pode ser definido como uma heurística de busca local.

$O$ procedimento de melhoria, funciona de modo semelhante ao anterior. A diferença é que este parte de uma solução factível e somente realiza movimentos que não infactibilizem a solução e ainda, melhorem o valor da função objetivo.

As quantidades avaliadas para as transferências são duas. Uma é a quantidade máxima que pode ser transferida $\left(\mathrm{M}_{i t t}\right)$ e a outra é uma quantidade aleatória sorteda dentro do intervalo uniformemente distribuído $\left[1, \mathrm{M}_{i t r}\right]$. $\mathrm{O}$ intuito do sorteio aleatório dessa quantidade, é dificultar a ocorrência de ciclagem na execução dos procedimentos. Lembrando que ciclagem é processo pelo qual, após um número de iterações, o algoritmo atinge uma solução visitada anteriormente. Através deste sorteio aleatório, o algoritmo pode partir de uma mesma solução várias vezes e chegar a soluções distintas.

A quantidade máxima permitida para uma transferência $(q, i, t, \tau)$, pode ser escrita como

$$
\mathrm{F}_{i r \tau}=\min \left\{\mathrm{M}_{i r \tau}, \mathrm{G}_{i \tau}\right\} \text {, }
$$

sendo $\mathrm{G}_{i \tau}=$ quantidade máxima do item $i$ que pode ser transferida do período $t$ para o período $\tau$, 
de modo que $\operatorname{Excesso}(\tau)$ não seja maior que zero. Assim

$$
\mathrm{G}_{i \tau}=\left\{\begin{array}{ll}
\frac{\mathrm{J}_{\tau}}{\mathrm{V}_{i \tau}}, & \text { se } x_{i t}>0 \\
\frac{\mathrm{J}_{\tau}-\mathrm{f}_{i \tau}}{\mathrm{V}_{i \tau}}, & \text { caso contrário }
\end{array},\right.
$$

sendo

$$
\mathrm{J}_{\tau}=b_{\tau}-\sum_{i=1}^{N}\left(\mathrm{v}_{i \tau} x_{i \tau}+\mathrm{f}_{i \tau} y_{i \tau}\right)
$$

que representa a quantidade de recursos não utilizados no período $\tau$.

A Razão foi modificada para aceitar apenas movimentos que melhorem o valor da função objetivo. Dessa forma, pode ser reescrita como

$$
\text { Razao }=\left\{\begin{array}{l}
\Delta \text { custo, se } \Delta \text { custo }<0 \\
\infty, \text { caso contrário }
\end{array} .\right.
$$

Do mesmo modo que o procedimento de factibilização, este também é dividido nos passos regressivo e progressivo. $\mathrm{O}$ algoritmo é executado sucessivamente até que um passo regressivo e um progressivo não consigam realizar nenhuma transferência, ou o número máximo de 50 iterações seja atingido. Nesse caso, o algoritmo termina com a solução obtida até então ou, na pior das hipóteses com a solução inicial.

Apresentamos a seguir, os pseudo-códigos dos passos regressivo e progressivo do procedimento de melhoria. 


\section{- PASSO REGRESSIVO de FACTIBILIZAÇÃo}

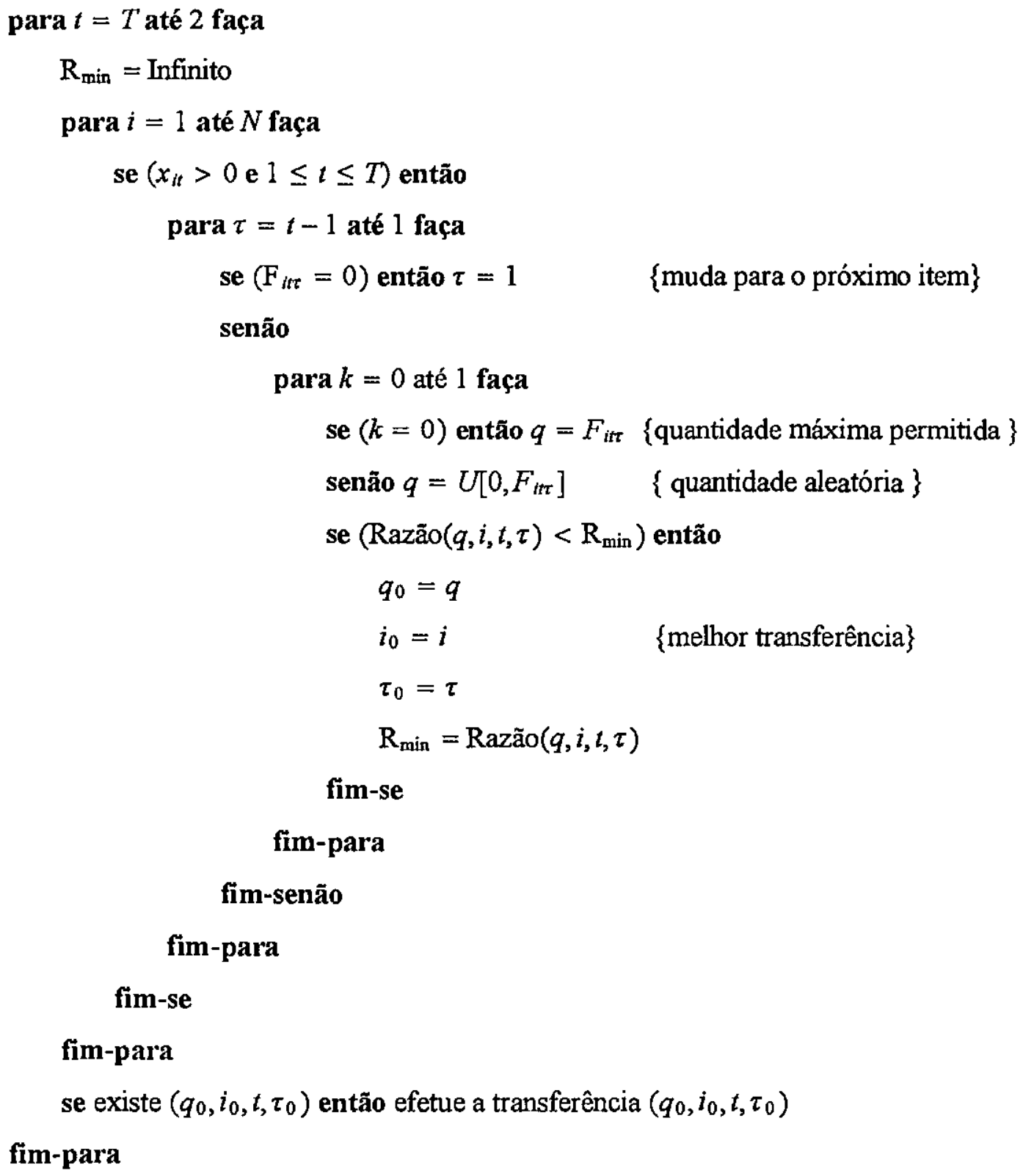




\section{- PASSO PROGRESSIVO DE FACTIBILIZAÇÃo}

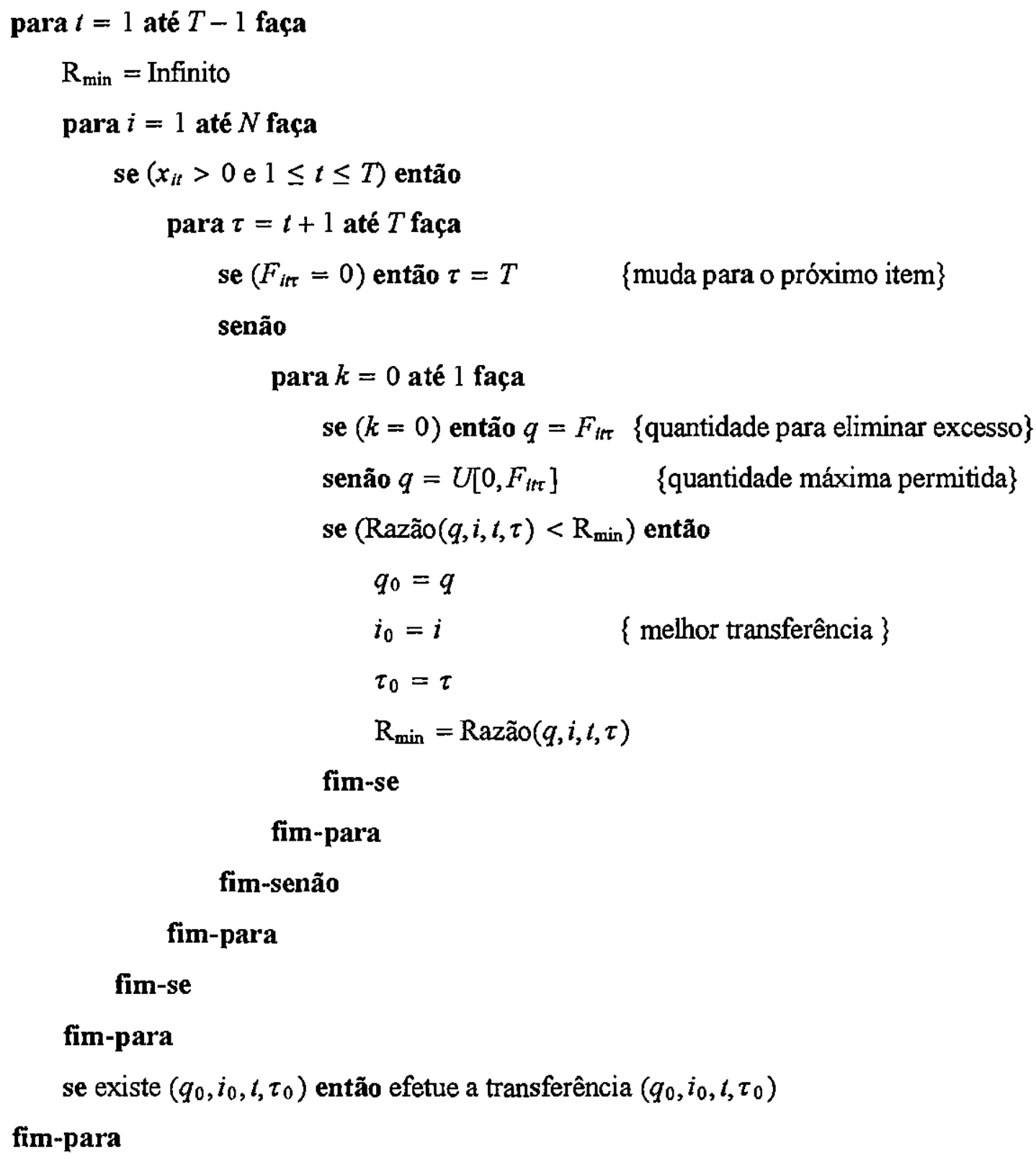

Nesse procedimento, assim como nos anteriores há a possibilidade de não existirem movimentos possíveis que melhorem a função objetivo. Em razão disso, um procedimento altemativo que permite reiniciar todo o processo a partir de uma nova solução é proposto. Descrevemos esse procedimento a seguir. 


\subsection{Procedimento de Alteração - P4}

Esse procedimento tem por objetivo reconfigurar uma solução, para que então um dos procedimentos anteriores possa novamente ser aplicado. Partindo de uma solução factível ou infactível, e terminando numa solução factível ou não.

As transferências são analisadas para cada item, num único passo, e uma quantidade aleatória é sorteada dentro do intervalo uniforme $\left[1, \mathrm{M}_{i t r}\right]$. Os períodos considerados como origem e destino das transferências são ordenados de acordo com a utilização dos recursos. Para calcular a utilização dos recursos em cada período, definimos a seguinte função

$$
\operatorname{Folga}(t)=\frac{b_{t}-\sum_{i=1}^{N}\left(\mathrm{v}_{i t} x_{i t}+\mathrm{f}_{i t} y_{i t}\right)}{b_{t}},
$$

que representa a quantidade de recursos não utilizados no período. Esta função pode assumir inclusive valores negativos, em períodos para os quais as capacidades foram violadas. A partir destes valores, os períodos são ordenados em ordem decrescente, ou seja, o procedimento tenta transferir produção dos períodos em que a função Folga $(t)$ apresenta menores valores para os períodos com maior valor. Dessa forma procedimento tenta transferências de produção daqueles períodos com menor folga para os peridos com maior folga, para o item analisado. A primeira transferência possível é realizada, não ocorrendo avaliações entre possíveis movimentos. Assim que uma transferência é realizada, o algoritmo passa para o item seguinte, isto é, somente uma transferência para cada item é efetuada. Após a análise dos $N$ itens, o procedimento é finalizado.

A seguir descrevemos o pseudo-código desse procedimento. 


\section{- PROCEDIMENTO DE ALTERAÇÃo}

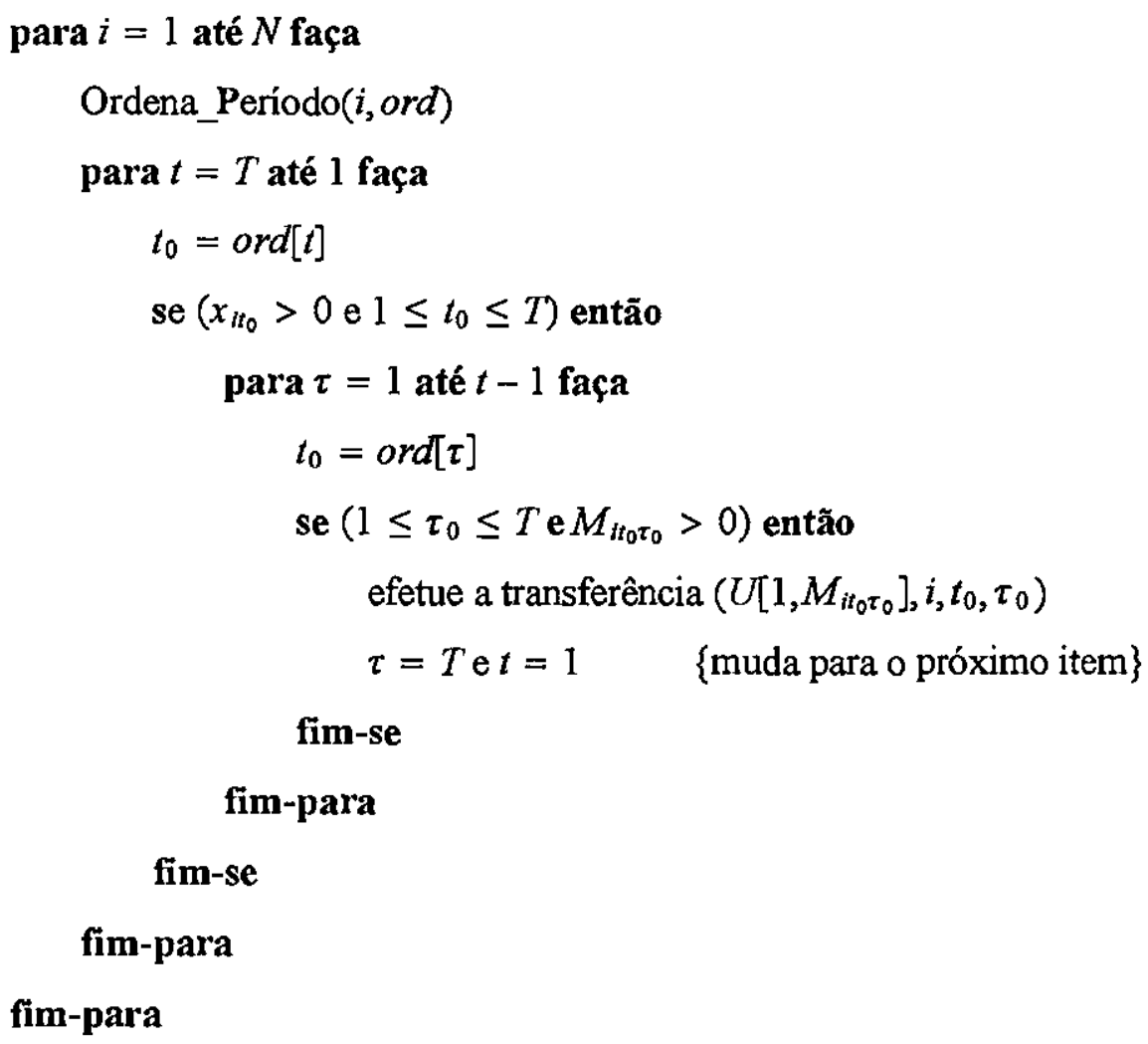

onde ord $=$ períodos ordenados em ordem crescente de Folga $(t)$.

A seguir, descrevemos a heurística que utiliza esses quatro procedimentos para a resolução do problema de dimensionamento de lotes. Maiores detalhes destes procedimentos podem ser encontrados em França et al.(1997).

\subsection{Pseudo-código da Heurística de França et al.(1997)}

Esse algoritmo é a reunião dos quatro procedimentos descritos, para resolução do problema de dimensionamento de lotes multiestágio capacitado, com custos e tempos de preparação. A Figura 3.1 a seguir mostra como os quatro procedimentos interagem durante a execução do algoritmo. 


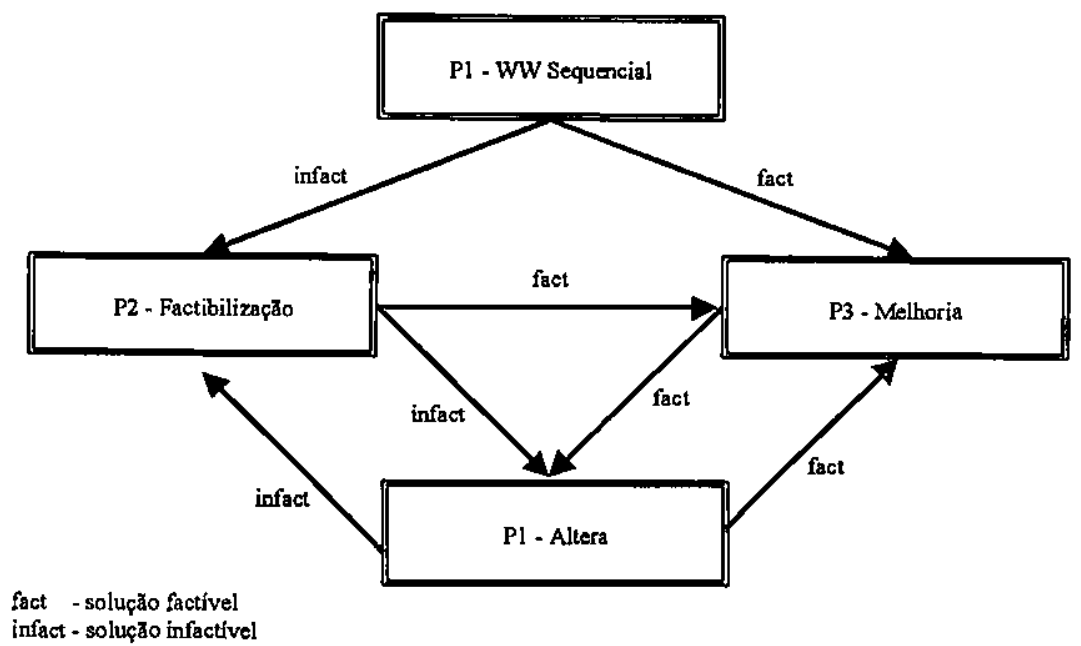

Figura 3. I Diagrama da Heurística Inicial.

A seguir apresentamos o pseudo-código da heurística.

\section{- HEURÍSTICA INICIAL}

\section{BEGIN}

iter $=0, \mathrm{~S}^{*} \leftarrow$ infactível e $\mathrm{f}\left(\mathrm{S}^{*}\right)=\infty$

$\mathrm{S}^{r} \leftarrow P 1$

\{ construção da solução inicial \}

para $i t=1$ até $I t M a x$ faça

se ( $S^{i t}$ é infactível ) então

$$
\mathrm{S}^{i t} \leftarrow P 2 \quad \text { \{procedimento de factibilização }
$$

fim-se

se ( $S^{\text {it }}$ é factível ) então

$$
\mathrm{S}^{i t} \leftarrow P 3 \quad \text { \{procedimento de melhoria }
$$$$
\text { se } \mathrm{f}\left(S^{i t}\right)<\mathrm{f}\left(S^{*}\right) \text { então } S^{*}=S^{i t}
$$

\section{fim-se}

$$
\mathrm{S}^{i t} \leftarrow P 4 \quad \text { \{procedimento de alteração }
$$

\section{fim-para}

se ( $S^{*}$ é infactível ) então "método falhou"

senão $S^{*}$ é a melhor solução encontrada

END 
Sendo

it $\quad=$ contador de iterações

$\mathrm{S}^{r} \quad=$ solução obtida na iteração $\mathrm{r}$

$f\left(S^{r}\right)=$ valor da solução $S^{r}$ na função objetivo

$\mathrm{S}^{*} \quad=$ solução incumbente

ItMax = número máximo de iterações

O número máximo de iterações do algoritmo será comentado juntamente com os testes computacionais. O procedimento P3 é aplicado somente nas soluções factíveis, enquanto não há uma solução factível os procedimentos P2 e P4 são aplicados. O procedimento P4 não é aplicado na última iteração.

O fato da heurística não encontrar nenhuma solução factivel não implica que o problema seja infactível, pois a heurística não garante que encontrará uma solução factível.

No próximo capítulo, descrevemos as meta-heurísticas evolutivas implementadas. 


\section{CAPÍTULO 4}

\section{META-HEURÍSTICAS EVOLUTIVAS IMPLEMENTADAS}

\subsection{Introdução}

Nesse capítulo apresentamos as meta-heurísticas evolutivas implementadas durante o trabalho, mais especificamente, algoritmos genéticos e meméticos. Inicialmente descrevemos os aspectos comuns aos dois algoritmos, que são: representação da solução e estrutura da população, função de avaliação, construção da população inicial, mecanismos de seleção e operadores de reprodução. A seguir apresentamos os pseudo-códigos dos algoritmos, juntamente com os aspectos específicos de cada um.

\subsection{Componentes Básicos}

Embora existam diferenças conceituais entre alguns elementos que compõem um algoritmo 
genético e um memético, como foi citado no capítulo dois, na prática vários destes conceitos podem ser tratados como iguais. Nesse trabalho, assumiremos, por exemplo, a semelhança entre os conceitos de indivíduo/agente e cruzamento/recombinação.

Detalhamos em seguida cada um dos componentes básicos dos algoritmos evolutivos, além de características inerentes à implementação de cada um desses elementos.

\subsubsection{Representação e Estrutura Populacional}

Um dos primeiros passos na implementação de um algoritmo genético ou memético, é definir a representação das características de uma solução através de um indivíduo. Como o problema de dimensionamento de lotes trabalha com um número muito grande de variáveis, a primeira preocupação é adotar uma estrutura de dados eficiente que permita manipular as informações do problema sem prejudicar o processo evolutivo.

Assim consideremos uma solução para o problema de dimensionamento de lotes, que pode ser representada por três variáveis $(x, I, y)$, sendo que cada uma delas depende ainda de $(i, t)$. Logo, podemos representar uma solução pela seguinte matriz

$$
\left[\begin{array}{cccc}
x_{11} & x_{12} & \ldots & x_{1 T} \\
I_{11} & I_{12} & \ldots & I_{1 T} \\
y_{11} & y_{12} & \ldots & y_{1 T} \\
\vdots & \ddots & \ldots & \vdots \\
x_{N 1} & x_{N 2} & \ldots & x_{N T} \\
I_{N 1} & I_{N 2} & \ldots & I_{N T} \\
y_{N 1} & y_{N 2} & \ldots & y_{N T}
\end{array}\right]_{3 N x T}
$$

sendo $N$ é o número de itens e $T$ o número de períodos.

No entanto, analisando a dependência entre as variáveis $x$ e $y$, temos

$$
y=\left\{\begin{array}{l}
1, \text { se } x \neq 0 \\
0, \text { se } x=0
\end{array}\right.
$$

Com isso, podemos então suprimir a variável $y$ da matriz sem danos à representação, pois para determinar o valor de $y$ basta conhecer o valor de $x$. Isto faz com que $N$ linhas da matriz sejam eliminadas, gerando uma razoável economia de recursos computacionais.

Desse modo, fazemos uso de uma representação que consiste de uma matriz bidimensional, com $2 N$-linhas e $T$-colunas. Ou seja, 


$$
\left[\begin{array}{cccc}
x_{11} & x_{12} & \ldots & x_{1 T} \\
I_{11} & I_{12} & \ldots & I_{1 T} \\
\vdots & \ddots & \ldots & \vdots \\
x_{N 1} & x_{N 2} & \ldots & x_{N T} \\
I_{N 1} & I_{N 2} & \ldots & I_{N T}
\end{array}\right]_{2 N x T}
$$

Nessa matriz armazenamos os valores de produção $\left(x_{i t}\right)$ e estoque $\left(I_{i t}\right)$ de uma solução dada. Como será utilizada uma representação direta das soluções, estabelecemos a semelhança entre os conceitos de indivíduo e solução, uma vez que um indivíduo é uma solução codificada.

Uma maneira de organizar os agentes na população, de acordo com algum critério, é definindo uma estrutura para população. Assim, optamos pelo uso de uma estrutura em árvore temária com 3 níveis, com um número fixo de 13 agentes, conforme a Figura 3.2. Esta estrutura é a mesma utilizada por Berretta e Moscato (1999) para o problema de partição de números.

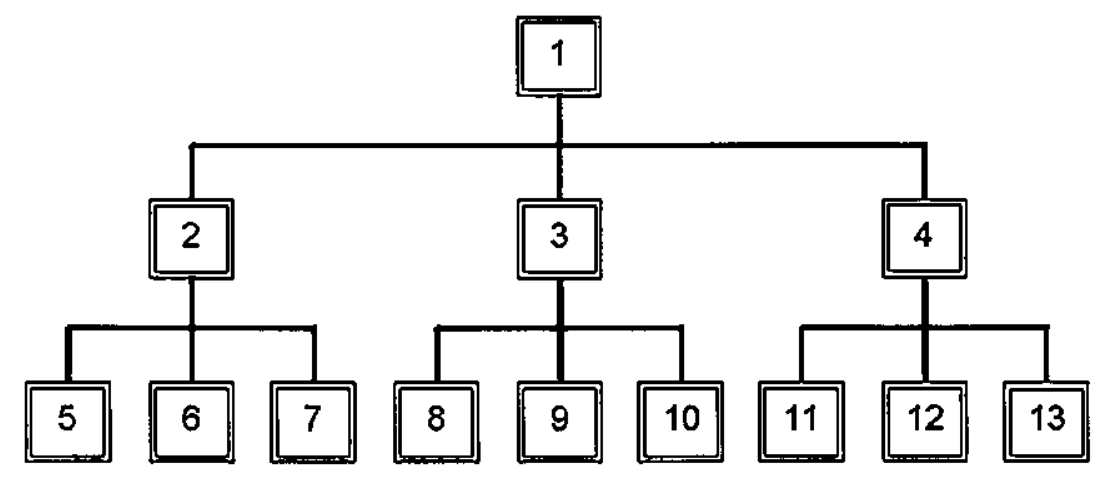

Figura 3.2 Estrutura em árvore da população.

A população é formada hierarquicamente por líderes e subordinados. Esta classificação é feita de acordo com o valor da solução que esse agente representa no problema, ou seja, o líder possui sempre melhor valor em relação aos seus subordinados. Dessa forma, temos uma estrutura ordenada de acordo com a qualidade das soluções que estes agentes representam. Logo, teremos armazenado no agente 1 , sempre a melhor solução encontrada na população.

Analisando cada nível da estrutura, podemos dividir a árvore em quatro subpopulações, onde cada subpopulação tem um lider e três subordinados. Assim, o primeiro agente será líder da subpopulação que tem como subordinados os agentes 2,3 e 4 . $O$ agente 2 , tem como subordinados os elementos 5, 6 e 7, e o agente 3 tem como subordinados os agentes 8,9 e 10, e assim por diante.

Cada agente na população representa dois indivíduos ou duas soluções, um chamado pocket $\mathrm{e}$ o outro current. O pocket é sempre melhor que o current, isto é, a solução representada por esse - indivíduo possui melhor valor para o problema. Quando um current é melhor que um pocket, então 
efetuamos a troca do indivíduo que está armazenado em current para o pocket, e vice-versa.

$\mathrm{O}$ indivíduo pocket de um líder possui melhor valor que os indivíduos pockets de seus subordinados. Quando isso não ocorre, ou seja, existe um agente na subpopulação que tem o individuo pocket melhor que o do líder, então os indivíduos desses agentes são trocados de posição. Lembrando que nesse caso estamos comparando e trocando somente indivíduos pockets, pois nesta fase já foram efetuadas as comparações entre pockets e currents para garantir que os melhores indivíduos sejam armazenados nas pockets. Com isso, garantimos que todo líder terá a melhor solução da sua subpopulação, e conseqüentemente o agente 1 ou raiz da árvore, terá no indivíduo pocket sempre a melhor solução da população.

Logo, sempre que uma solução sofrer alterações, será necessário efetuarmos comparações e trocas, se for o caso, para garantir esta hierarquia. $O$ processo de comparação e troca entre pockets e currents é chamado no pseudo-código de Atualiza_Pocket( ), e o de comparar e trocar as pockets líderes com as subordinadas é chamado de Ordena_Arvore( ).

Portanto, temos uma estrutura em árvore para a população, ordenada de acordo com a qualidade dos indivíduos. Uma medida referente a essa qualidade é atribuída pela função de avaliação.

\subsubsection{Função de Avaliação}

Para que seja possivel a utilização da estrutura populacional mencionada, precisamos estabelecer uma função de avaliação que atribua a cada indivíduo, um valor referente a qualidade desta solução para o problema. Assim, a cada indivíduo na população é atribuído um valor definido pela função de avaliação, denominado fitness, que está relacionado com o valor da solução na função objetivo.

Uma idéia natural que surge é a utilização do valor desta solução (custo) na função objetivo, ou seja, usar como função de avaliação a própria função objetivo. No entanto, numa população podemos ter soluções factíveis e infactíveis, inviabilizando o uso somente do custo. Uma solução infactivel pode possuir um custo muito menor que o de uma factível, entretanto não é melhor que a factível.

Uma alternativa para gerenciar a infactibilidade na população, é o uso combinado de duas informações para a função de avaliação, como a informação de factibilidade e a do custo. Assim, temos uma função de avaliação dada por

$$
\mathrm{f}_{\mathrm{a}}(s)=(\text { custo }, f a c),
$$


sendo

$$
\begin{aligned}
& s \\
& \text { custo }=\text { indivíduo que representa uma solução do problema } \\
& \text { fac da solução } s \text { na função objetivo } \\
& =\left\{\begin{array}{l}
1, \text { se a solução } s \text { é factível } \\
0, \text { caso contrário }
\end{array}\right.
\end{aligned}
$$

Logo, o valor de fitness de um indivíduo é representado por um par ordenado, ou seja, é um valor bidimensional que armazena as informações de custo e factibilidade de uma solução.

Como exemplo, sejam as seguintes soluções com seus respectivos valores de fitness.

\begin{tabular}{|c|c|c|c|}
\hline$s$ & 1 & 2 & 3 \\
\hline $\mathrm{f}_{a}(s)$ & $(30,1)$ & $(25,0)$ & $(28,1)$ \\
\hline
\end{tabular}

Analisando a qualidade dessas soluções através de seus valores de fitness, temos que a solução 2 embora possua menor custo é infactível, logo tem pior fitness do que as outras duas. Dentre as factíveis (1 e 3) a que possui menor custo é a 3, e portanto é a melhor solução do conjunto. A partir desse conceito podemos ordenar os elementos dentro da população.

\subsubsection{População Inicial}

Na criação de uma solução inicial, utilizamos o algoritmo de Wagner-Whitin, juntamente com um procedimento para factibilização da capacidade, uma vez que o método fomece na maioria das vezes uma solução infactível com relação à capacidade. Esses procedimentos (P1 e P2), encontrados em França et al.(1997), estão descritos na seção anterior.

Para a construção da população inicial, efetuamos variações nos custos de preparação utilizados pelo algoritmo de Wagner-Whitin, para obter um número desejado de indivíduos distintos que irão compor a população inicial. Lembrando que a população é composta por 26 indivíduos.

Para modificar os custos em cada período, seus valores são multiplicados ou divididos por 100, de forma aleatória. Essas variações fazem com que os custos de preparação, inviabilizem a produção em determinados períodos (custos muito altos) e forcem a produção em outros (custos muito baixos). Isso provoca uma boa diversidade de soluções obtidas com o algoritmo de Wagner-Whitin.

Depois de construída uma solução pelo algoritmo de Wagner-Whitin, com custos de 
preparação alterados, se a solução for infactível o procedimento de factibilização é aplicado, e em seguida calculamos o valor de fitness desta solução com base nos custos originais.

\subsubsection{Mecanismos de Seleção dos Pais}

Depois de constituída a população inicial, é necessária a definição de mecanismos de seleção dos indivíduos que irão se reproduzir para gerar os novos componentes da população, e ainda como estes novos indivíduos serão introduzidos na população.

Nesse caso, serão selecionados para o cruzamento somente os pockets. Em cada subpopulação o indivíduo pocket do líder cruzará com todos os indivíduos pockets de seus subordinados. Como em cada subpopulação temos três subordinados, irão ocorrer portanto três cruzamentos em cada subpopulação, gerando um total de doze cruzamentos na população. Dessa forma, podemos definir que uma geração será formada a cada doze cruzamentos.

Cada cruzamento entre um pocket líder e um pocket subordinado resultará num indivíduo filho, e esse filho substituirá o indivíduo current do subordinado. Suponha por exemplo, que tenhamos selecionados o pocket do agente 1 (líder) e do agente 2 (subordinado) para aplicação do operador de reprodução. $O$ indivíduo resultante desta operação, será armazenado no lugar do indivíduo current do agente 2. Essa substituição não precisa estar condicionada a qualidade da nova solução, porque temos a garantia de que a current eliminada não é melhor do que os pais que geraram a nova solução.

Uma vez estabelecidos os critérios de seleção e substituição dos indivíduos, o operador de cruzamento pode então ser aplicado.

\subsubsection{Estratégia de Reprodução}

A maior dificuldade na elaboração de um algoritmo genético para esse problema, é a determinação de operadores de reprodução entre duas soluções. Após a reprodução podemos obter uma solução infactível com relação às restrições de capacidade e em relação aos estoques, envolvendo a dependência entre os itens. A infactibilidade em relação às restrições de capacidade pode ser retornada pelo procedimento de factibilização descrito anteriormente (França et al., 1997), mas a infactibilidade em relação aos estoques é dificil de ser retomada.

A estratégia de reprodução proposta nesse trabalho, conserva a factibilidade dos estoques mas 
não garante a de capacidade. Assim, logo após a reprodução, se for o caso, aplicamos o procedimento de factibilização.

Uma vez selecionados dois indivíduos, que aqui denominaremos de pai e mãe, o operador de cruzamento é então aplicado.

O operador de cruzamento consiste em, primeiro fixar os itens finais (isto é, itens sem sucessores), para em seguida determinar a produção $\left(x_{i t}\right)$ e estoque $\left(I_{i t}\right)$ do filho para estes itens, do período $l$ até o periodo $T$. Essa ordem de aplicação do operador faz com que a factibilidade inter-escalão seja mantida. A produção e o estoque do item $i$ num período $t$ são calculados pela seguinte expressão

$$
\begin{aligned}
& \left\{\begin{array}{ll}
x_{i t}^{\text {filho }}=0 & \text { se } a_{i t} \leq 0 \\
I_{i t}^{\text {filho }}=-a_{1 t}
\end{array},\right. \\
& \begin{cases}x_{i t}^{\text {filho }}=U\left[a_{i t}, \max \left\{a_{i t}, x_{i t}^{\mathrm{pai}}, x_{i t}^{\mathrm{mae}}\right\}\right] & \text { se } a_{i t}>0 \\
I_{t t}^{\text {filho }}=x_{i t}-a_{i t} & \end{cases}
\end{aligned}
$$

sendo

$$
a_{i t}=d_{i t}+\sum_{j \in S(i)} r_{i j} x_{j t}-I_{i, t-1}
$$

A equação (41) indica a quantidade de produção necessária do item $i$ no período $t$, que é dada pela demanda do item mais a quantidade necessária para compor o lote dos seus sucessores imediatos, menos o estoque do periodo anterior. Se $a_{i t} \leq 0$, então não há necessidade de produção do item neste período. Caso contrário, isto é, $a_{i t}>0$ indica que há necessidade de produção, e $a_{i t}$ será a quantidade mínima que deve ser produzida do item, para que tenhamos respeitada a factibilidade em relação aos estoques. Nesse caso, um valor entre $a_{i t}$ e o máximo entre $\left[a_{i t}, x_{i t}^{\mathrm{pai}}, x_{i t}^{\mathrm{mae}}\right]$ é sorteado (onde $x_{i t}^{\mathrm{pai}}$ é a produção do item $i$ no período $t$, do indivíduo "pai"). $\mathrm{O}$ objetivo do sorteio aleatório é estimular a diversi dade da população.

Em seguida, calculamos a nova demanda (conforme a equação (28)) dos itens predecessores imediatos, com base na solução obtida anteriormente, e aplicamos novamente as mesmas regras para obtenção da solução para estes itens. Repetimos esse processo até que sejam determinadas todas as quantidades de produção e estoque para todos os itens em todos os períodos.

Vale ressaltar, que esse operador não impede que ao final do horizonte de planejamento ocorram sobras de produção. Esse excesso de produção, pode ser verificado pela variável estoque, isto é, quando esta for diferente zero ao final do horizonte de planejamento. Poderíamos argumentar que este excesso, na prática será utilizado no próximo horizonte de planejamento, logo 
não devemos considerá-lo como sobra de produção. Entretanto, sua eliminação certamente reduzirá custos de estoque e produção, e dependendo da quantidade até custos de preparação, o que provocará certamente uma melhoria na qualidade das soluções.

Com o intuito de reduzir custos provocados por esses excessos de produção, elaboramos um procedimento denominado Ajuste. Esse procedimento é aplicado após o operador de cruzamento, e faz com que os excessos de produção sejam eliminados. Apresentaremos mais a frente uma descrição detalhada desse procedimento.

No pseudo-código a seguir apresentamos o operador de cruzamento.

\section{- PSEUDO-CÓDIGO DO OPERADOR DE CRUZAMENTO}

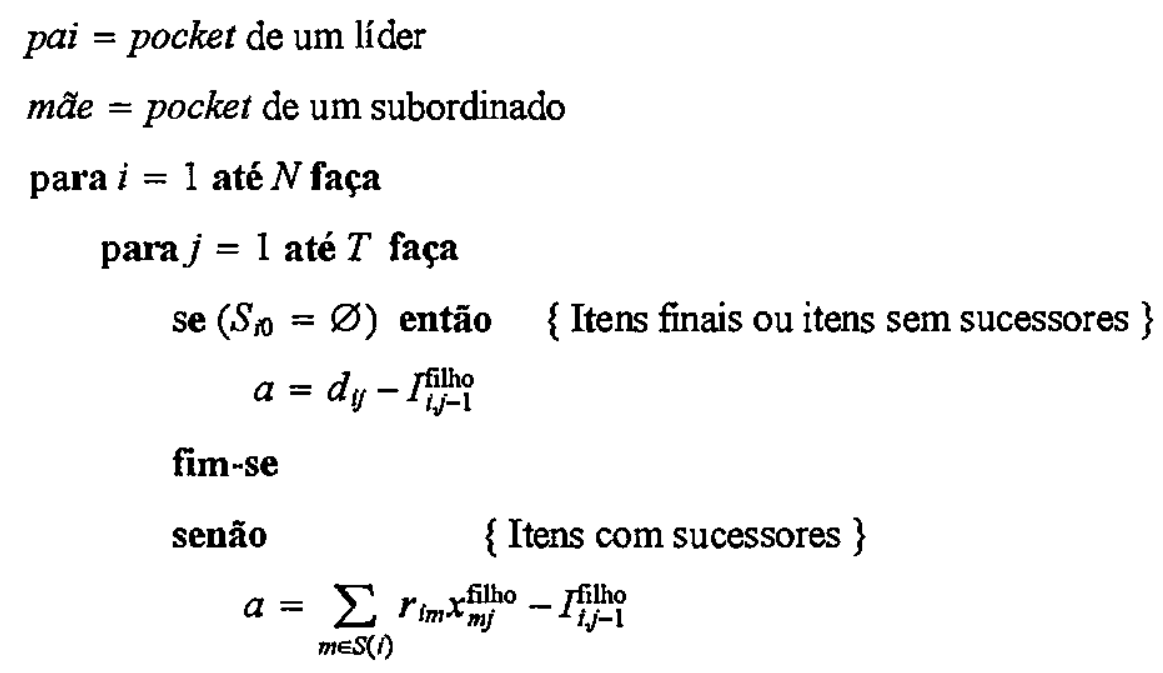

fim-senão

se $a \leq 0$ então

$$
\begin{aligned}
& x_{i j}^{\text {filho }}=0 \\
& I_{i j}^{\text {filho }}=-a
\end{aligned}
$$

fim-se

senão

$$
\begin{aligned}
& x_{i j}^{\mathrm{filho}}=U\left[a, \max \left\{a, x_{i j}^{\mathrm{pai}}, x_{i j}^{\mathrm{mane}}\right\}\right] \\
& I_{i j}^{\mathrm{filho}}=x_{i j}^{\mathrm{filho}}-a
\end{aligned}
$$

fim-senão

\section{fim-para}

fim-para

Ajuste(filho)

current $^{\text {mate }}=$ filho $\{$ Individuo current do subordinado recebe of flho $\}$ 
A seguir, aplicamos o operador de cruzamento num exemplo numérico.

\section{Exemplo 4.1 Aplicação do Operador de Cruzamento}

Para um melhor entendimento do operador de cruzamento, consideremos como exemplo um produto com a estrutura geral dada a seguir.

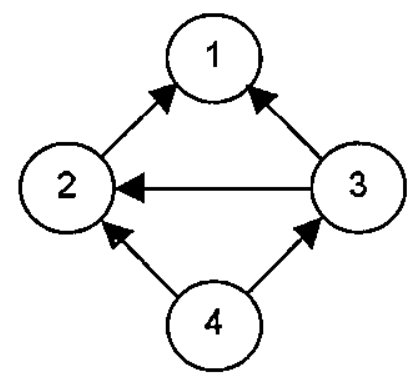

Seja um horizonte de planejamento com 3 períodos e considere a seguinte demanda

\begin{tabular}{cccc}
$t$ & 1 & 2 & 3 \\
\hline$d_{1 t}$ & 10 & 20 & 30 \\
\hline$d_{2 t}$ & 0 & 0 & 0 \\
\hline$d_{3 t}$ & 0 & 0 & 0 \\
\hline$d_{4 t}$ & 0 & 0 & 0
\end{tabular}

e duas soluções quaisquer, dadas por

\begin{tabular}{|c|c|c|c|c|c|c|c|}
\hline Pai & $t=1$ & $t=2$ & $t=3$ & Mãe & $t=1$ & $t=2$ & $t=3$ \\
\hline$x_{1 t}$ & 30 & 0 & 30 & $x_{1 t}$ & 10 & 20 & 30 \\
\hline$I_{1 t}$ & 20 & 0 & 0 & $I_{1 t}$ & 0 & 0 & 0 \\
\hline$x_{2 t}$ & 40 & 20 & 0 & $x_{2 t}$ & 20 & 40 & 0 \\
\hline$I_{2 t}$ & 10 & 30 & 0 & $I_{2 t}$ & 10 & 30 & 0 \\
\hline$\overline{x_{3 t}}$ & 80 & 10 & 30 & $x_{3 t}$ & 90 & 0 & 30 \\
\hline$I_{3 t}$ & 10 & 0 & 0 & $I_{3 t}$ & 60 & 0 & 0 \\
\hline$x_{4 t}$ & 120 & 60 & 0 & $x_{4 t}$ & 110 & 40 & 30 \\
\hline$I_{4 t}$ & 0 & 30 & 0 & $I_{4 t}$ & 0 & 0 & 0 \\
\hline
\end{tabular}

Note que estamos considerando que todos os estoque iniciais são iguais a zero, ou seja, 
$I_{10}=0, \forall i$. Aplicando o operador de reprodução nestas duas soluções, temos:

Fixando $i=1$ :

$$
\begin{aligned}
& a_{1 t}=d_{1 t}-I_{1, t-1}^{\text {filho }} \\
& a_{1 t} \leq 0 \Rightarrow\left\{\begin{array}{l}
x_{1 t}^{\text {filho }}=0 \\
I_{1 t}^{\text {filho }}=-a_{1 t}
\end{array}\right. \\
& a_{1 t}>0 \Rightarrow\left\{\begin{array}{l}
x_{1 t}^{\text {filho }}=U\left[a_{1 t}, \max \left\{a_{1 t}, x_{1 t}^{\text {pai }}, x_{1 t}^{\text {mae }}\right\}\right] \\
I_{1 t}^{\text {filho }}=x_{1 t}^{\text {fillho }}-a_{1 t}
\end{array}\right.
\end{aligned}
$$

$t=1$

$$
\begin{aligned}
& a_{11}=d_{11}-I_{10}^{\text {filho }}=10-0=10 \\
& a_{11}>0 \Rightarrow\left\{\begin{array}{l}
x_{11}^{\text {filho }}=U[10, \max \{10,30,10\}]=U[10,30]=30 \\
I_{11}^{\text {filho }}=x_{11}^{\text {filho }}-a_{11}=30-10=20
\end{array}\right.
\end{aligned}
$$

$t=2$

$$
\begin{aligned}
& a_{12}=d_{12}-I_{11}^{\text {fitho }}=20-20=0 \\
& a_{12} \leq 0 \Rightarrow\left\{\begin{array}{l}
x_{12}^{\text {filho }}=0 \\
I_{12}^{\text {filho }}=-a_{11}=0
\end{array}\right.
\end{aligned}
$$

$t=3$

$$
\begin{aligned}
& a_{13}=d_{13}-I_{12}^{\text {filho }}=30-0=30 \\
& a_{13}>0 \Rightarrow\left\{\begin{array}{l}
x_{13}^{\text {filho }}=U[30, \max \{30,30,30\}]=U[30,30]=30 \\
I_{13}^{\text {filho }}=x_{13}^{\text {filho }}-a_{13}=30-30=0
\end{array}\right.
\end{aligned}
$$

Fixando $i=2$ :

$$
\begin{aligned}
& a_{2 t}=d_{2 t}+\sum_{j \in S(2)} r_{2 j} x_{j t}^{\text {filho }}-I_{2, t-1}^{\text {filloo }} \\
& a_{2 t} \leq 0 \Rightarrow\left\{\begin{array}{l}
x_{2 t}^{\text {fillo }}=0 \\
I_{2 t}^{\text {filho }}=-a_{2 t}
\end{array}\right. \\
& a_{2 t}>0 \Rightarrow\left\{\begin{array}{l}
x_{2 t}^{\text {filho }}=U\left[a_{2 t}, \max \left\{a_{2 t}, x_{2 t}^{\text {pai }}, x_{2 t}^{\text {mae }}\right\}\right] \\
I_{2 t}^{\text {filto }}=x_{2 t}^{\text {fillo }}-a_{2 t}
\end{array}\right.
\end{aligned}
$$

Lembrando que, nesse exemplo temos 


$$
\begin{aligned}
S(2) & =\{1\} \\
d_{i t} & =0, \forall i, t(i>1) \\
r_{i j} & =1, \forall i, j
\end{aligned}
$$

$t=1$

$$
\begin{aligned}
& a_{21}=d_{21}+r_{21} x_{11}^{\text {filho }}-I_{20}^{\text {filho }}=0+30-0=30 \\
& a_{21}>0 \Rightarrow\left\{\begin{array}{l}
x_{21}^{\text {filho }}=U\left[a_{21}, \max \left\{a_{21}, x_{21}^{\text {pat }}, x_{21}^{\text {mar }}\right\}\right]=U[30, \max \{30,40,20\}]=35 \\
I_{21}^{\text {filho }}=x_{21}^{\text {fillo }}-a_{21}=35-30=5
\end{array}\right.
\end{aligned}
$$

$t=2$

$$
\begin{aligned}
& a_{22}=r_{21} x_{12}^{\text {filho }}-I_{21}^{\text {fillho }}=0-5=-5 \\
& a_{22} \leq 0 \Rightarrow\left\{\begin{array}{l}
x_{22}^{\text {filho }}=0 \\
I_{22}^{\text {filho }}=-a_{22}=-(-5)=5
\end{array}\right.
\end{aligned}
$$

$t=3$

$$
\begin{aligned}
& a_{23}=r_{21} x_{13}^{\text {filho }}-I_{22}^{\text {fillo }}=30-5=25 \\
& a_{23}>0 \Rightarrow\left\{\begin{array}{l}
x_{23}^{\text {filho }}=U[25, \max \{25,0,0\}]=U[25,25]=25 \\
I_{23}^{\text {filho }}=x_{23}^{\text {fillo }}-a_{23}=25-25=0
\end{array}\right.
\end{aligned}
$$

Fixando $i=3: S(3)=\{1,2\}$

$t=1$

$$
\begin{aligned}
& a_{31}=r_{31} x_{11}^{\text {filho }}+r_{32} x_{21}^{\text {filho }}-I_{30}^{\text {filho }}=30+35=65 \\
& a_{31}>0 \Rightarrow\left\{\begin{array}{l}
x_{31}^{\text {filho }}=U[65, \max \{65,80,90\}]=U[65,90]=70 \\
I_{31}^{\text {filho }}=x_{31}^{\text {filho }}-a_{31}=70-65=5
\end{array}\right.
\end{aligned}
$$

$t=2$

$$
\begin{aligned}
& a_{32}=r_{31} x_{12}^{\text {filho }}+r_{32} x_{22}^{\text {filho }}-I_{31}^{\text {filho }}=0+0-5=-5 \\
& a_{32} \leq 0 \Rightarrow\left\{\begin{array}{l}
x_{32}^{\text {fillho }}=0 \\
I_{32}^{\text {filho }}=-a_{32}=5
\end{array}\right.
\end{aligned}
$$

$t=3$

$$
\begin{aligned}
& a_{33}=r_{31} x_{13}^{\text {filho }}+r_{32} x_{23}^{\text {filho }}-I_{32}^{\text {filho }}=30+25-5=50 \\
& a_{33}>0 \Rightarrow\left\{\begin{array}{l}
x_{33}^{\text {filho }}=U[50, \max \{50,30,30\}]=U[50,50]=50 \\
I_{33}^{\text {filho }}=x_{33}^{\text {filho }}-a_{33}=50-50=0
\end{array}\right.
\end{aligned}
$$


Fixando $i=4: S(4)=\{2,3\}$

$t=1$

$$
\begin{aligned}
& a_{41}=d_{41}+r_{42} x_{21}^{\text {filho }}+r_{43} x_{31}^{\text {filho }}-I_{40}^{\text {filho }}=0+35+70-0=105 \\
& a_{41}>0 \Rightarrow\left\{\begin{array}{l}
x_{4 t}^{\text {filho }}=U[105, \max \{105,120,110\}]=U[105,120]=115 \\
I_{4 t}^{\text {filho }}=x_{4 t}^{\text {filho }}-a_{4 t}=115-105=10
\end{array}\right.
\end{aligned}
$$

$t=2$

$$
\begin{aligned}
& a_{42}=r_{42} x_{22}^{\text {fillo }}+r_{43} x_{32}^{\text {filho }}-I_{41}^{\text {filho }}=0+0-10=-10 \\
& a_{42} \leq 0 \Rightarrow\left\{\begin{array}{l}
x_{42}^{\text {filho }}=0 \\
I_{42}^{\text {filho }}=-a_{42}=-(-10)=10
\end{array}\right.
\end{aligned}
$$

$t=3$

$$
\begin{aligned}
& a_{43}=r_{42} x_{23}^{\text {fillho }}+r_{43} x_{33}^{\text {filho }}-I_{42}^{\text {fillho }}=25+50-10=65 \\
& a_{43}>0 \Rightarrow\left\{\begin{array}{l}
x_{43}^{\text {filho }}=U[65, \max \{65,0,30\}]=U[65,65]=65 \\
I_{43}^{\text {filho }}=x_{43}^{\text {fillho }}-a_{43}=65-65=0
\end{array}\right.
\end{aligned}
$$

Assim, do cruzamento surge a seguinte solução

\begin{tabular}{cccc} 
Filho & $t=1$ & $t=2$ & $t=3$ \\
\hline$x_{1 t}$ & 30 & 0 & 30 \\
$I_{1 t}$ & 20 & 0 & 0 \\
\hline$x_{2 t}$ & 35 & 0 & 25 \\
$I_{2 t}$ & 5 & 5 & 0 \\
\hline$x_{3 t}$ & 70 & 0 & 50 \\
$I_{3 t}$ & 5 & 5 & 0 \\
\hline$x_{4 t}$ & 115 & 0 & 65 \\
$I_{4 t}$ & 10 & 10 & 0
\end{tabular}

A seguir apresentamos o procedimento para eliminação dos excessos de produção.

\section{- Ajuste nos Estoques Finais}

Esse procedimento tem por objetivo eliminar as sobras de produção que podem ocorrer após a aplicação do operador de cruzamento, ou seja, itens para os quais o estoque no último período é 
maior que zero. Nesse procedimento determinamos quais itens possuem sobras de produção, através da análise dos estoques no último período $\left(I_{i T}\right)$. Em seguida, analisamos em quais períodos pode ser eliminado tal excesso, ou seja, quais os períodos que apresentam produção para eliminar esse excesso. Os períodos são analisados de trás para frente, começando pelo período $T$ e regredindo até o período 1 ou até que todo excesso seja eliminado. Após a análise de cada item, atualizamos o estoque desse item e o do próximo item a ser analisado. Isso é feito porque sempre que alteramos a produção de um item, a produção de seus predecessores também deverá ser ajustada a fim de que se possa perceber os novos excessos de produção para esses itens. Dessa forma o processo se repete, a partir dos itens finais para os itens intermediários, ou seja, do item $i=1$ até $i=N$. Essa ordem garante também que a factibilidade inter-escalão seja preservada pelo procedimento.

Apresentamos a seguir o pseudo-código desse procedimento.

\section{- PSEUDO-CÓDIGO DO AJUSTE}

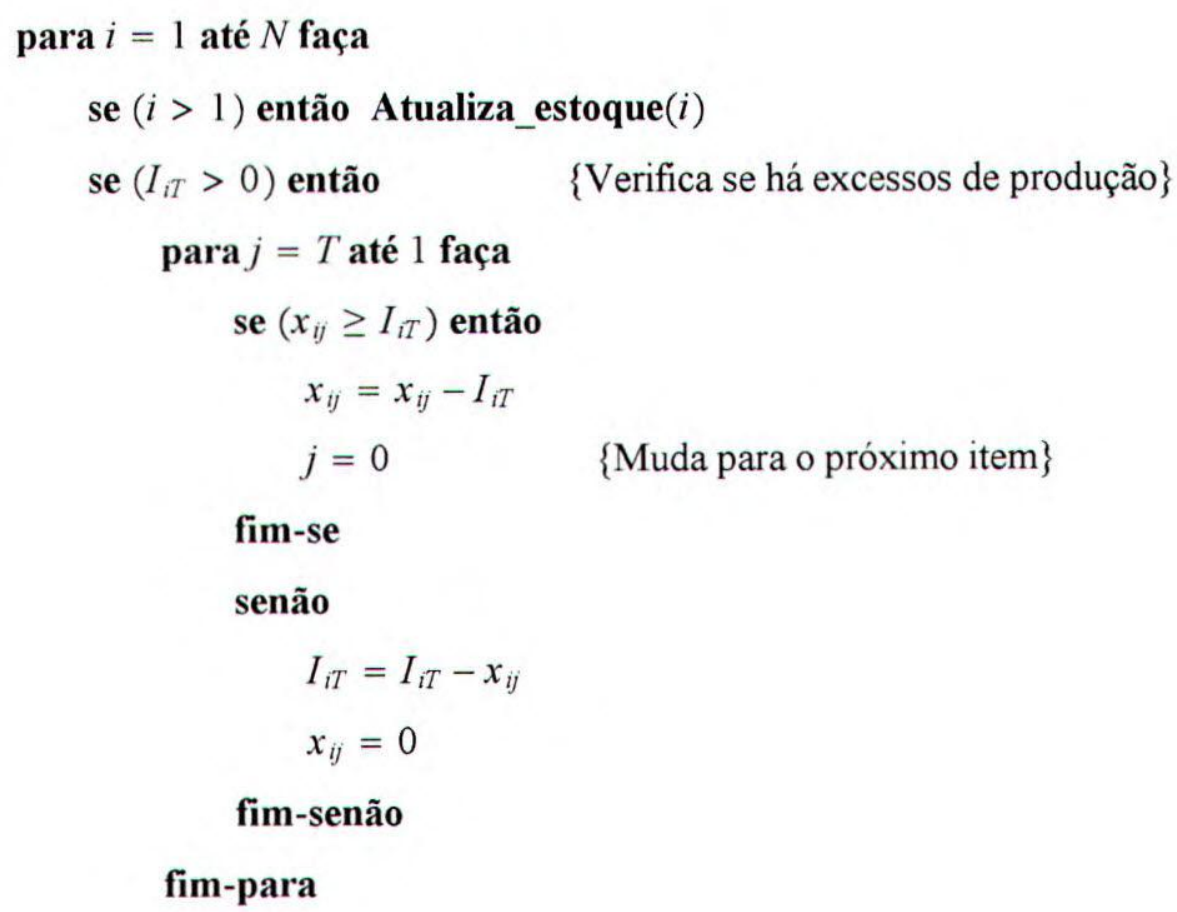

fim-se

Atualiza_estoque $(i)$

fim-para

Para um melhor entendimento desse procedimento apresentamos a seguir um exemplo. 


\section{Exemplo 4.2 Aplicação do Ajuste}

Consideremos um produto com seguinte estrutura

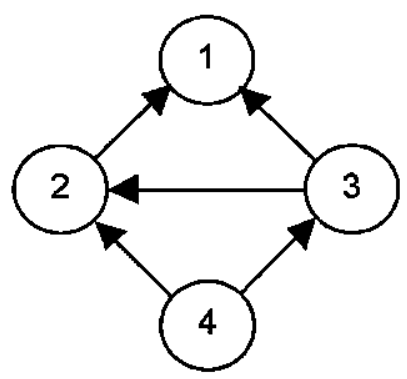

sendo $r_{i j}=1$ para todo $i, j$.

Suponhamos um horizonte de planejamento com 3 períodos e com a seguinte demanda

\begin{tabular}{cccc} 
& $t=1$ & $t=2$ & $t=3$ \\
\hline$d_{1 t}$ & 10 & 20 & 30 \\
\hline$d_{2 t}$ & 0 & 0 & 0 \\
\hline$d_{3 t}$ & 0 & 0 & 0 \\
\hline$d_{4 t}$ & 0 & 0 & 0
\end{tabular}

Cruzando duas soluções quaisquer, obtemos uma solução dada por:

\begin{tabular}{cccc} 
& $t=1$ & $t=2$ & $t=3$ \\
\hline$x_{1 t}$ & 17 & 44 & 0 \\
$I_{1 t}$ & 7 & 31 & 1 \\
\hline$x_{2 t}$ & 25 & 49 & 0 \\
$I_{2 t}$ & 8 & 13 & 13 \\
\hline$x_{3 t}$ & 49 & 86 & 0 \\
$I_{3 t}$ & 7 & 0 & 0 \\
\hline$x_{4 t}$ & 165 & 44 & 0 \\
$I_{4 t}$ & 91 & 0 & 0
\end{tabular}

Como podemos notar a solução anterior apresenta excessos de produção nos itens 1 e 2, ou seja, $I_{13}$ e $I_{23}$ são maiores que zero. Aplicando o Ajuste nessa solução, item a item, começando pelo item final, temos:

Item 1: Como podemos observar esse item possui excessos de produção, sendo o valor dado 
pelo seu estoque no último periodo, ou seja, $I_{13}=1$. Como no período 2 há produção sufuciente desse item para eliminar todo o excesso, então

$$
x_{12}=44-1=43 \text {. }
$$

Atualizando a solução com base nessa alteração, temos

\begin{tabular}{cccc} 
& $t=1$ & $t=2$ & $t=3$ \\
\hline$x_{1 t}$ & 17 & 43 & 0 \\
$I_{1 t}$ & 7 & 30 & 0 \\
\hline$x_{2 t}$ & 25 & 49 & 0 \\
$I_{2 t}$ & 8 & 14 & 14 \\
\hline$x_{3 t}$ & 49 & 86 & 0 \\
$I_{3 t}$ & 7 & 1 & 1 \\
\hline$x_{4 t}$ & 165 & 44 & 0 \\
$I_{4 t}$ & 91 & 0 & 0
\end{tabular}

Como podemos notar, agora surgiu excesso de produção no item 3 e o excesso do item 2 aumentou. Isso ocorre devido a dependência existente entre os itens, ou seja, quando eliminamos produção do item 1, por exemplo, essa mesma quantidade eliminada sobrará nos estoques dos seus predecessores (itens 2 e 3 ).

Item 2: A quantidade que deve ser eliminada da produção do item 2 é dada por

$$
I_{2 T}=14
$$

como no período 2 temos produção suficiente para eliminar o excesso,

$$
x_{22}=x_{22}-14=49-14=35
$$

Em seguida atualizamos novamente a solução. 


\begin{tabular}{|c|c|c|c|}
\hline & $t=1$ & $t=2$ & $t=3$ \\
\hline$x_{1 t}$ & 17 & 43 & 0 \\
\hline$I_{1 t}$ & 7 & 30 & 0 \\
\hline$x_{2 t}$ & 25 & 35 & 0 \\
\hline$I_{2 t}$ & 8 & 0 & 0 \\
\hline$x_{3 t}$ & 49 & 86 & 0 \\
\hline$I_{3 t}$ & 7 & 15 & 15 \\
\hline$x_{4 t}$ & 165 & 44 & 0 \\
\hline$I_{4 t}$ & 91 & 14 & 14 \\
\hline
\end{tabular}

Item 3: Calculando o excesso para esse item, que é dado pelo seu estoque atualizado no último período, e eliminando essa quantidade no período 2 , temos

$$
x_{32}=x_{32}-15=86-15=71
$$

Novamente atualizando a solução

\begin{tabular}{cccc} 
& $t=1$ & $t=2$ & $t=3$ \\
\hline$x_{1 t}$ & 17 & 43 & 0 \\
$I_{1 t}$ & 7 & 30 & 0 \\
\hline$x_{2 t}$ & 25 & 35 & 0 \\
$I_{2 t}$ & 8 & 0 & 0 \\
\hline$x_{3 t}$ & 49 & 71 & 0 \\
$I_{3 t}$ & 7 & 0 & 0 \\
\hline$x_{4 t}$ & 165 & 44 & 0 \\
$I_{4 t}$ & 91 & 29 & 29
\end{tabular}

Item 4: Finalmente, eliminando o excesso para esse item

$$
x_{42}=44-29=15 \text {, }
$$

e, atualizando a solução o procedimento é então finalizado. 


\begin{tabular}{cccc} 
& $t=1$ & $t=2$ & $t=3$ \\
\hline$x_{1 t}$ & 17 & 43 & 0 \\
$I_{1 t}$ & 7 & 30 & 0 \\
\hline$x_{2 t}$ & 25 & 35 & 0 \\
$I_{2 t}$ & 8 & 0 & 0 \\
\hline$x_{3 t}$ & 49 & 71 & 0 \\
$I_{3 t}$ & 7 & 0 & 0 \\
\hline$x_{4 t}$ & 165 & 15 & 0 \\
$I_{4 t}$ & 91 & 0 & 0
\end{tabular}

Como podemos observar o procedimento obteve sucesso, ou seja, a nova solução não apresenta excessos de produção.

Para o operador mutação utilizamos uma variação do procedimento de alteração (P4), que é aplicado ao filho, após o cruzamento. Dentro do procedimento, todos os movimentos possíveis são efetuados a uma probabilidade de $10 \%$, ou seja, selecionada uma possível transferência a mesma é efetuada com uma probabilidade de $10 \%$.

Definidos os elementos principais para implementação dos algoritmos genéticos e meméticos, nas próximas seções apresentamos as estruturas desses algoritmos com suas particularidades e seus respectivos pseudo-códigos.

\subsection{Algoritmo Genético - GA}

A reunião dos componentes descritos anteriormente, constituirão o algoritmo genético para o problema de dimensionamento de lotes multiestágio capacitado, com custos e tempos de preparação. $\mathrm{O}$ algoritmo funciona do modo descrito a seguir.

Inicialmente gera as soluções que irão formar a população inicial, através do procedimento Pl e, caso as soluções geradas por esse procedimento sejam infactíveis, o procedimento P2 é então aplicado nessas soluções. Depois disso, o algoritmo realiza a avaliação de fitness da população inicial, para em seguida ordená-la de acordo com esses valores. Com base nos mecanismos de seleção estabelecidos, o operador de cruzamento é aplicado. A seguir o procedimento P4 é aplicado com uma probabilidade de $10 \%$ de realizar uma transferência (mutação). Mais uma vez, caso a solução seja infactível o procedimento P2 é executado. A cada nova geração a população é 
ordenada, com base nos valores de fitness atualizados. Novas gerações são obtidas até que o limite GerMax seja atingido. Ao final do processo a solução estará armazenada em pocket[1].

O pseudo-código do algoritmo é dado a seguir.

\section{- PSEUDO-CÓDIGO DO ALGORITMO GENÉTICO}

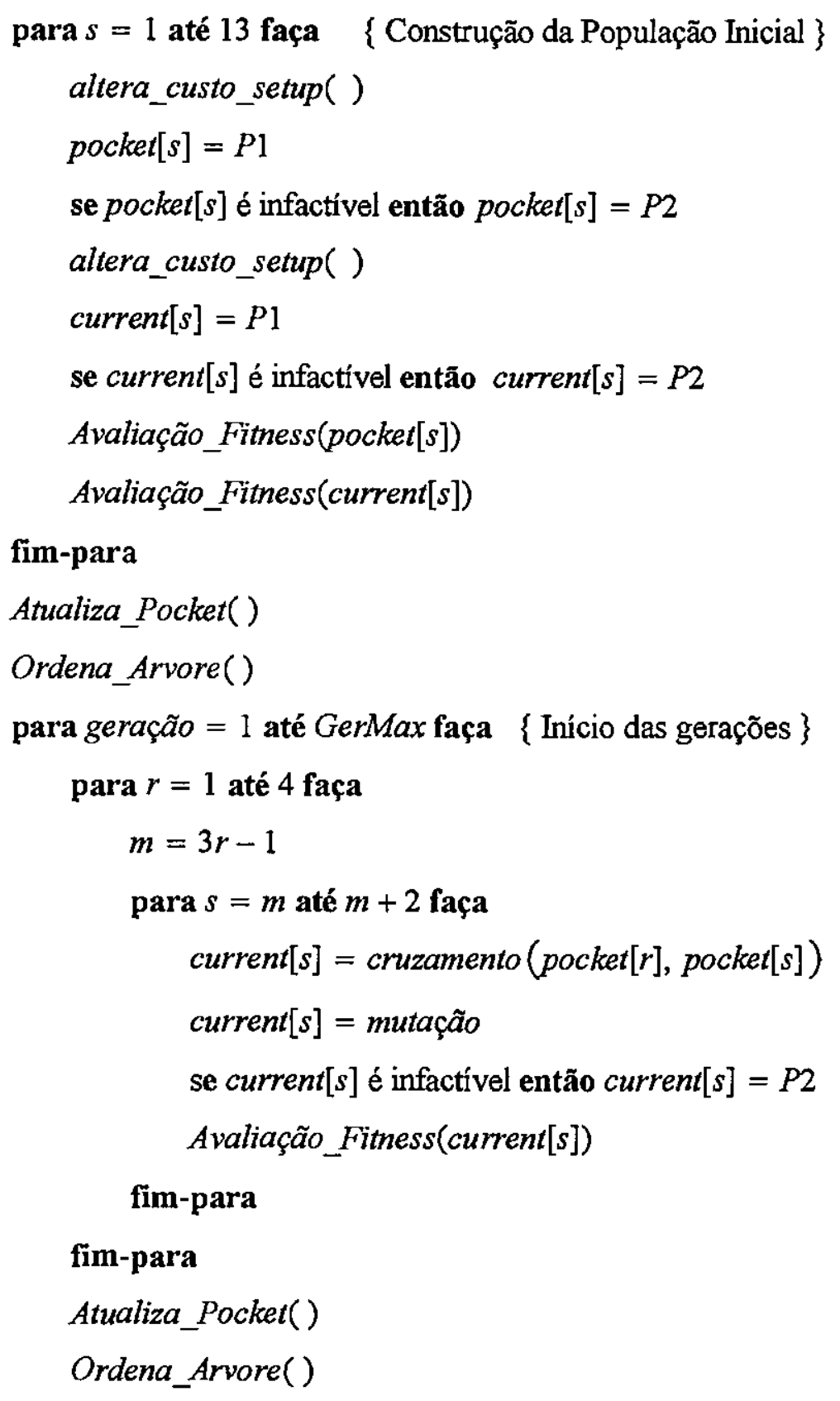

\section{fim-para}

se pocket[1] é infactível então o "algoritmo falhou" senão pocket[1] é a melhor solução encontrada 
sendo

$$
\begin{aligned}
& \text { altera_custo_setup }()=\left\{\begin{array}{l}
\text { procedimento que altera de modo aleatório } \\
\text { os custos de preparação }
\end{array}\right. \\
& \text { Avaliação_Fitness(ind) }=\text { procedimento que avalia o valor de fitness do indivíduo } \\
& \text { Atualiza_Pocket ( ) }=\left\{\begin{array}{l}
\text { procedimento de comparação e troca entre pockets } \mathrm{e} \\
\text { currents }
\end{array}\right. \\
& \text { Ordena_Arvore ( ) }=\left\{\begin{array}{l}
\text { procedimento que ordena os individuos pockets de } \\
\text { acordo com o seu valor de fitness }
\end{array}\right.
\end{aligned}
$$

A variável GerMax é o número máximo de gerações (ou iterações) do algoritmo, ou um tempo limite de execução. Sempre que uma solução factível for armazenada em pocket[1], a geração em que isto ocorre é chamada de geração ótima, que está representada no pseudo-código por "ger_otima".

Se ao final do algoritmo nenhuma solução factível foi encontrada, também não podemos afirmar que o problema é infactível, pois o algoritmo não garante que encontrará uma solução factível, muito menos podemos avaliar quão próxima uma solução está do ótimo.

A seguir apresentamos o algoritmo memético implementado.

\subsection{Algoritmo Memético - MA}

A diferença entre esse algoritmo e o anterior, está na utilização de uma heurística de busca local, que é o procedimento de melhoria (P3), encontrado em França et al.(1997) e que descrevemos em detalhes anteriormente. $O$ intuito dessa busca é explorar mais profundamente regiões do espaço, tentando alcançar soluções com menor custo.

Esse algoritmo funciona do mesmo modo que o genético. A população inicial é obtida pelo uso dos procedimentos $\mathrm{P} 1$ e P2, seguido da avaliação de fitness e aplicação do operador de cruzamento e mutação. Para cada nova solução gerada, o procedimento de melhoria é aplicado. O algoritmo é executado até que o limite de gerações (GerMax) seja atingido.

A seguir o pseudo-código do algoritmo memético é apresentado. 


\section{- PSEUDO-CÓDIGO DO ALGORITMO MEMÉTICO}

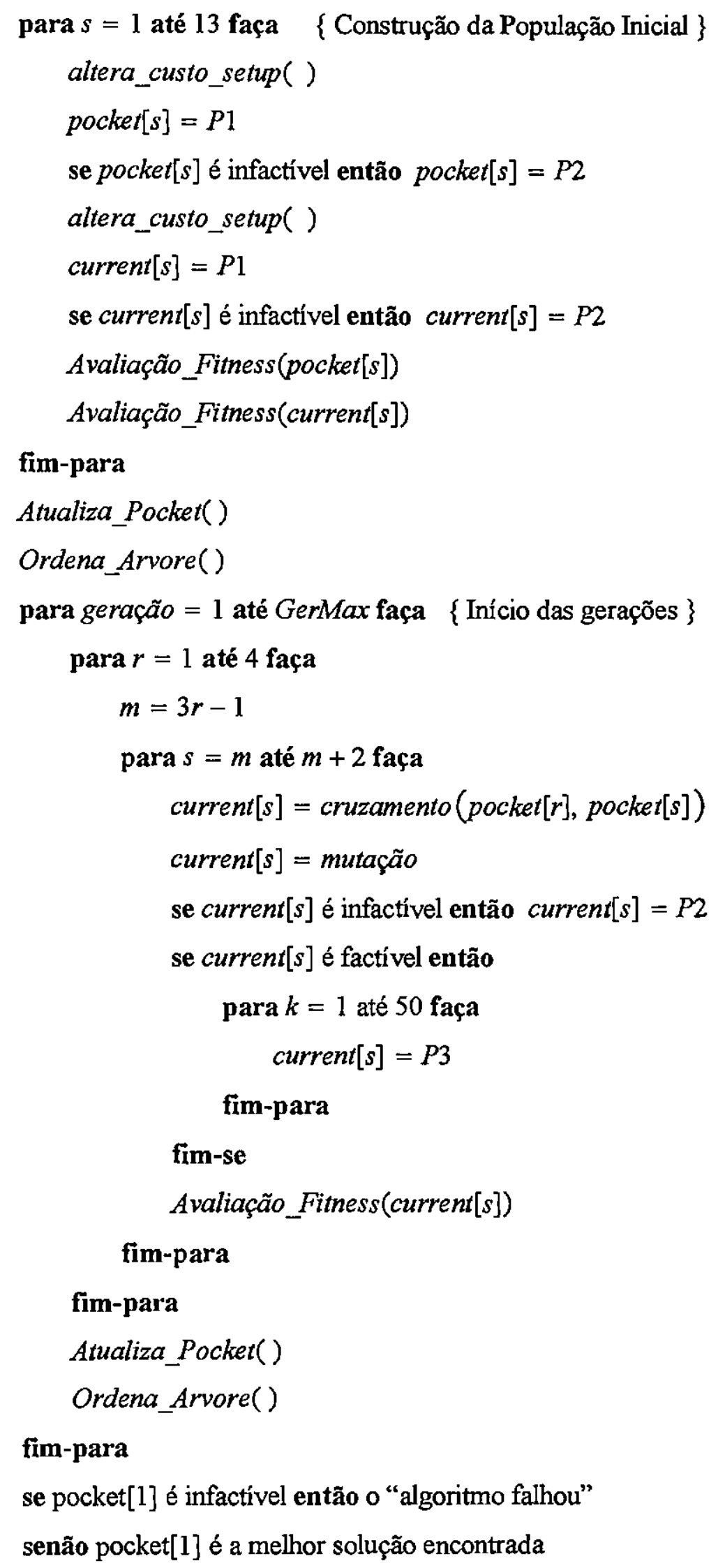


No procedimento $\mathrm{P} 3$, após o cruzamento, os passos regressivo e progressivo são executados no máximo 50 vezes. Ou seja, os passos são executados até que o limite de 50 iterações seja atingido, ou até que os dois passos sejam executados sem conseguir realizar nenhuma transferência.

No próximo capítulo apresentamos os resultados computacionais dos testes realizados com estes algoritmos. 


\section{CAPÍTULO 5}

\section{RESULTADOS COMPUTACIONAIS}

\subsection{Introdução}

Nesse capítulo apresentamos os resultados dos testes computacionais realizados com o objetivo de avaliar as meta-heurísticas evolutivas propostas no capítulo anterior. As implementações foram feitas em linguagem $\mathrm{C}$, utilizando nos testes um computador Pentium II $400 \mathrm{Mhz}$.

Na próxima seção, descrevemos a geração dos exemplos utilizados nos testes. Nas seções seguintes, comparamos os resultados obtidos pelos algoritmos, separados em dois grupos distintos de exemplos numéricos, um para problemas de médio porte e outro para problemas de pequeno porte. Os critérios usados para comparação foram a eficácia em obter soluções factíveis, a qualidade das soluções e uma medida referente à infactibilidade, quando os algoritmos não encontraram soluções factíveis. Analisamos ainda os tempos computacionais envolvidos na execução dos algoritmos.

A análise da qualidade das soluções é feita através da comparação dos custos obtidos pelas heurísticas implementadas com outro método conhecido. Além disso, para os problemas de pequeno porte comparamos os resultados com a solução ótima do problema, obtidas pelo pacote CPLEX. Esse pacote contém rotinas para resolução de problemas de Otimização Combinatória, utilizando o método Branch and Bound. Nos problemas de médio porte, os custos das soluções são 
comparados com um limitante inferior, obtido através da Relaxação Lagrangiana aplicada ao modelo (22)-(28).

\subsection{Geração dos Exemplos Numéricos}

Os testes computacionais foram realizados num conjunto de exemplos numéricos gerados aleatoriamente através de uma distribuição uniforme. Os intervalos de valores utilizados para essa geração foram baseados no trabalho de Clark e Armentano (1995) e estão descritos a seguir.

\begin{tabular}{|c|c|c|c|}
\hline Parâmetro & & Intervalo & Observação \\
\hline custo unitário de produção & $\mathbf{c}_{i t}$ & $U[1,5 ; 2]$ & \\
\hline custo de preparação & $\mathrm{s}_{i t}$ & $\begin{array}{l}U[5 ; 95] \\
U[50 ; 950]\end{array}$ & $\begin{array}{l}\text { custo baixo de preparação } \\
\text { custo alto de preparação }\end{array}$ \\
\hline custo de estoque de escalão & $\mathrm{e}_{i t}$ & $U[0,2 ; 0,4]$ & \\
\hline recurso unitário para produção & $\mathrm{v}_{i t}$ & $U[1,5 ; 2]$ & \\
\hline recurso para preparação & $\mathrm{f}_{i t}$ & $U[150 ; 200]$ & \\
\hline demanda & $\mathrm{d}_{i t}$ & $\begin{array}{l}U[0 ; 180] \\
U[0 ; 18]\end{array}$ & $\begin{array}{l}\text { para itens finais } \\
\text { para demais itens }\end{array}$ \\
\hline
\end{tabular}

O parâmetro $r_{i j}$ é constante e igual a 1 para todos os exemplos. Para a capacidade $\left(b_{t}\right)$, foram feitos cálculos para que seus valores estejam relacionados com a quantidade de recursos necessários e os valores gerados da demanda.

Inicialmente utilizamos a solução obtida com a aplicação de uma política lote-por-lote. Nessa política, para cada período $t$, calculamos a quantidade de recursos utilizados, caso a produção nesse período seja exatamente a demanda do período, isto é,

$$
C_{t}=\left\{\begin{array}{ll}
\sum_{t=1}^{N}\left(\mathrm{f}_{i t}+\mathrm{v}_{t} D_{i t}\right), & \text { se } D_{i t} \neq 0 \\
0, & \text { caso contrário }
\end{array},\right.
$$

para $t=1, \ldots, T$.

A partir disso calculamos uma média para garantir que a quantidade de recurso em cada período $t$ seja a mesma, ou seja, 


$$
C_{t} \leftarrow \frac{\sum_{\delta=1}^{T}\left(C_{\delta}\right)}{T}, \quad t=1, \ldots, T .
$$

Depois de determinada a capacidade disponível de recurso em cada periodo, os problemas foram divididos em duas categorias, segundo a disponibilidade desses recursos:

$$
\begin{aligned}
& \mathrm{c}_{1} \leftarrow \mathrm{b}_{t}=C_{t} \quad \text { com } t=1, \ldots, T . \\
& \mathrm{c}_{2} \leftarrow \mathrm{b}_{t}=1,1 C_{t} \quad \text { com } t=1, \ldots, T
\end{aligned}
$$

Desse modo, cada grupo de exemplos é caracterizado por:

- Estrutura do produto

- Quantidade de itens

- Quantidade de períodos

- Custos de preparação (alto e baixo)

- Capacidade disponível ( $c_{1}$ : capacidade normal e $c_{2}$ : capacidade folgada)

- Quantidade de sementes usadas para gerar os dados

A seguir os dois grupos de exemplos que serão utililizados.

\begin{tabular}{|l|c|c||}
\hline & Grupo 1 & Grupo 2 \\
\hline Estrutura & geral e serial & geral e serial \\
\hline $\mathrm{N}$ & 3,6 e 10 & 10,17 e 40 \\
\hline $\mathrm{T}$ & 6 e 12 & 12 e 18 \\
\hline custo de preparação & baixo e alto & baixo e alto \\
\hline capacidade & $\mathrm{c}_{1}$ e $\mathrm{c}_{2}$ & $\mathrm{c}_{1}$ e $\mathrm{c}_{2}$ \\
\hline sementes & 5 & 5 \\
\hline Total & 240 & 240 \\
\hline
\end{tabular}

As principais estruturas consideradas nos testes estão nas Figuras 5.1, 5.2 e 5.3 a seguir. 


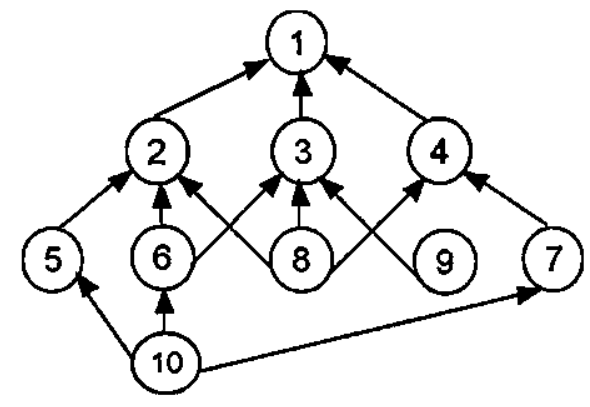

Figura 5.1 Estrutura com 10 itens encontrada em Clark (1990).

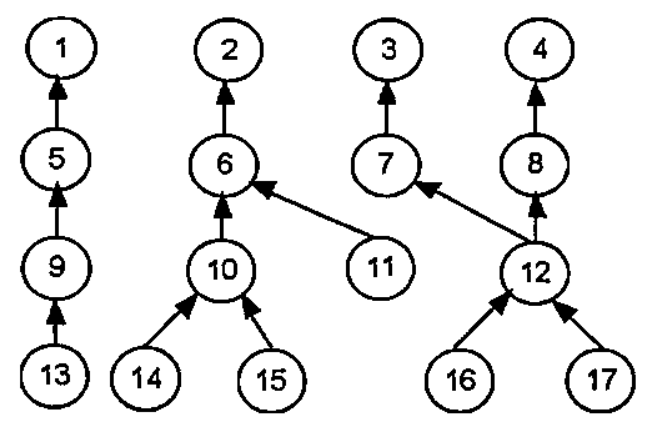

Figura 5.2 Estrutura com 17 itens encontrada em Maes e McClain (1991).

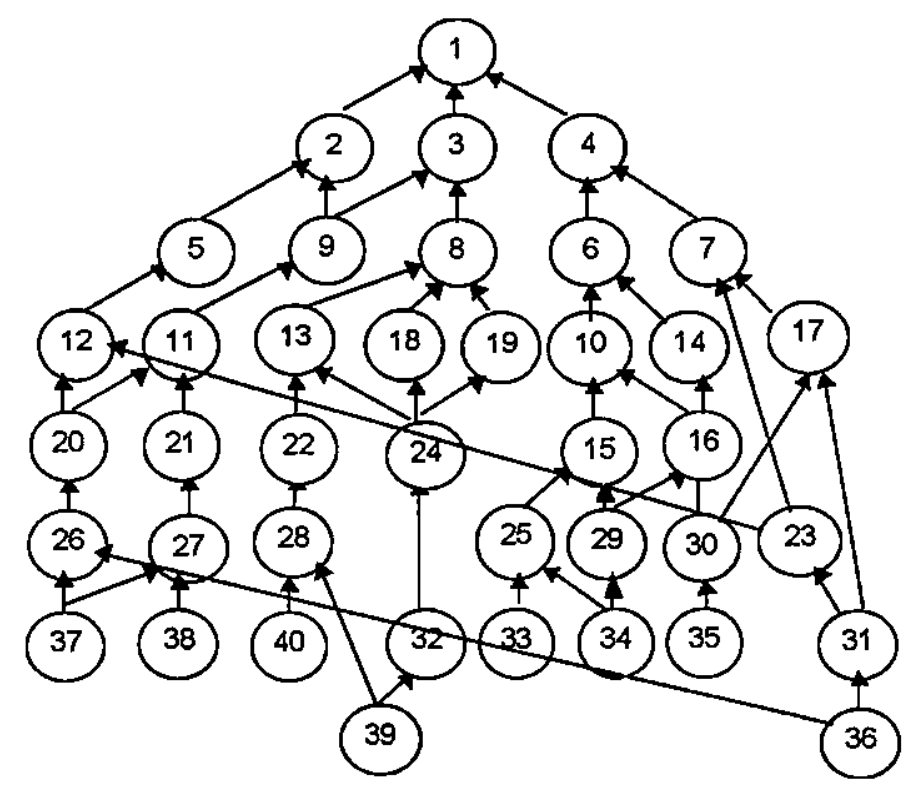

Figura 5.3 Estrutura com 17 itens encontrada em Maes e McClain (1991).

A seguir apresentamos inicialmente os resultados para o Grupo 2. 


\subsection{Análise dos Resultados para o Grupo 2}

Nesta seção analisamos os resultados para o Grupo 2 de exemplos. Os exemplos foram resolvidos utilizando as técnicas descritas no capítulo anterior, sendo que as nomenclaturas adotadas para representar as características específicas de cada um dos algoritmos são descritas a seguir.

\begin{tabular}{|ll|}
\hline H0 & $:$ Heurística encontrada em França et al., 1997 \\
\hline GA01 & $:$ Algoritmo Genético \\
\hline GA02 & $:$ Algoritmo Genético com critério de diversificação \\
\hline MA01 & $:$ Algoritmo Memético com critério de diversificação \\
\hline MA02_R1 $:$ & $\begin{array}{l}\text { Algoritmo Memético com critério de diversificação e } \\
\text { reinicialização das pockets a cada } 50 \text { gerações }\end{array}$ \\
\hline MA02_R2 $:$ & $\begin{array}{l}\text { Algoritmo Memético com critério de diversificação e reinicialização } \\
\text { das pockets com } 10 \text { iterações de H0 a cada } 50 \text { gerações }\end{array}$ \\
\hline
\end{tabular}

O "critério de diversificação" e a reinicialização mencionados anteriormente, são estratégias comumente utilizadas nas meta-heurísticas, e ambas tem por objetivo dificultar a estagnação do processo de busca.

O critério de diversificação é utilizado normalmente quando a mutação não consegue garantir uma certa diversidade de soluções na população, o que ocorre freqüentemente em problemas muito restritos. Nesse caso, na tentativa de aumentar a variedade de soluções na população, utilizamos o procedimento de alteração (P4), descrito no Capítulo 3. A estratégia é utilizada sempre que um certo número de gerações tenha sido executada sem que a solução ótima tenha sido atualizada. A partir da centésima geração sempre que o número de gerações for três vezes maior do que a geração ótima (geração em que ocorreu a última atualização da pocket[1]), aplicamos o procedimento P4 com uma probabilidade de $50 \%$ nas soluções pockets (exceto pocket[1]) da população atual. Efetuamos diversas variações dos parâmetros utilizados nesse critério, sendo 
esses os que apresentaram melhores resultados.

A reinicialização do algoritmo é uma estratégia utilizada quando a população apresentar índices muito baixos de diversidade, indicando nesse caso, que o critério de diversificação não conseguiu manter a diversidade da população ao longo do processo evolutivo. Quando isso acontece é necessário reinicializar toda a população, armazendo na memória a melhor solução da população atual. No algoritmo MA02_R1 a reinicialização é feita com base nos mesmos critérios utilizados para geração da população inicial. Para o algoritmo MA02_R2 a diferença está na substituição do procedimento P2 utilizado na geração população inicial pela heurística H0. Desse modo, para cada nova solução gerada pelo algoritmo de Wagner-Within com custo de preparação modificado, aplicamos a heurística HO por 10 iterações.

Os resultados obtidos com o algoritmo que não utiliza o critério de diversificação (GA01) não foram reportados aqui devido a baixa qualidade desses resultados quando comparados aos demais algoritmos.

Avaliamos os algoritmos inicialmente com relação ao número de exemplos em que o algoritmo encontrou soluções factíveis. Para avaliar a qualidade das soluções, calculamos o gap entre o valor obtido pelo algoritmo e o limitante inferior obtido pela Relaxação Lagrangiana aplicada ao problema. Finalmente para problemas em que o algoritmo não encontrou soluções factíveis, analisamos uma medida referente a infactibilidade dessas soluções.

O critério de parada utilizado nos testes foi o número de gerações, mais especificamente 500 gerações, ou iterações no caso da heuristica inicial. Uma análise da evolução do custo da melhor solução e dos tempos computacionais requeridos pelos algoritmos é feita mais a frente.

Na próxima seção analisamos o desempenho dos algoritmos no que se refere a capacidade de encontrar soluções factíveis.

\subsubsection{Eficácia na Obtenção de Soluções Factíveis}

Os percentuais médios de exemplos em que foram encontradas soluções factíveis (FAC), estão nos gráficos a seguir, divididos de acordo com os custos de preparação (baixo e alto). Para cada tamanho utilizamos dois horizontes de planejamento (isto é, $T=12$ e $T=18$ ), num total de 240 exemplos para esse grupo. 


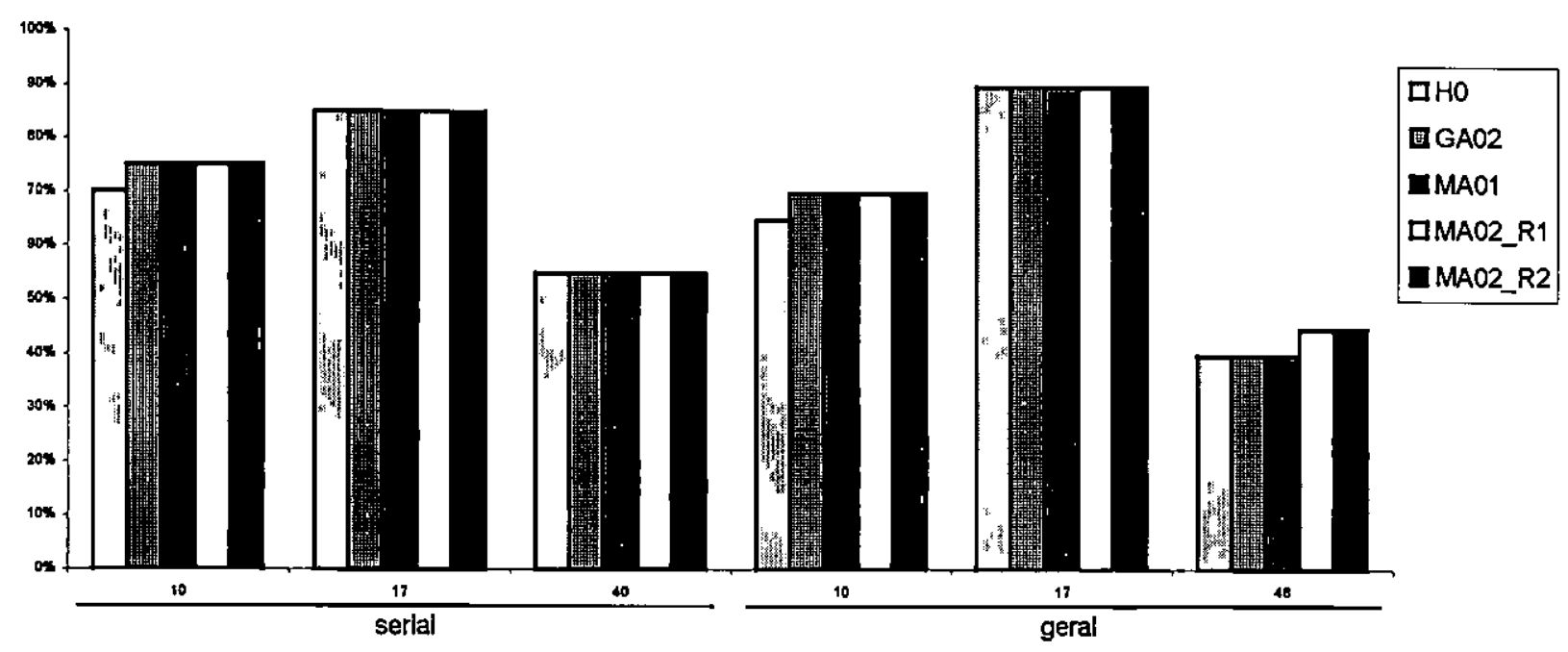

Gráfico 5.4 FAC em exemplos com custos de preparação baixos.

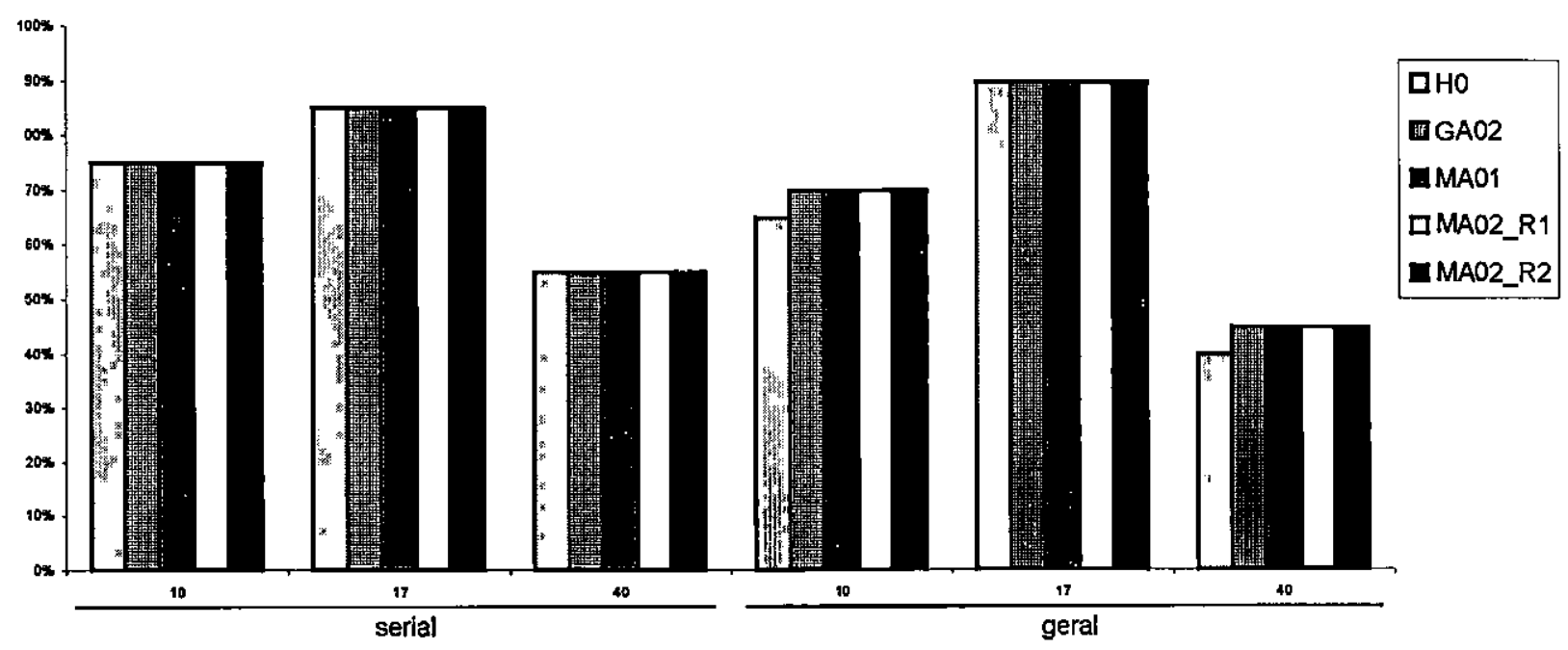

Gráfico 5.5 FAC em exemplos com custos de preparação altos.

Analisando o Gráfico 5.4 referente aos exemplos com custo de preparação baixo, notamos um aumento no número de soluções factíveis encontradas pelos algoritmos evolutivos em relação a H0. $\mathrm{Na}$ estrutura serial com 17 e 40 itens todos os algoritmos obtiveram os mesmos resultados, para os exemplos com 10 itens os algoritmos evolutivos mostraram-se mais eficientes. $\mathrm{Na}$ estrutura geral para os exemplos com 17 itens todos os algoritmos apresentaram a mesma performance. No entanto, nos problemas com 10 itens os algoritmos evolutivos novamente superam $\mathrm{H} 0$, e naqueles com 40 itens os algoritmos MA02_R1 e MA02_R2 apresentaram melhor desempenho do que os demais. 
Considerando o Gráfico 5.5 para os exemplos com custo de preparação alto, temos um desempenho semelhante dos algoritmos na estrutura serial. Para a estrutura geral, o algoritmo H0 apresentou desempenho inferior aos demais, especificamente para os casos com 10 e 40 itens. Comparando os resultados quando variamos os custos de preparação, conforme os Gráficos 5.4 e 5.5, podemos notar que os algoritmos MA02_Rl e MA02_R2 apresentam os mesmo desempenho, enquanto que os demais algoritmos apresentam uma ligeira melhora nos exemplos com custo alto de preparação.

Na tabela 5.1 a seguir, apresentamos uma síntese dos resultados obtidos com relação ao número médio de soluções factíveis, para esse grupo de exemplos.

Tabela 5.1 FAC para as estruturas serial e geral.

\begin{tabular}{||l|c|c|c||}
\hline & Serial & Geral & Média \\
\hline H0 & $70.83 \%$ & $65.00 \%$ & $67.92 \%$ \\
\hline GA02 & $71.67 \%$ & $67.50 \%$ & $69.58 \%$ \\
\hline MA01 & $71.67 \%$ & $67.50 \%$ & $69.58 \%$ \\
\hline MA02_R1 & $71.67 \%$ & $68.33 \%$ & $70.00 \%$ \\
\hline MA02_R2 & $71.67 \%$ & $68.33 \%$ & $70.00 \%$ \\
\hline
\end{tabular}

Logo, podemos concluir através desses resultados que os algoritmos MA02_R1 e MA02_R2 se mostraram mais eficientes, no que se refere a capacidade de encontrar soluções factíveis.

A seguir apresentamos uma análise referente a qualidade dessas soluções.

\subsubsection{Qualidade das Soluções Obtidas}

Nessa seção, avaliamos a qualidade das soluções através dos gaps entre as soluções obtidas pelos algoritmos e os limitantes inferiores. Como alguns algoritmos se mostraram mais eficientes do que outros na obtenção de soluções factíveis, existirão problemas em que alguns encontraram soluções factíveis e outros não. Nesse caso, para efeito de cálculo dos valores médios de gap, serão considerados apenas os problemas em que todos os algoritmos encontraram soluções factíveis.

Nas Tabelas 5.2 e 5.3 apresentamos em detalhes os valores de gaps obtidos para as estruturas serial e geral. 
Tabela 5.2 Gaps para a estrutura serial.

\begin{tabular}{|c|c|c|c|c|c|c|c|}
\hline \multirow{2}{*}{ Preparação } & \multirow{2}{*}{ Capacidade } & & \multicolumn{5}{|c|}{ GAP } \\
\hline & & NxT & HO & GA02 & MA01 & MA02_R1 & MA02_R2 \\
\hline \multirow{15}{*}{ baixo } & \multirow{7}{*}{$\mathbf{C 1}$} & $10 \times 12$ & $5,23 \%$ & $6,72 \%$ & $4,67 \%$ & $4,49 \%$ & $4,49 \%$ \\
\hline & & $10 \times 18$ & $6,36 \%$ & $8,60 \%$ & $5,98 \%$ & $5,84 \%$ & $5,79 \%$ \\
\hline & & $17 \times 12$ & $6,09 \%$ & $7,78 \%$ & $5,55 \%$ & $5,65 \%$ & $4,95 \%$ \\
\hline & & $17 \times 18$ & $6,53 \%$ & $8,36 \%$ & $5,34 \%$ & $5,41 \%$ & $5,14 \%$ \\
\hline & & $40 \times 12$ & $2,82 \%$ & $2,78 \%$ & $2,73 \%$ & $2,76 \%$ & $2,77 \%$ \\
\hline & & $40 \times 18$ & & & & & \\
\hline & & Media & $5,81 \%$ & $7,44 \%$ & $5,18 \%$ & $5,17 \%$ & $4,86 \%$ \\
\hline & \multirow{7}{*}{$\mathbf{C}_{2}$} & $10 \times 12$ & $3,69 \%$ & $5,09 \%$ & $3,27 \%$ & $3,21 \%$ & $3,20 \%$ \\
\hline & & $10 \times 18$ & $4,75 \%$ & $6,11 \%$ & $4,03 \%$ & $4,00 \%$ & $3,92 \%$ \\
\hline & & $17 \times 12$ & $6,15 \%$ & $6,87 \%$ & $5,22 \%$ & $4,71 \%$ & $4,24 \%$ \\
\hline & & $17 \times 18$ & $5,37 \%$ & $6,50 \%$ & $4,68 \%$ & $4,53 \%$ & $4,45 \%$ \\
\hline & & $40 \times 12$ & $0,91 \%$ & $0,92 \%$ & $0,91 \%$ & $0,91 \%$ & $0,90 \%$ \\
\hline & & $40 \times 18$ & $1,17 \%$ & $1,17 \%$ & $1,16 \%$ & $1,16 \%$ & $1,15 \%$ \\
\hline & & Media & $3,57 \%$ & $4,31 \%$ & $3,13 \%$ & $3,00 \%$ & $2,89 \%$ \\
\hline & Média & & $4,32 \%$ & 5,35\% & $3,81 \%$ & $3,72 \%$ & $\overline{3,55 \%}$ \\
\hline \multirow{15}{*}{ alto } & \multirow{7}{*}{$\mathbf{C 1}$} & $10 \times 12$ & $23,55 \%$ & $25,44 \%$ & $24,04 \%$ & $22,93 \%$ & $19,67 \%$ \\
\hline & & $10 \times 18$ & $29,45 \%$ & $30,94 \%$ & $30,19 \%$ & $27,79 \%$ & $26,09 \%$ \\
\hline & & $17 \times 12$ & $32,85 \%$ & $34,75 \%$ & $32,63 \%$ & $29,07 \%$ & $25,62 \%$ \\
\hline & & $17 \times 18$ & $25,85 \%$ & $33,28 \%$ & $26,64 \%$ & $24,94 \%$ & $21,70 \%$ \\
\hline & & $40 \times 12$ & $42,34 \%$ & $42,57 \%$ & $42,35 \%$ & $42,57 \%$ & $42,04 \%$ \\
\hline & & $40 \times 18$ & & & & & \\
\hline & & Media & $29,54 \%$ & $32,35 \%$ & $29,87 \%$ & $27,66 \%$ & $24,84 \%$ \\
\hline & \multirow{7}{*}{$\mathrm{C}_{2}$} & $10 \times 12$ & $17,47 \%$ & $18,96 \%$ & $17,16 \%$ & $16,96 \%$ & $14,78 \%$ \\
\hline & & $10 \times 18$ & $23,23 \%$ & $25,13 \%$ & $22,79 \%$ & $22,76 \%$ & $18,75 \%$ \\
\hline & & $17 \times 12$ & $21,34 \%$ & $24,52 \%$ & $16,93 \%$ & $16,76 \%$ & $14,81 \%$ \\
\hline & & $17 \times 18$ & $20,60 \%$ & $28,17 \%$ & $19,83 \%$ & $19,83 \%$ & $16,82 \%$ \\
\hline & & $40 \times 12$ & $24,70 \%$ & $26,70 \%$ & $23,04 \%$ & $22,36 \%$ & $21,36 \%$ \\
\hline & & $40 \times 18$ & $26,02 \%$ & $28,93 \%$ & $22,64 \%$ & $22,43 \%$ & $22,60 \%$ \\
\hline & & Media & $22,25 \%$ & $25,31 \%$ & $20,33 \%$ & $20,11 \%$ & $18,22 \%$ \\
\hline & Média & & $24,79 \%$ & $27,77 \%$ & $23,66 \%$ & $22,74 \%$ & $20,52 \%$ \\
\hline \multicolumn{2}{|c|}{ MÉDIA (SERIAL) } & & $14,68 \%$ & $16,69 \%$ & $13,85 \%$ & $13,34 \%$ & $12,14 \%$ \\
\hline
\end{tabular}


Tabela 5.3 Gaps para a estrutura geral.

\begin{tabular}{|c|c|c|c|c|c|c|c|}
\hline \multirow{2}{*}{ Preparação } & \multirow{2}{*}{ Capacidade } & & \multicolumn{5}{|c|}{ GAP } \\
\hline & & $\mathrm{NxT}$ & $\mathrm{HO}$ & GA02 & MA01 & MA02_R1 & MA02_R2 \\
\hline \multirow{15}{*}{ baixo } & \multirow{7}{*}{ C1 } & $10 \times 12$ & $4,06 \%$ & $6,43 \%$ & $4,07 \%$ & $4,12 \%$ & $3,71 \%$ \\
\hline & & $10 \times 18$ & $5,57 \%$ & $8,69 \%$ & $5,72 \%$ & $5,65 \%$ & $5,04 \%$ \\
\hline & & $17 \times 12$ & $1,44 \%$ & $2,96 \%$ & $1,13 \%$ & $1,09 \%$ & $1,05 \%$ \\
\hline & & $17 \times 18$ & $1,60 \%$ & $3,04 \%$ & $1,51 \%$ & $1,39 \%$ & $1,32 \%$ \\
\hline & & $40 \times 12$ & & & & & \\
\hline & & $40 \times 18$ & $5,21 \%$ & $6,90 \%$ & $5,88 \%$ & $5,15 \%$ & $3,85 \%$ \\
\hline & & Media & $2,91 \%$ & $4,83 \%$ & $2,86 \%$ & $2,77 \%$ & $2,47 \%$ \\
\hline & \multirow{7}{*}{ C2 } & $10 \times 12$ & $2,73 \%$ & $3,66 \%$ & $2,36 \%$ & $2,28 \%$ & $2,23 \%$ \\
\hline & & $10 \times 18$ & $3,11 \%$ & $4,30 \%$ & $2,79 \%$ & $2,67 \%$ & $2,55 \%$ \\
\hline & & $17 \times 12$ & $1,79 \%$ & $2,49 \%$ & $1,27 \%$ & $1,13 \%$ & $1,07 \%$ \\
\hline & & $17 \times 18$ & $1,62 \%$ & $2,53 \%$ & $1,34 \%$ & $1,28 \%$ & $1,26 \%$ \\
\hline & & $40 \times 12$ & $2,25 \%$ & $2,92 \%$ & $2,24 \%$ & $2,29 \%$ & $2,20 \%$ \\
\hline & & $40 \times 18$ & $2,75 \%$ & $3,99 \%$ & $2,88 \%$ & $2,89 \%$ & $2,82 \%$ \\
\hline & & Media & $2,29 \%$ & $3,20 \%$ & $2,03 \%$ & $1,97 \%$ & $1,91 \%$ \\
\hline & Média & & $2,51 \%$ & $3,78 \%$ & $2,33 \%$ & $2,26 \%$ & $2,11 \%$ \\
\hline \multirow{15}{*}{ alto } & \multirow{7}{*}{ C1 } & $10 \times 12$ & $21,40 \%$ & $24,01 \%$ & $21,75 \%$ & $21,14 \%$ & $18,62 \%$ \\
\hline & & $10 \times 18$ & $17,62 \%$ & $21,02 \%$ & $20,48 \%$ & $20,14 \%$ & $18,04 \%$ \\
\hline & & $17 \times 12$ & $7,14 \%$ & $12,46 \%$ & $6,89 \%$ & $6,47 \%$ & $6,02 \%$ \\
\hline & & $17 \times 18$ & $9,63 \%$ & $13,51 \%$ & $9,72 \%$ & $9,01 \%$ & $8,76 \%$ \\
\hline & & $40 \times 12$ & $27,26 \%$ & $35,92 \%$ & $35,92 \%$ & $35,92 \%$ & $20,98 \%$ \\
\hline & & $40 \times 18$ & & & & & \\
\hline & & Media & $13,84 \%$ & $18,13 \%$ & $\overline{14,90 \%}$ & $14,39 \%$ & $12,29 \%$ \\
\hline & \multirow{7}{*}{ C2 } & $10 \times 12$ & $13,36 \%$ & $15,47 \%$ & $14,27 \%$ & $14,21 \%$ & $12,50 \%$ \\
\hline & & $10 \times 18$ & $14,83 \%$ & $16,55 \%$ & $16,31 \%$ & $15,28 \%$ & $14,00 \%$ \\
\hline & & $17 \times 12$ & $7,57 \%$ & $10,85 \%$ & $5,87 \%$ & $5,50 \%$ & $5,34 \%$ \\
\hline & & $17 \times 18$ & $6,35 \%$ & $9,91 \%$ & $5,94 \%$ & $5,87 \%$ & $5,53 \%$ \\
\hline & & $40 \times 12$ & $13,49 \%$ & $18,15 \%$ & $12,73 \%$ & $12,34 \%$ & $11,91 \%$ \\
\hline & & $40 \times 18$ & $15,26 \%$ & $19,28 \%$ & $13,48 \%$ & $14,03 \%$ & $14,08 \%$ \\
\hline & & Media & $11,23 \%$ & $14,45 \%$ & $10,83 \%$ & $\overline{10,61 \%}$ & $9,9,95 \%$ \\
\hline & Média & & $12,16 \%$ & $15,77 \%$ & $12,29 \%$ & $11,97 \%$ & $10,79 \%$ \\
\hline \multicolumn{2}{|c|}{ MÉDIA (GERAL) } & & $7,34 \%$ & $9,78 \%$ & $7,31 \%$ & $7,11 \%$ & $6,45 \%$ \\
\hline
\end{tabular}

Apresentamos a seguir esses resultados graficamente, novamente divididos de acordo com os custos de preparação. 


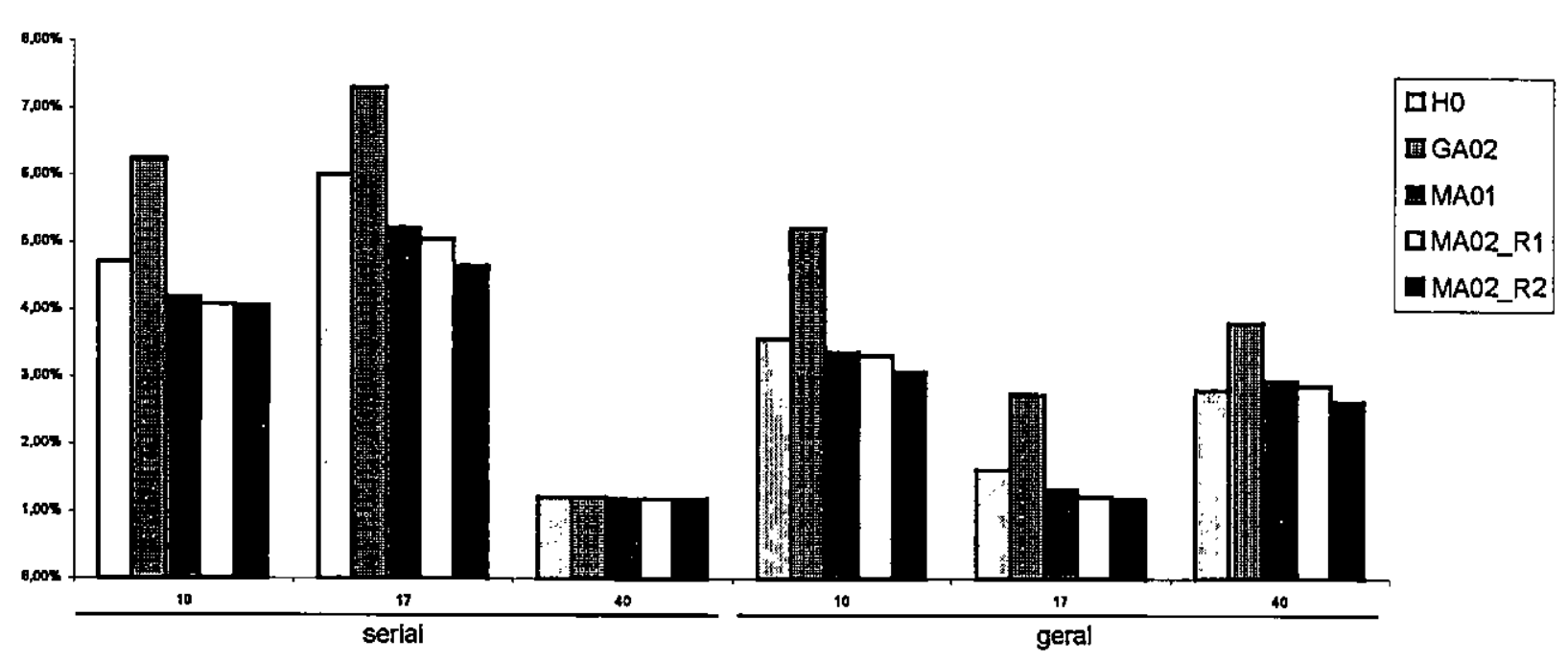

Gráfico 5.6 Gaps para os exemplos com custos de preparação baixos.

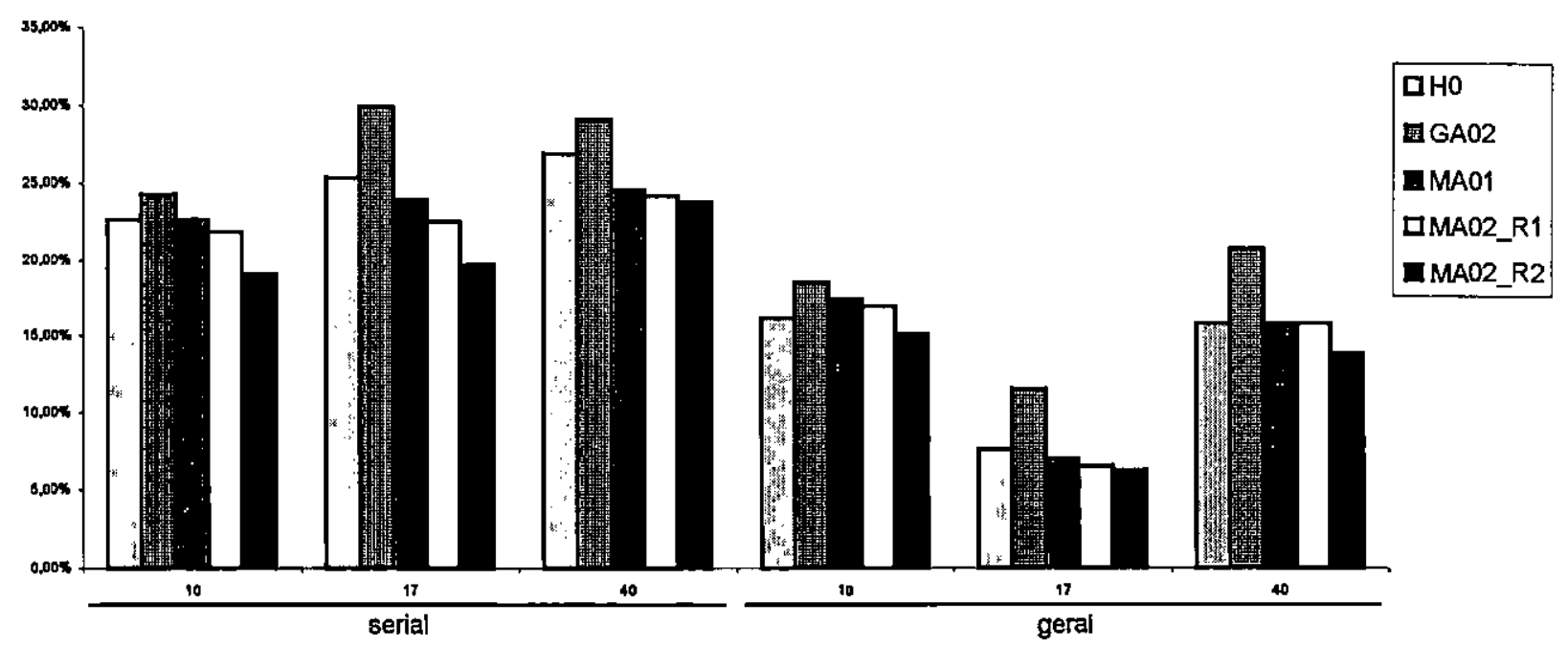

Gráfico 5.7 Gaps para os exemplos com custos de preparação altos.

Analisando o Gráfico 5.6 podemos observar que os algoritmos meméticos apresentaram soluções com custos menores em todos os tamanhos, tanto para a estrutura serial quanto para a geral. Dentre os algoritmos meméticos, o MA02_R2 apresentou melhor desempenho também em todos os exemplos. A melhora do algoritmo memético é significativa se levarmos em conta os pequenos valores de gap (4\% em média) envolvidos. $O$ algoritmo genético (GA02) foi o que apresentou pior desempenho para esse conjunto de exemplos considerando custos baixos de preparação.

Para os exemplos com custos altos de preparação (Gráfico 5.7), novamente o algoritmo GA02 
apresentou os piores resultados, para todos os tamanhos em ambas estruturas. Analogamente aos exemplos anteriores, os algoritmos meméticos obtiveram os melhores resultados em média. Os algoritmos MA01 e MA02_Rl perdem para H0 apenas na estrutura geral com 10 itens, embora essa diferença seja muito pequena, e empatam nos exemplos com 40 itens. O algoritmo MA02_R2 apresentou novamente a melhor performance, obtendo resultados melhores em todos os exemplos. Essa diferença tomou-se mais acentuada nos exemplos com 17 itens e 40 itens da estrutura serial, alcançando mais de cinco pontos percentuais de diferença em relação a HO.

$\mathrm{Na}$ tabela a seguir, um resumo dos gaps médios obtidos para esses exemplos, divididos de acordo com os custos de preparação.

Tabela 5.4 Gaps para as estruturas serial e geral.

\begin{tabular}{|l|c|c|c|c|c|c||}
\hline & \multicolumn{2}{|c|}{ Custo preparação baixo } & \multicolumn{3}{c|}{ Custo preparação alto } \\
\hline & 10 & 17 & 40 & 10 & 17 & 40 \\
\hline H0 & $4.16 \%$ & $3.76 \%$ & $1.88 \%$ & $19.65 \%$ & $16.22 \%$ & $22.26 \%$ \\
\hline GA02 & $5.74 \%$ & $4.96 \%$ & $2.31 \%$ & $21.62 \%$ & $20.47 \%$ & $25.64 \%$ \\
\hline MA01 & $3.79 \%$ & $3.21 \%$ & $1.92 \%$ & $20.22 \%$ & $15.22 \%$ & $20.95 \%$ \\
\hline MA02_R1 & $3.71 \%$ & $3.09 \%$ & $1.90 \%$ & $19.59 \%$ & $14.35 \%$ & $20.73 \%$ \\
\hline MA02_R2 & $3.58 \%$ & $2.86 \%$ & $1.80 \%$ & $17.24 \%$ & $12.80 \%$ & $19.62 \%$ \\
\hline \hline
\end{tabular}

Desse modo, podemos então concluir que o algoritmo memético MA02_R2 obteve o melhor desempenho no que se refere a qualidade das soluções encontradas, quando comparamos com o limitante inferior dado pela aplicação da Relaxação Lagrangiana. Novamente, sintetizamos na Tabela 5.5 os resultados obtidos para as estruturas serial e geral.

Tabela 5.5 Gaps para o Grupo 2 de exemplos.

\begin{tabular}{||l|c|c||}
\hline & Serial & Geral \\
\hline H0 & $14.68 \%$ & $7.34 \%$ \\
\hline GA02 & $16.69 \%$ & $9.78 \%$ \\
\hline MA01 & $13.85 \%$ & $7.31 \%$ \\
\hline MA02_R1 & $13.34 \%$ & $7.11 \%$ \\
\hline MA02_R2 & $12.14 \%$ & $6.45 \%$ \\
\hline \hline
\end{tabular}

Comparando agora a diferença percentual entre os custos das soluções obtidas pela heurística $\mathrm{H} 0$ com os demais algoritmos, temos o ganho em termos percentuais dos algoritmos em relação a 
H0. Ilustramos esses resultados no Gráfico 5.8 a seguir.

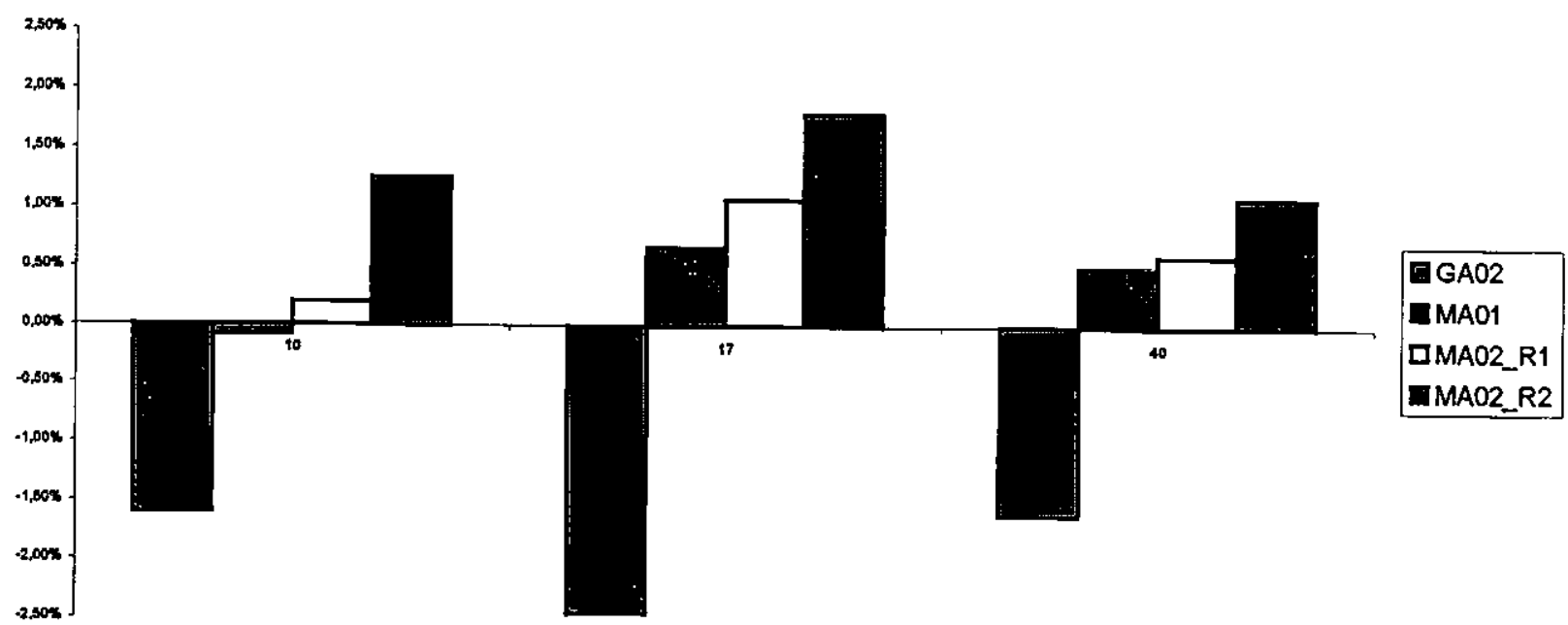

Gráfico 5.8 Comparação do ganho percentual em relação a H0.

No Gráfico 5.8 os valores positivos indicam melhora em relação a $\mathrm{H} 0$, enquanto os valores negativos indicam piora. Este gráfico resume a análise feita para os gaps, mostrando os exemplos em que os algoritmos evolutivos superaram $\mathrm{H} 0$ e onde foram inferiores.

Na próxima seção apresentamos a análise dos exemplos em que os algoritmos não encontraram soluções factíveis, através da análise de medidas que quantificam essa infactibilidade.

\subsubsection{Análise da Infactibilidade}

Em situações reais saber o quanto uma solução é infactivel pode ser extremamente importante, pois muitas vezes a partir de uma solução infactivel a empresa avalia a disponibilidade de recursos e pode optar por uma solução alternativa, uma vez que na prática, normalmente não se tem a opção de não produzir.

Através dessa análise podemos avaliar a “qualidade” das soluções infactíveis, ou seja, permite avaliar o comportamento do algoritmo nos problemas em que não foi possível obter nenhuma solução factível.

Uma maneira de medir a infactibilidade de uma solução, é determinando o quanto a capacidade de recursos disponiveis foi excedida em média, ao longo do horizonte de planejamento. Para isso, 
tomamos como referência a solução com menor excesso médio e analisamos as informações descritas a seguir.

\begin{tabular}{|l} 
exc_med $=$ excesso médio na solução com menor excesso médio \\
\hline exc_max $=$ excesso máximo na solução com menor excesso médio \\
\hline exc_t $=$ porcentagem de períodos com excesso na solução com menor excesso médio
\end{tabular}

Desse modo, apresentamos na Tabela 5.6 os resultados para esse conjunto de exemplos.

Tabela 5.6 Excessos nas soluções com menor excesso médio.

\begin{tabular}{|c|c|c|c|c|c|c|c|}
\hline \multirow{2}{*}{ Estrutura } & & \multicolumn{3}{|c|}{ HO } & \multicolumn{3}{|c|}{ MA02_R2 } \\
\hline & $\mathbf{N}$ & exc_med & exc_max & exc_t & exc_med & exc_max & exc_t \\
\hline \multirow{4}{*}{ Serial } & 10 & $0,59 \%$ & $9,27 \%$ & $3,25 \%$ & $0,44 \%$ & $7,55 \%$ & $2,50 \%$ \\
\hline & 17 & $0,34 \%$ & $6,07 \%$ & $1,50 \%$ & $0,32 \%$ & $5,65 \%$ & $1,50 \%$ \\
\hline & 40 & $0,60 \%$ & $9,50 \%$ & $4,50 \%$ & $0,57 \%$ & $8,93 \%$ & $4,50 \%$ \\
\hline & Media & $\overline{0,51 \%}$ & $8,28 \%$ & $3,08 \%$ & $\overline{0.44 \%}$ & $7,37 \%$ & $2,83 \%$ \\
\hline \multirow{4}{*}{ Geral } & 10 & $1,11 \%$ & $18,09 \%$ & $3,50 \%$ & $0,86 \%$ & $14,15 \%$ & $3,00 \%$ \\
\hline & $\overline{17}$ & $0,14 \%$ & $1,90 \%$ & $1,00 \%$ & $0,13 \%$ & $1,73 \%$ & $1,00 \%$ \\
\hline & 40 & $1,54 \%$ & $23,59 \%$ & $6,00 \%$ & $1,35 \%$ & $20,59 \%$ & $5,50 \%$ \\
\hline & Media & $0,93 \%$ & $14,53 \%$ & $3,50 \%$ & $0,78 \%$ & $12,16 \%$ & $3,17 \%$ \\
\hline \multicolumn{2}{|c|}{ Média } & $\overline{00,72 \%}$ & $11,40 \%$ & $3,29 \%$ & $0,61 \%$ & $\mathbf{9 , 7 7 \%}$ & $3,00 \%$ \\
\hline
\end{tabular}

Como podemos observar pela Tabela 5.6, o algoritmo memético obteve melhor performance, ou seja, nos problemas em que a obtenção de soluções factíveis não foi possível, MA02_R2 encontrou as soluções com menor grau de infactibilidade. Vale ressaltar, que os baixos valores dos excessos indicam que mesmo sem obter soluções factíveis para esses exemplos, os algoritmos apresentaram um bom desempenho.

A seguir, analisamos o desempenho dos algoritmos ao longo das gerações através da atualização da incumbente, ou seja, a evolução do custo da melhores soluções no decorrer da execução dos algoritmos.

\subsubsection{Evolução da Incumbente}

Com o objetivo de avaliar o desempenho dos algoritmos GA02 e MA02_R2 em relação a H0, plotamos nos Gráficos 5.9 e 5.10 a evolução do custo da incumbente para os exemplos com 40 itens, considerando custos altos de preparação. Para isso, os algoritmos genéticos e meméticos foram executados durante 1500 gerações e Ho por 30 mil iterações, correspondendo a 
aproximadamente uma hora de execução para cada algoritmo. Vale lembrar que nos algoritmos evolutivos a incumbente é representada pelo melhor individuo na população (isto é, o individuo pocket[1]).

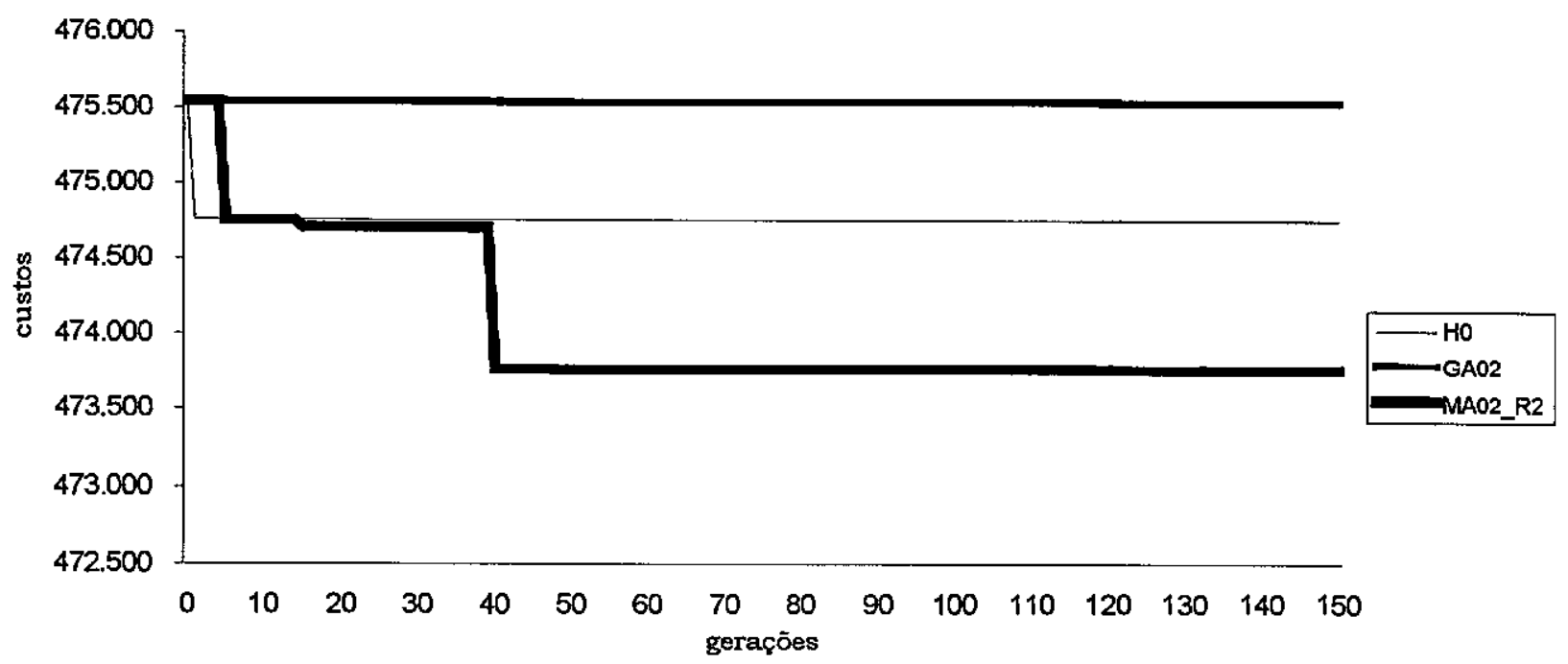

Gráfico 5.9 Evolução da incumbente para a estrutura serial.

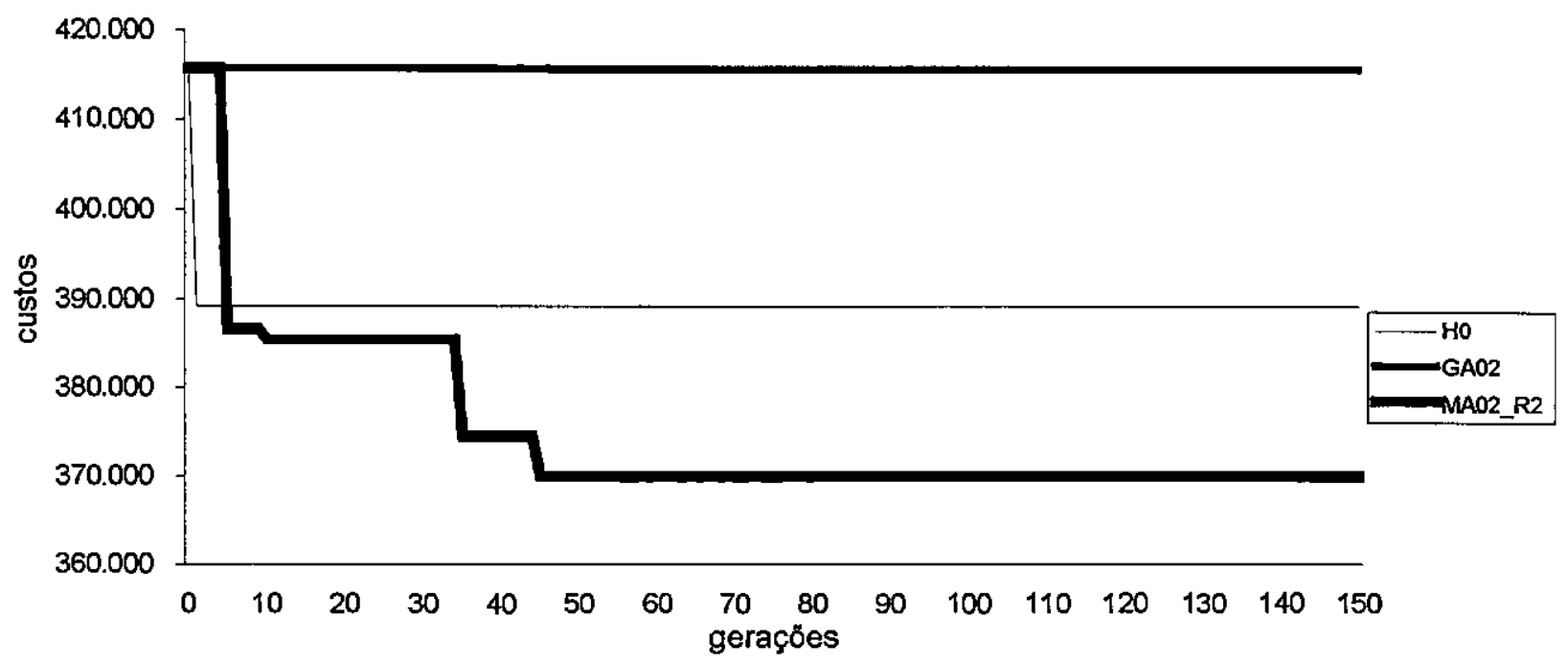

Gráfico 5.10 Evolução da incumbente para a estrutura geral.

Como podemos observar pelos gráficos anteriores, a redução de custos obtida pelo algoritmo MA02_R2 mostrou-se muito mais acentuada do que os demais, ou seja, o algoritmo memético consegue ao longo do processo evolutivo reduzir o custo da incumbente com mais eficiência. $O$ algoritmo genético (GA02) no entanto, não apresenta a mesma eficácia, sendo que nesses dois 
exemplos mais especificamente, não consegue reduzir o valor da incumbente. Logo, o algoritmo memético tende a obter um melhor desempenho do que $\mathrm{HO}$ ao longo do tempo.

Com o intuito de avaliar o performance dos algoritmos durante um intervalo de tempo maior, apresentamos na Tabela 5.7 os valores dos gaps obtidos pelos algoritmos quando variamos o número de gerações.

Tabela 5.7 Gaps para diferentes números de gerações.

\begin{tabular}{||l|c|c|c|c|c|c||}
\hline & \multicolumn{3}{|c|}{ serial } & \multicolumn{3}{c||}{ geral } \\
\hline & 500 & 1.000 & 1.500 & 500 & 1.000 & 1.500 \\
\hline H0 & $14.68 \%$ & $14.59 \%$ & $14.53 \%$ & $7.34 \%$ & $7.20 \%$ & $7.17 \%$ \\
\hline GA02 & $16.69 \%$ & $16.69 \%$ & $16.68 \%$ & $9.78 \%$ & $9.76 \%$ & $9.67 \%$ \\
\hline MA01 & $13.85 \%$ & $13.65 \%$ & $13.50 \%$ & $7.31 \%$ & $7.28 \%$ & $7.13 \%$ \\
\hline MA02_R1 & $13.34 \%$ & $13.16 \%$ & $12.97 \%$ & $7.11 \%$ & $7.11 \%$ & $6.96 \%$ \\
\hline MA02_R2 & $12.14 \%$ & $11.92 \%$ & $11.83 \%$ & $6.45 \%$ & $6.35 \%$ & $6.31 \%$ \\
\hline \hline
\end{tabular}

Como podemos observar pela Tabela 5.7 quando variamos o número de gerações de 500 para 1500 , não ocorrem variações significativas nos gaps, principalmente no caso da heurística Ho. Com isso podemos concluir que o número máximo de 500 gerações como um possível critério de parada é apropriado para esse conjunto de exemplos.

Apresentamos em seguida a análise dos tempos computacionais envolvidos na execução do algoritmo MA02_R2.

\subsubsection{Análise do Tempo Computacional}

Os tempos computacionais envolvidos na resolução de um algoritmo constituem um fator importante para a análise da sua eficiência. Para isso, selecionamos o algoritmo MA02_R2, pois além do fato de ter apresentado melhor performance para esse grupo de exemplos é também o que necessita de tempos mais altos.

Para o cálculo dos tempos médios, o algoritmo foi executado até que o número máximo de 500 gerações fosse atingido ou até que 20 gerações tenham ocorrido sem que nenhuma solução factível tenha sido encontrada, ou ainda, após 200 gerações sem que nenhuma melhora na incumbente tenha sido alcançada. Esses critérios foram estabelecidos a partir de uma análise prévia dos resultados obtidos pelos algoritmos para o Grupo 2 de exemplos. 
Na Tabela 5.8 apresentamos os tempos computacionais médios (em segundos) requeridos por esse algoritmo, dividos de acordo com a estrutura e o tamanho dos exemplos.

Tabela 5.8 Tempos médios de execução do MA02_R2 (em segundos).

\begin{tabular}{||l|c|c|c||}
\hline \hline & \multicolumn{3}{|c|}{ itens } \\
\hline & 10 & 17 & 40 \\
\hline serial & 80,52 & 207,16 & $1.230,21$ \\
geral & 119,94 & 261,11 & $1.204,90$ \\
\hline média & 100,23 & 234,14 & $1.217,56$ \\
\hline
\end{tabular}

Desse modo, temos que o algoritmo MA02_R2 necessita em média de aproximadamente 2 minutos para executar os problemas com 10 itens, 4 minutos para os problemas com 17 itens e 20 minutos para os problemas com 40 itens. Para efeito de comparação, temos que a heurística H0 leva em média 4 segundos para executar os problemas com 10 itens, 8 segundos para aqueles com 17 itens e 1 minuto os problemas com 40 itens. Apesar dos tempos computacionais serem mais elevados quando comparados com a heurística H0, essa última não atinge soluções com a mesma qualidade, mesmo quando executada durante o mesmo tempo computacional que MA02_R2.

A seguir apresentamos a análise do resultados obtidos para o Grupo 1 de exemplos.

\subsection{Análise dos Resultados para o Grupo 1}

Para esse grupo de exemplos, analisamos a performance dos algoritmos na obtenção de soluções factiveis e a qualidade dessas soluções. A diferença é que para esse grupo de exemplos, os resultados são comparados com as soluções ótimas obtidas pelo CPLEX, nos exemplos em que isso foi possível.

Os exemplos numéricos testados para esse grupo estão descritos a seguir. 


\begin{tabular}{||l|c||}
\hline \multicolumn{2}{|c|}{ Grupo 1 } \\
\hline Estrutura & geral e serial \\
\hline $\mathrm{N} \times \mathrm{T}$ & $3 \times 6,3 \times 12,6 \times 6 \mathrm{e} \mathrm{10 \times 6}$ \\
\hline custo de preparação & baixo e alto \\
\hline capacidade & $\mathrm{c}_{1} \mathrm{e} \mathrm{c}_{2}$ \\
\hline sementes & 5 \\
\hline Total & 160 \\
\hline \hline
\end{tabular}

Para esse grupo de exemplos os algoritmos foram executados novamente durante 500 gerações, exceto o programa CPLEX, que foi executado até que a solução ótima fosse encontrada ou até o limite da capacidade de memória da estação de trabalho.

\subsubsection{Eficácia na Obtenção de Soluções Factíveis}

Apresentamos nos gráficos a seguir, os resultados dos testes para o Grupo 1 de exemplos. Os valores plotados representam as porcentagens de exemplos em que foram obtidas soluções factíveis (FAC). Os gráficos estão separados de acordo com os custos de preparação utilizados.

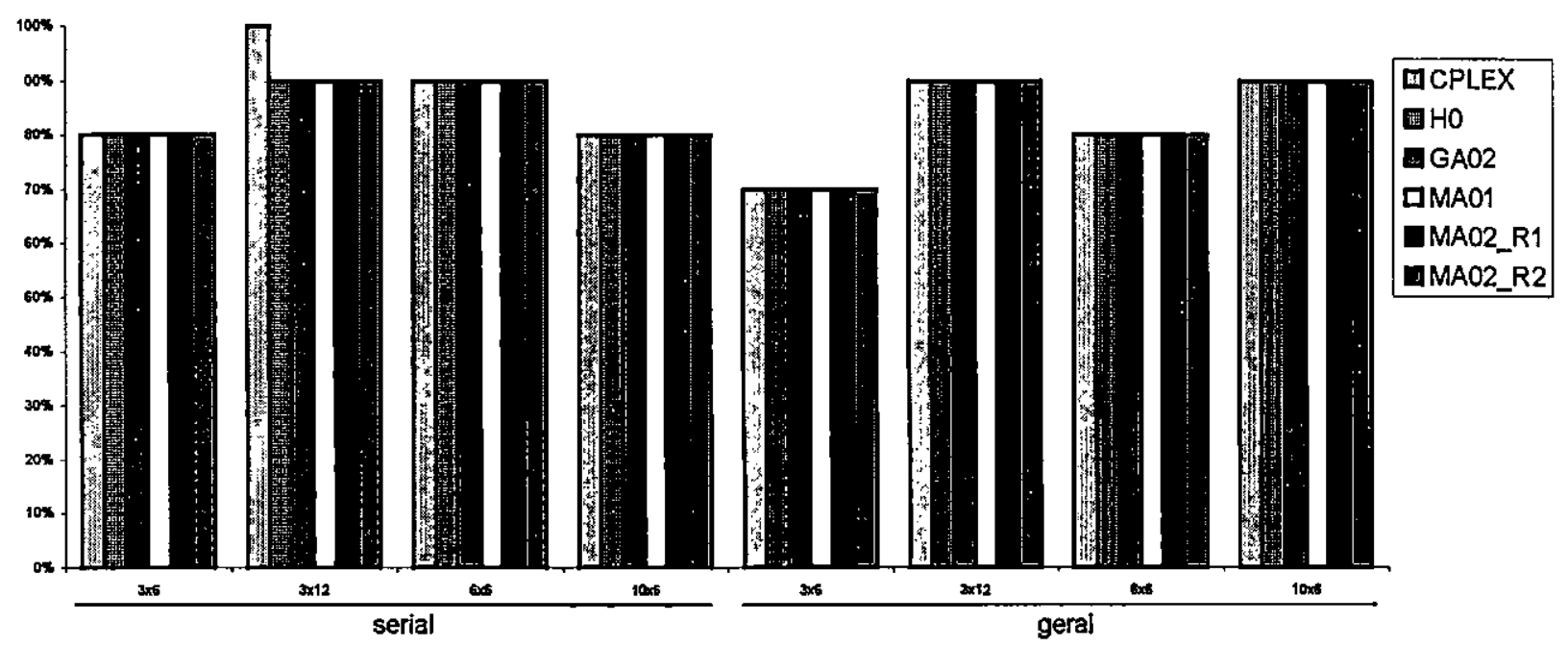

Gráfico 5.11 FAC em exemplos com custos de preparação baixos. 


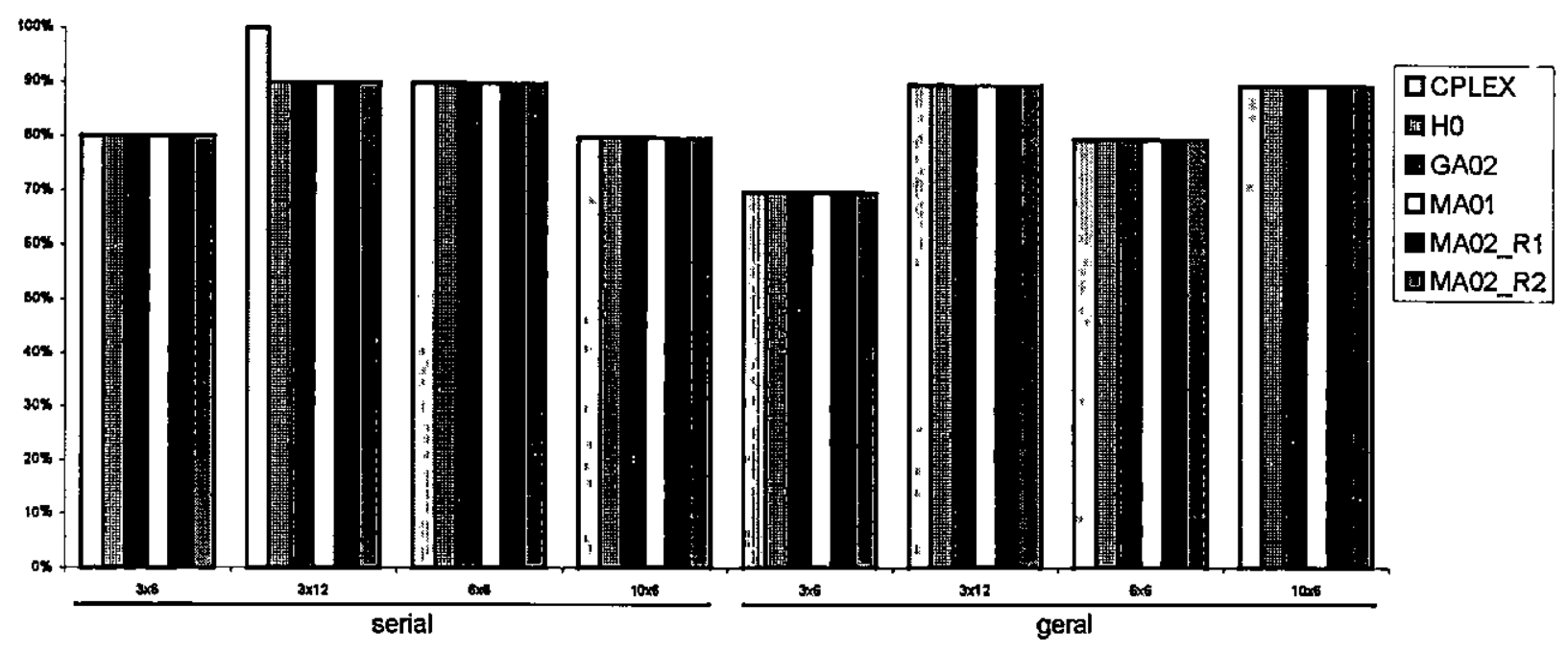

Gráfico 5.12 FAC em exemplos com custos de preparação altos.

Nos Gráficos 5.11 e 5.12 os algoritmos apresentaram o mesmo desempenho do CPLEX, exceto para o exemplo com 3 itens e 12 períodos, na estrutura serial. Podemos observar que para esse grupo de exemplos, ao contrário do anterior, que o número de soluções factíveis obtidas permanece constante quando variamos o custo de preparação.

A tabela a seguir sintetiza os resultados para esse grupo de exemplos, com relação à capacidade de encontrar soluções factíveis.

Tabela 5.8 FAC para o Grupo 1 de exemplos.

\begin{tabular}{|c|cc|c|}
\hline & Serial & Geral & Média \\
\hline CPLEX & $87.50 \%$ & $82.5 \%$ & $85.00 \%$ \\
\hline OUTROS & $85.00 \%$ & $82.5 \%$ & $83.75 \%$ \\
\hline
\end{tabular}

A seguir, analisamos a qualidade das soluções obtidas pelos algoritmos comparando com o ótimo obtido pelo CPLEX.

\subsubsection{Qualidade das Soluções Obtidas}

Nessa seção analisamos a qualidade das soluções obtidas pelas heurísticas, através da comparação com as soluções ótimas encontradas pelo CPLEX. Na tabela a seguir, apresentamos o 
número de problemas para os quais o CPLEX encontrou a solução ótima.

Tabela 5.9 Número de soluções ótimas obtidas pelo CPLEX.

\begin{tabular}{|c|cc|cc|}
\hline & Serial & Geral & Total & $\% \mathrm{~T}$ \\
$3 \times 6$ & 16 & 14 & 30 & $75 \%$ \\
$6 \times 6$ & 18 & 16 & 34 & $85 \%$ \\
$3 \times 12$ & 20 & 18 & 38 & $95 \%$ \\
$10 \times 6$ & 16 & 18 & 34 & $85 \%$ \\
\hline Total & 70 & 66 & 136 & $85 \%$ \\
\hline
\end{tabular}

Na Tabela 5.9 o símbolo \% representa em termos percentuais, o número de exemplos onde foi encontrada a solução ótima em relação ao total de exemplos, que nesse grupo é de 40 para cada tamanho. Isso significa que o programa CPLEX não encontrou a solução ótima em 24 (15\%) dos 160 exemplos testados, sendo que nesse caso, são todos problemas infactíveis.

Para esse grupo de exemplos utilizaremos duas nomenclaturas diferentes para representar o gap, uma quando comparamos o valor encontrado pelo algoritmo com a solução ótima dada pelo CPLEX e outra quando comparamos com o limitante inferior dada pela Relaxação Lagrangiana. Apresentamos a seguir essas nomenclaturas.

$$
\begin{aligned}
& \text { GapO = Diferença percentual entre o valor obtido pelo algoritmo e a solução ótima } \\
& \text { GapL }=\text { Diferença percentual entre o valor obtido pelo algoritmo e o limitante inferior }
\end{aligned}
$$

Nas tabelas 5.10 e 5.11 apresentamos os resultados divididos de acordo com as estruturas utilizadas. $\mathrm{O}$ asterístico nas tabelas $\left(^{*}\right)$ indica os problemas que foram resolvidos pelo CPLEX com tolerância de $1 \%$ para o ótimo. 
Tabela 5.10 GapO para problemas com a estrutura serial.

\begin{tabular}{|c|c|c|c|c|c|c|}
\hline \multirow{2}{*}{ Preparação } & & \multicolumn{5}{|c|}{ GapO } \\
\hline & NxT & $\mathrm{HO}$ & GA02 & MA01 & MA02_R1 & MA02_R2 \\
\hline \multirow{5}{*}{ baixo } & $03 \times 06$ & $0,61 \%$ & $0,84 \%$ & $0,04 \%$ & $0,03 \%$ & $0,03 \%$ \\
\hline & $03 \times 12$ & * $0,79 \%$ & $1,53 \%$ & $0,22 \%$ & $0,10 \%$ & $0,08 \%$ \\
\hline & $06 \times 06$ & $0,93 \%$ & $0,98 \%$ & $0,78 \%$ & $0,69 \%$ & $0,09 \%$ \\
\hline & $10 \times 06$ & $0,51 \%$ & $0,96 \%$ & $0,24 \%$ & $0,25 \%$ & $0,17 \%$ \\
\hline & Média & $0, \overline{73} \%$ & $1,11 \%$ & $0,33 \%$ & $0,27 \%$ & $0,09 \%$ \\
\hline \multirow{5}{*}{ alto } & $03 \times 06$ & $3,80 \%$ & $2,72 \%$ & $0,57 \%$ & $0,54 \%$ & $0,01 \%$ \\
\hline & $03 \times 12$ & * $4,68 \%$ & $8,94 \%$ & $3,19 \%$ & $2,05 \%$ & $0,43 \%$ \\
\hline & $06 \times 06$ & $2,13 \%$ & $1,00 \%$ & $2,76 \%$ & $2,73 \%$ & $0,35 \%$ \\
\hline & $10 \times 06$ & $2,06 \%$ & $1,66 \%$ & $0,62 \%$ & $0,25 \%$ & $0,10 \%$ \\
\hline & Média & $3,28 \%$ & $3,85 \%$ & $1,94 \%$ & $1,48 \%$ & $0,25 \%$ \\
\hline \multicolumn{2}{|c|}{ MÉDIA (SERIAL) } & $2,01 \%$ & $2,48 \%$ & $1,14 \%$ & $0,88 \%$ & $0,17 \%$ \\
\hline
\end{tabular}

Tabela 5.11 GapO para problemas com a estrutura geral.

\begin{tabular}{|c|c|c|c|c|c|c|}
\hline \multirow{2}{*}{ Preparação } & \multirow[b]{2}{*}{ NxT } & \multicolumn{5}{|c|}{ GapO } \\
\hline & & $\mathrm{HO}$ & GA02 & MA01 & MA02_R1 & MA02_R2 \\
\hline \multirow{5}{*}{ baixo } & $03 \times 06$ & $0,25 \%$ & $0,50 \%$ & $0,05 \%$ & $0,02 \%$ & $0,03 \%$ \\
\hline & $03 \times 12$ & * $0,91 \%$ & $1,05 \%$ & $0,07 \%$ & $0,08 \%$ & $0,06 \%$ \\
\hline & $06 \times 06$ & $0,19 \%$ & $0,67 \%$ & $0,05 \%$ & $0,03 \%$ & $0,03 \%$ \\
\hline & $10 \times 06$ & $\star 0,45 \%$ & $1,52 \%$ & $0,21 \%$ & $0,32 \%$ & $0,14 \%$ \\
\hline & Média & $0,47 \%$ & $0,97 \%$ & $\overline{0,10 \%}$ & $0,12 \%$ & $0,07 \%$ \\
\hline \multirow{5}{*}{ alto } & $03 \times 06$ & $4,14 \%$ & $2,45 \%$ & $0,52 \%$ & $0,21 \%$ & $0,18 \%$ \\
\hline & $03 \times 12$ & * $3,57 \%$ & $6,16 \%$ & $1,68 \%$ & $1,28 \%$ & $0,83 \%$ \\
\hline & $06 \times 06$ & $3,12 \%$ & $3,33 \%$ & $1,74 \%$ & $0,75 \%$ & $0,92 \%$ \\
\hline & $10 \times 06$ & * $4,35 \%$ & $5,76 \%$ & $2,25 \%$ & $2,06 \%$ & $0,99 \%$ \\
\hline & Média & $3,79 \%$ & $4,58 \%$ & $1,60 \%$ & $1,14 \%$ & $\mathbf{0 , 7 6 \%}$ \\
\hline \multicolumn{2}{|c|}{ MÉDIA (GERAL) } & $2,13 \%$ & $2,77 \%$ & $0,85 \%$ & $0,63 \%$ & $0,41 \%$ \\
\hline
\end{tabular}

$\mathrm{Na}$ estrutura serial (Tabela 5.10) considerando os exemplos com custos baixos de preparação, temos que apenas o algoritmo genético apresenta soluções a mais de $1 \%$ do ótimo. Nos exemplos com custos altos de preparação o MA02_R2 obteve soluções inferiores a 1\% do ótimo. Desse modo, para a estrutura serial o MA02_R2 obteve em média soluções a menos de 0,5\% do ótimo.

Analisando a Tabela 5.11 para os exemplos com custos baixos de preparação, todos os algoritmos alcançaram soluções a menos de $1 \%$ do ótimo. Nos exemplos com custos altos de preparação apenas o MA02_R2 obteve soluções a menos de $1 \%$ do ótimo. Os resultados médios para a estrutura geral mostram que o MA02_R2 obteve o melhor desempenho dentre os algoritmos, atingindo em média soluções a menos de $0,5 \%$ do ótimo.

Apresentamos a seguir um resumo desses resultados. 
Tabela 5.12 Resumo dos resultados (GapO).

\begin{tabular}{|l|c|c|}
\hline GapO & Serial & Geral \\
\hline H0 & $2,01 \%$ & $2,13 \%$ \\
\hline GA02 & $2,48 \%$ & $2,77 \%$ \\
\hline MA01 & $1,14 \%$ & $0,85 \%$ \\
\hline MA02_Rl & $0,88 \%$ & $0,63 \%$ \\
\hline MA02_R2 & $0,17 \%$ & $0,41 \%$ \\
\hline
\end{tabular}

Dessa forma, os algoritmos meméticos apresentaram melhor performance para esse conjunto de exemplos. Dentre eles o MA02_R2 foi o que mais destacou, obtendo soluções médias praticamente ótimas nas duas estruturas.

Para o Grupo 2 de exemplos, ao invés de compararmos o custo obtido pela heurística com o valor ótimo, comparamos com um limitante inferior obtido utilizando Relaxação Lagrangiana, uma vez que o cálculo do valor ótimo para aqueles exemplos era inviável. No entanto, é necessário que tenhamos uma idéia da qualidade dos limitantes inferiores utilizados.

Uma maneira de avaliarmos a qualidade desses limitantes, é comparando com os valores ótimos obtidos pelo CPLEX. Para isso, basta comparar o gap entre o custo obtido pela heurística e o obtido pelo CPLEX (GapO) como fizemos anteriormente, com o gap entre o custo obtido pela heurística e o limitante inferior (GapL) dado pela Relaxação Lagrangiana.

Assim temos os seguintes resultados médios para o Grupo 1.

Tabela 5.13 Gap de dualidade.

\begin{tabular}{||c|cc|cc|cc||}
\hline \multirow{2}{*}{} & \multicolumn{2}{|c|}{ Serial } & \multicolumn{2}{c|}{ Geral } & \multicolumn{2}{c||}{ Diferença } \\
\cline { 2 - 7 } & GapO & GapL & GapO & GapL & Serial & Geral \\
\hline H0 & $2,01 \%$ & $14,17 \%$ & $2,13 \%$ & $13,23 \%$ & $12,16 \%$ & $11,10 \%$ \\
\hline GA02 & $2,48 \%$ & $14,67 \%$ & $2,77 \%$ & $13,91 \%$ & $12,19 \%$ & $11,14 \%$ \\
\hline MA01 & $1,14 \%$ & $13,15 \%$ & $0,85 \%$ & $11,72 \%$ & $12,01 \%$ & $10,87 \%$ \\
\hline MA02_R1 & $0,88 \%$ & $12,83 \%$ & $0,63 \%$ & $11,45 \%$ & $11,95 \%$ & $10,82 \%$ \\
\hline MA02_R2 & $0,17 \%$ & $12,02 \%$ & $0,41 \%$ & $11,22 \%$ & $11,85 \%$ & $10,81 \%$ \\
\hline \hline
\end{tabular}

A Tabela 5.13 mostra também a diferença absoluta entre o GapO e o GapL, essa diferença é conhecida como gap de dualidade do problema. A análise desses valores indica que existe um gap de dualidade alto para esses problemas (superior a 10\%), indicando que os resultados obtidos para o Grupo 2 podem ser muito melhores do que aparentam. 


\section{CAPÍTULO 6}

\section{CONCLUSÃO E PROPOSTAS FUTURAS}

Estudamos nesse trabalho o problema de dimensionamento de lotes com restrições de capacidade em sistemas multiestágios, considerando custos e tempos de preparação. A proposta consistiu na elaboração de meta-heurísticas evolutivas, mais especificamente algoritmos genéticos e meméticos.

O problema de dimensionamento de lotes tem por objetivo determinar o tamanho dos lotes de produção de modo a minimizar os custos de produção, estoque e preparação, sujeito a um conjunto de restrições.

Em sistemas de produção multiestágio o planejamento de cada item ainda depende do planejamento de outros itens, situados em níveis hierárquicos inferiores.

O fato de considerar custos e tempos de preparação diferentes de zero, faz com que o problema seja modelado como um problema inteiro-misto, tornando dificil mesmo a obtenção de planos factíveis. Devido as dificuldades de resolução, fazemos uso de métodos heurísticos em lugar de exatos.

Na fase inicial do trabalho estudamos as heurísticas propostas por França et al.(1997), as quais foram utilizadas como base para as meta-heurísticas evolutivas desenvolvidas e também na avaliação dos resultados obtidos. A seguir iniciamos o desenvolvimento dos aspectos mais relevantes na implementação dos algoritmos genéticos, como geração da população inicial, estrutura da população, operadores de cruzamento, mecanismos de seleção e eliminação dos indivíduos na população.

Durante essa fase testamos diversas variações nos parâmetros utilizados por esses 
componentes com base em experimentos computacionais. A partir dos resultados obtidos pelos algoritmos genéticos, iniciamos a implementação dos algoritmos meméticos, através de modificações nos algoritmos implementados até então. A principal diferença desses algoritmos está na utilização do procedimento de melhoria, proposto em França et al.(1997), que funciona como busca local nos algoritmos meméticos. Nesse período, a análise de alguns resultados indicou a necessidade de estratégias para inibir a acentuada perda de diversidade na população. Com isso, propomos o critério de diversificação e a reinicialização do algoritmo, ambos usados nos algoritmos meméticos.

$\mathrm{Na}$ etapa final selecionamos os algoritmos que obtiveram melhores resultados e realizamos testes em 480 exemplos numéricos gerados aleatóriamente, dividos em dois grupos distintos, um para problemas de pequeno porte e outro para problemas de médio porte. Através desses resultados, analisamos a performance dos algoritmos com relação a capacidade de encontrar soluções factíveis, a qualidade das soluções obtidas e o desempenho desses algoritmos em problemas para os quais não encontraram soluções factiveis.

Os algoritmos meméticos obtiveram para esses exemplos, os melhores resultados em média para todos os critérios analisados. Em particular, o MA02_R2 foi o de melhor performance, alcançando soluções praticamente ótimas para os exemplos de pequeno porte, e reduzindo em até $5 \%$ os gaps obtidos pela heurística proposta por França et al.(1997) para os exemplos de médio porte. Analisamos a performance desse algoritmo também com relação aos tempos computacionais necessários à sua execução, indicando que apesar de consumir um tempo maior, seu desempenho durante o tempo é melhor que a heurística proposta por França et al.(1997).

Desse modo, podemos concluir que a heurística proposta nesse trabalho conseguiu melhorar satisfatoriamente os resultados quando comparado a um método conhecido na literatura. No entanto, uma análise do desempenho do algoritmo para problemas de grande porte ainda se faz necessária, uma vez que na prática encontramos freqüentemente problemas maiores.

Apresentamos a seguir algumas sugestões para desenvolvimento de futuras pesquisas, assim como possíveis alternativas de melhorias para os algoritmos propostos.

> operadores de recombinação (reprodução) nos algoritmos meméticos utilizando mais de duas soluções para gerar um filho.

- divisão do problema em dois subproblemas, um para variáveis binárias e outro para reais, utilizando Programação Linear para resolver o problema envolvendo variáveis reais, e em seguida utilizar algoritmos evolutivos para resolução do problema resultante.

- incorporação de penalidades na função de avaliação, sendo essas penalidades restrições do problema, tornando o problema menos restrito e reduzindo a dificuldade no uso dos operadores de reprodução. 


\section{BIBLIOGRAFIA}

ADENSO-DÍAZ B. e LAGUNA M. (1997), A Technique to Minimize Overtime in the Capacitated MRP Problem, Production and Operations Management, 5 (4): 357-370.

AFENTAKIS P., GAVISH B. e KARMAKAR U. (1984), Computationally Efficient Optimal Solutions to the Lot-Sizing Problem in Multistage Assembly Systems, Management Science, 30 (2): 222-239.

BAFL H. C., RITZMAN L. P. e GUPTA J. N. D. (1987), Determining Lot Sizes and Resource Requirements: A Review, Operations Research Society of America, 35 (3): 329-345.

BERRETTA R. E. (1997), Heuristicas para Otimização do Planejamento da Produção em Sistemas MRP, Tese de Doutorado, UNICAMP.

BERRETTA R. E. e MOSCATO, P. (1999), The Number Partitioning Problem: An Open Challenge for Evolutionary Computation?, capitulo 17, apud em CORNE et al.(1999).

BLLINGTON P. J., McCLAIN J. O. e THOMAS L. J. (1983), Mathematical Programming Approaches to Capacity MRP Systems: Review, Formulation and Problem Reduction, Management Science, 29 (10): 1126-1141. 
BILLINGTON P. J., McCLAIN J. O. e THOMAS L. J. (1986), Heuristics for Multilevel Lot-Sizing with a Bottleneck, Management Science, 32 (8): 989-1006.

BLACKBURN J. D. e MILLEN R. A. (1984), Simultaneous Lot-Sizing and Capacity Planning in Muli-Stage Assembly Processes, European Journal of Operation Research, 16: 84-93.

CLARK A. J. e SCARF H. (1960), Optimal Policies for a Multi-Echelon Inventory Problem, Management Science, 6: 475-490.

CLARK A. R. e ARMENTANO V. A. (1993), Echelon Stock Formulation for Multi-Stage Lot-Sizing with Component Lead Times, International Journal of Systems Sciences, 24 (9): 1759-1775.

CLARK A. R. e ARMENTANO V. A. (1995), A Heuristic for a Resource-Capacitated Multi-Stage Lot-Sizing Problem with Lead Times, Journal of the Operational Research Society, 46: 1208-1222.

CORNE D., DORIGO M. e GLOVER F. (1999), New Ideas in Optimisation, McGraw-Hill, United Kingdom.

DAVIS L. (1991), Handbook of Genetic Algorithms, Van Nostrand Reinhold, New York, apud em Reeves (1993).

DE JONG K. A. (1975), An Analysis of the Behavior of a Class of Genetic Adaptive Systems, Tese de Doutorado, University of Michigan, apud em Reeves (1993).

DÍAZ A., GLOVER F., GHAZIRI H. M., GONZÁLEZ J. L., LAGUNA M., MOSCATO P. e TSENG F. T. (1996), Optmización Heurística y Redes Neuronales, en Dirección de Operaciones e Ingenieria, Editorial Paraninfo, Madrid.

DIXON P. S. e SILVER E. A. (1981), A Heuristic Solution Procedure for the Multi-item, Single-level, Limited Capacity Lot-sizing Problem, Journal of Operational Management, 2: 23-39, apud em Helber (1995). 
FRANÇA P. M., ARMENTANO V. A., BERRETTA R. E. e CLARK A. R. (1997), A Heuristic for Lot-Sizing in Multi-Stage Systems, Computers and Operations Research, a ser publicado.

GABBAY H. (1979), Multi-Stage Production Planning, Management Science, 25 (11): 1138-1148.

GAREY M. e JOHNSON D. (1979), Computers, Complexity and Intractibility: $A$ Guide to Theory of NP-Completeness, Freeman, San Francisco.

GOLDBERG D. E. (1989), Genetic Algorithms in Search, Optimization and Machine Learning, Addison Wesley, Massachusetts.

GLOVER F. e LAGUNA M. (1997), Tabu Search, Klumer Academic Publishers, Norwell, Massachusetts.

HAASE K. e KOHLMORGEN U. (1998), Parallel Genetic Algorithm for the Capacitated Lot-Sizing Problem, Working Paper 332, University of Karlsruhe, Germany.

HARRISON T. P. e LEWIS H. S. (1996), Lot Sizing in Serial Assembly Systems with Multiple Constrained Resources, Management Science, 42 (1): 19-36.

HELBER S. (1994), Kapazitätsorientierte LosgröBenplanung in PPS-Systemen, M\&P Verlag für Wissenschaft und Forschung, Stuttgart, apud em Helber (1995).

HELBER S. (1995), Lot Sizing in Capacitated Production Planning and Control Systems, OR Spektrum, 17: 5-18.

HOLLAND J. H. (1975), Adaptation in Natural and Artificial Systems, University of Michigan Press, Ann Arbor.

KATOK E., LEWIS H. S. e HARRISON T. P. (1998), Lot Sizing in General Assembly Systems with Setup Costs, Setup Times an Multiple Constrained Resources, Management Science, 44, 6(1998): 859-877. 
KIMMS A. (1999), A Genetic Algorithm for Multi-level, Multi-machine Lot Sizing and Scheduling, Computers Operations Research, 26: 829-848.

KIRCA Ö. e KÖKTEN M.(1994), A New Heuristic Approach for the Multi-item Dynamic Lot Sizing Problem, European Journal of Operation Research, 75:332-341, apud em Haase e Kohlmorgen (1998).

KIRKPATRICK S., GELATT C. D. e VECCHI M. P. (1983), Optimization by Simulated Annealing, Science, 220: 671-680.

KUIK R. e SALOMON M. (1990), Multi-Level Lot-Sizing Problem: Evaluation of a Simulated Annealing Heuristic, European Journal of Operation Research, 45: 25-37.

KUIK R., SALOMON M., VAN WASSENHOVE L. N. e MAES J. (1993), Linear Programming, Simulated Annealing and Tabu Search Heuristics for Lotsizing in Bottleneck Assembly Systems, IIE Transactions, 25 (1): 62-72.

KUIK R., SALOMON M. e VAN WASSENHOVE L. N. (1994), Batching Decisions: Structure and Models, European Journal of Operation Research, 75: 243-263.

LAMBRECHT M. e VANDERVECKEN J. (1978), A Facilities in Series Capacity Constrained Dynamic Lot-Size Model, European Journal of Operational Research, 2: 42-49.

MAES J., McCLAIN J. O. e VAN WASSENHOVE L. N. (1991), Multilevel Capacitated LotSizing Complexity and LP based Heuristics, European Journal of Operational Research, 53: 131-148.

MAhomepage (2000), Memetic Algorithms Homepage, http://www.densis.fee.unicamp.br/ moscato/memetic_home.html

MOSCATO P. (1989), On Evolution, Search, Optimization, Genetic Algorithms and Martial Arts: Towards Memetic Algorithms, C3P Report 826, California Institute of Technology, Pasadena, CA 91125. 
MOSCATO P. e NORMAN M. G. (1992), A Memetic Approach for the Traveling Salesman Problem. Implementation of a Computational Ecology for Combinatorial Optimization on Message-Passing Systems, editado por M. Valero, E. Onate, M. Jane, J. L. Larriba e B. Suarez, Parallel Computing an Transputer Applications, Ed. IOS Press, 187-194.

MOSCATO P. (1999), Memetic Algorithms: A Short Introduction, capítulo 14, apud em Come et al.(1999).

OZDAMAR L. e BIRBIL S. I. (1998), Hybrid Heuristics for the Capacitated Lot Sizing an Loading Problem with Setup Times and Overtime Decisions, European Journal of Operational Research, 110: 525-547.

REEVES C. R. (1993), Modern Heuristic Techniques for Combinatorial Problems, John Wiley \& Sons, New York.

ROLL Y. e KARNI R. (1991), Multi-item, Multi-level Lot Sizing with an Aggregate Capacity Constraint, European Journal of Operational Research, 51: 73-87.

SALOMON M. (1991), Deterministic Lot Sizing Models for Production Planning, Springer, New York, apud em Helber (1995).

SILVER E. A., VIDAL R. V. e de WERRA D. (1980), A Tutorial on Heuristic Methods, European Journal of Operational Research, 5, apud em Díaz et al.(1996).

SLACK N., CHAMBERS S., HARLAND C., HARRISON A. e JOHNSTON R. (1997), Adminstração da Produção, Editora Atlas, São Paulo, 10: 315-472.

STEINBERG E. e NAPIER H. A. (1980, Optimal Multi-Level Lot Sizing for Requirements Planning Systems, Management Science, 26 (12): 1258-1271.

TEMPELMEIER H. e DERSTROFF M. (1993), A Lagrangean-based Heuristic for Dynamic Multi-level Multi-item Constrained LotSizing, Working paper, apud em Helber (1995). 
TEMPELMEIER H. e DERSTROFF M. (1996), A Lagrangean-based Heuristic for Dynamic Multi-level Multi-item Constrained LotSizing with Setup Times, Management Science, 42 (5): 738-757.

TEMPELMEIER H. (1997), Resource-Constrained Materials Requirements Planning- MRP rc, Production Planning \& Control, 8 (5): 451-461.

TOKLU B. e WILSON J. M. (1992), A Heuristic for Multi-Level Lot-Sizing Problems with a Bottleneck, International Journal of Production Research, 30 (4): 787-798.

TOKLU B. e WILSON J. M. (1995), An Analysis of Multi-Level Lot-Sizing Problems with a Bottleneck under a Rolling Schedule Environment, International Journal of Production Research, 33 (7): 1835-1847.

TRIGERRO W. W., THOMAS L. J. E McCLANN J.O. (1989), Capacitated Lot Sizing With Setup Times, Management Science, 35 (3): 353-366.

WAGNER, H. M. E WHITIN, T. M. (1958), Dynamic Version of the Economic Lot Size Model, Management Science, 5 (1): 89-96.

WHITLEY D. (1989), The GENITOR Algorithm an Selection Pressure: Why Rank-Based Allocation of Reproductive Trials is Best, Los Altos, CA: 116-121, apud em Reeves (1993).

ZANAKIS S. H., EVANS J. R. e VAZACOPOULOS A. A. (1989), Heuristic Methods and Applications: a categorized survey, EJOR, 43: 88-110, apud em Reeves (1993).

ZANAKIS S. H. e EVANS J. R. (1981), "Heuristic 'Optimization': Why, When, and How to Use It", Interfaces, 11 (5), apud em Díaz et al.(1996). 